Universidade de São Paulo

Faculdade de Filosofia, Ciências e Letras de Ribeirão Preto

Departamento de Química

Programa de Pós-Graduação em Química

\title{
Considerações sobre a liberação fotoquímica de óxido nítrico, sensibilizada por corantes, a partir de um nitrosilo de rutênio
}

Ana Paula Segantin Gaspari

Dissertação apresentada à Faculdade de Filosofia, Ciências e Letras de Ribeirão Preto da Universidade de São Paulo, como parte das exigências para a obtenção do título de Mestre em Ciências. Área: Química

RIBEIRÃO PRETO/SP 
Universidade de São Paulo

Faculdade de Filosofia, Ciências e Letras de Ribeirão Preto

Departamento de Química

Programa de Pós-Graduação em Química

\title{
Considerações sobre a liberação fotoquímica de óxido nítrico, sensibilizada por corantes, a partir de um nitrosilo de rutênio
}

\author{
Ana Paula Segantin Gaspari \\ Orientador: Prof. Dr. Elia Tfouni
}

Dissertação apresentada à Faculdade de Filosofia, Ciências e Letras de Ribeirão Preto da Universidade de São Paulo, como parte das exigências para a obtenção do título de Mestre em Ciências. Área: Química

RIBEIRÃO PRETO/SP 
AUTORIZO A REPRODUÇÃO E DIVULGAÇÃO TOTAL OU PARCIAL DESTE TRABALHO, POR QUALQUER MEIO CONVENCIONAL OU ELETRÔNICO, PARA FINS DE ESTUDO E PESQUISA, DESDE QUE CITADA A FONTE.

\section{FICHA CATALOGRÁFICA}

\section{Gaspari, Ana Paula Segantin.}

Considerações sobre a liberação fotoquímica de óxido nítrico, sensibilizada por corantes, a partir de um nitrosilo de rutênio. Ribeirão Preto, 2013.

$$
132 \text { p. : il. ; } 30 \mathrm{~cm}
$$

Dissertação de Mestrado, apresentada à Faculdade de Filosofia, Ciências e Letras de Ribeirão Preto/USP. Área de Concentração: Química Inorgânica.

Orientador: Tfouni, Elia.

1. Liberação fotoquímica de óxido nítrico. 2. Sensibilização por corantes. 3. Tetraaminpiridinanitrosilrutênio. 4. Nitrosilos de rutênio. 
Dedico este trabalho aos meus pais, Alceu e Cláudia que me apoiaram muito em todo meu percurso, mas principalmente à "Belinha" (Belarmina Beretta Segantin - in memorian - 03/08/2012), minha avó/mãe que doou uma parte de sua vida a cuidar de mim, deixando de lado sua própria vida para poder estar comigo. Que me apoiou, acreditou em mim, me amou, me ensinou a lidar com as "feridas" da vida e, com seu caráter, carinho, amizade e humildade me mostrou o caminho a trilhar. Por cada segundo de ternura, por cada momento de alegria, por estar sempre com um sorriso estampado no rosto (mesmo quando cansada e com dor), agradeço profundamente tudo o que fez por mim. Até mesmo as broncas, pois foram de extrema importância para eu repensar minha opinião e, muitas vezes mudá-la em virtude de um bem maior. Obrigada. Amo-te muito minha avó/mãe, agora e sempre. Saudade infinita. 


\section{AGRADECIMENTOS}

- Ao Prof. Dr. Elia Tfouni, por acreditar em mim, por me receber de braços abertos em seu laboratório; por dedicar grande parte do seu tempo a me ensinar não somente questões profissionais, mas também, questões da vida, que tanto me ajudaram e contribuíram para o meu crescimento. Por ter sido mais do que um orientador, um pai e um excelente professor, um grande exemplo a ser seguido.

- Aos meus pais, Alceu e Cláudia, pelo grande apoio que me deram em todo o meu percurso. Por estarem ao meu lado nos momentos difíceis e me ajudarem ver uma "luz no fim do túnel", sempre me apoiando e me incentivando a atingir tudo aquilo que eu almejava.

- À minha irmã Fernanda, por ser a melhor amiga que alguém pode ter, que cresceu comigo e dividiu experiências inigualáveis.

- À minha avó Maria (In memorian, 01/12/2012), que partiu deste mundo deixando muita saudade. Obrigada por acreditar nos meus estudos e me apoiar.

- À minha madrinha, Rosa Maria Lopes Sampaio, por todo amor, carinho e apoio que tem me dado desde o momento em que nasci.

- Ao meu namorado, Diego, por sempre me apoiar em minhas decisões, pela dedicação e por ter passado ao meu lado momentos muito felizes, mas também, difíceis. À família Scarati, por me receber de braços abertos, com tanto amor e carinho ("vó" Nita, "vô" Raphael, Marlene e Natasha).

- Ao Prof. Dr. Kleber Queiroz Ferreira, do Instituto de Química da Universidade Federal do Bahia, pelo grande auxílio nos primeiros passos dessa jornada, por todos os ensinamentos que proporcionou no decorrer do trabalho e pela amizade.

- Ao Prof. Dr. Douglas Wagner Franco, do Instituto de Química de São Carlos IQSC/USP, por me receber em seu laboratório e pela grande ajuda ao disponibilizar 
seus equipamentos. Aos alunos Willy, Antônio, Gustavo e Daniela e, técnico Thiago que mesmo quando ocupados, estavam sempre prontos a ajudar.

- À Prof. Dra Rose Maria Carlos, do Departamento de Química da Universidade Federal de São Carlos (DQ/UFSCar) que disponibilizou seu laboratório sempre que preciso e me auxiliou nos experimentos de fotoquímica. Aos alunos Márcia, Carolina e Paulo, que acompanharam todos os experimentos realizados na UFSCar.

- Ao professor Dr. louri Borissevitch e Dr. Luciano Bachmann, do Departamento de Física da Faculdade de Filosofia, Ciências e Letras de Ribeirão Preto (DF/FFCLRP), por disponibilizar seu laboratório e tempo, sempre que necessário, além de ajudar com novas ideias para o aprimoramento do trabalho. Ao aluno de doutorado da física médica, Gustavo Parras, por ter me ajudado a conseguir realizar os experimentos no departamento de física.

- Aos professores Dra. Jaísa Fernandes Soares, Dra. Ana Luísa Lacava Lordello, Dr. Andersson Barison, Dr. Eduardo Lemos de Sá, Dr. Flávio Massao Matsumoto, Dra. Joanez Aparecida Aires, Dr. Herenilton Paulino Oliveira, Dra. Gláucia Maria da Silva Degrève, Dra. Sofia Nikolaou, Dr. José Fernando de Andrade e Dr. Osvaldo Antônio Serra pelos excelentes professores que foram.

- Aos meus amigos de Curitiba: Nelissa Pacheco, Ingrid Friedler, Thais dos Santos, Regina Persiani, Helder Marchini, Ana Victória, Mariana Mariussi, Francis Baungardt e Isis Lidiane, companheiros de muitos momentos divertidos e que fizeram minha estadia em Curitiba mais feliz.

- Aos amigos que fiz em Ribeirão Preto: Bárbara e Bruna Maróstica e Beatriz Biscola, da república, agradeço pela experiência trocada, pela amizade e as boas lembranças. À Paloma Nogueira, Marcela e Ana Paula Avelar, Suzany Rezende, Gabriela Solano, agradeço pela força que me deram em momentos complicados, me apoiando a enfrentar obstáculos que pareciam intransponíveis.

- Aos meus amigos de laboratório Gisdélia, Dunna e Leonardo (alunos do Prof. Dr. Elia Tfouni) e, Larissa, Rafael, André, Bruna e Roberta (alunos do Prof. Dr. José 
Maurício Almeida Caiut). E também, à Jeane e Bruna, que sempre estiveram do meu lado nos bons momentos, de risos e alegria, mas também nos difíceis.

- Aos técnicos de laboratório Aline Nunes Chiba, Ivana Aparecida Borin, Losane Mazzucato e Vinicius Palaretti.

- Ao aluno de mestrado do programa de pós-graduação em química Daniel Previdi, por sempre estar pronto a auxiliar na obtenção dos espectros de RMN.

- À Lâmia e todo o pessoal da secretaria da química, pela dedicação e disposição em ajudar sempre.

- Ao Coordenação de Aperfeiçoamento de Pessoal de Nível Superior (CAPES), pela bolsa concedida, ao Conselho Nacional de Desenvolvimento Científico e Tecnológico (CNPq) e à Fundação de Amparo à Pesquisa ao Estado de São Paulo (FAPESP) pelo financiamento do projeto temático ao qual nosso grupo pertence.

- Acima de tudo, à Deus, que é a partir Dele, que tudo é possível.

- À todos que de alguma forma me ajudaram, me apoiaram para a realização deste trabalho. 
"Porque aos Seus anjos dará ordem a teu respeito, para te guardarem em todos os teus caminhos". (Salmos 91:11) 


\section{RESUMO}

GASPARI, A. P. S. Considerações sobre a liberação fotoquímica de óxido nítrico, sensibilizada por corantes, a partir de um nitrosilo de rutênio. 2013. Dissertação de Mestrado. Faculdade de Filosofia, Ciências e Letras de Ribeirão Preto - Universidade de São Paulo. Ribeirão Preto, 2013.

O complexo conhecido trans-[Ru(NO) $\left.\left(\mathrm{NH}_{3}\right)_{4}(\mathrm{py})\right]\left(\mathrm{BF}_{4}\right)_{3}$ foi sintetizado e caracterizado por cromatografia líquida de alta eficiência e espectroscopias de $\mathrm{RMN}$ de ${ }^{1} \mathrm{H}$, de absorção eletrônica e de infravermelho e RPE. O espectro de absorção de infravermelho do complexo apresenta o pico de estiramento de NO em $1931 \mathrm{~cm}^{-1}$ e o seu espectro de absorção eletrônica apresenta bandas em $237 \mathrm{~nm}\left(\varepsilon=5200 \mathrm{~mol}^{-1} \mathrm{~L}\right.$ $\left.\mathrm{cm}^{-1}\right), 267\left(\varepsilon=2300 \mathrm{~mol}^{-1} \mathrm{~L} \mathrm{~cm}^{-1}\right)$, e $324 \mathrm{~nm}\left(\varepsilon=160 \mathrm{~mol}^{-1} \mathrm{~L} \mathrm{~cm}^{-1}\right)$, concordantes com a literatura.O corante azul do Nilo $\left(\lambda_{\operatorname{máx}}=635 \mathrm{~nm}\right)$ sofre fotoquímica quando irradiado com luz de $577 \mathrm{~nm}$, ao passo que os corantes rodamina-B $\left(\lambda_{\operatorname{máx}}=524 \mathrm{e}\right.$ $570 \mathrm{~nm})$, fluoresceína sódica $\left(\lambda_{\operatorname{máx}}=437 \mathrm{~nm}\right)$ e tartrazina $\left(\lambda_{\operatorname{máx}}=438 \mathrm{~nm}\right)$ não. $A$ fotólise do complexo em solução aquosa, $\mathrm{pH} \sim 3$, com luz de $313 \mathrm{~nm}$ leva à liberação de NO. Soluções aquosas de trans-[Ru(NO) $\left.\left(\mathrm{NH}_{3}\right)_{4}(\mathrm{py})\right]\left(\mathrm{BF}_{4}\right)_{3}$ em pH 7,4 (tampão fosfato) na presença da forma monomérica dos corantes rodamina-B ( $\lambda_{\text {irr }}=570 \mathrm{~nm}$ ), fluoresceína sódica $\left(\lambda_{\text {irr }}=440\right.$ e $\left.490 \mathrm{~nm}\right)$, tartrazina $\left(\lambda_{\text {irr }}=440 \mathrm{~nm}\right)$ e alaranjado de acridina $\left(\lambda_{\text {irr }}=440 \mathrm{~nm}\right)$ foram irradiadas com laser nas bandas de absorção máxima desses corantes. Para verificar se estava ocorrendo a liberação de NO pelo complexo através da sensibilização por corantes foram utilizados os capturadores de NO mioglobina e carboxy-PTIO. Os resultados indicam que não houve liberação de NO nesses casos, sugerindo que não ocorre transferência de energia de corantes para o complexo trans-[Ru(NO) $\left.\left(\mathrm{NH}_{3}\right)_{4}(\mathrm{py})\right]^{3+}$, ao se irradiar na banda de absorbância máxima dos corantes, pelo mecanismo de Förster (transferência de energia a longa distância). Para que ocorra, a fotoquímica deve estar associada a uma transferência de energia do tipo Dexter, onde o corante é ligado diretamente ao complexo.

Palavras-chave: Liberação fotoquímica de óxido nítrico, Sensibilização por corantes, tetraaminpiridinanitrosilrutênio, nitrosilos de rutênio. 


\begin{abstract}
GASPARI, A. P. S. Considerations on the dye-sensitized photochemical release of nitric oxide from a ruthenium nitrosyl. 2013. Dissertação de Mestrado. Faculdade de Filosofia, Ciências e Letras de Ribeirão Preto - Universidade de São Paulo. Ribeirão Preto, 2013.
\end{abstract}

The known complex trans-[Ru(NO) $\left.\left(\mathrm{NH}_{3}\right)_{4}(\mathrm{py})\right]\left(\mathrm{BF}_{4}\right)_{3}$ was synthesized and characterized by high performance liquid chromatography, ${ }^{1} \mathrm{H} N M R$, EPR, and electronic and infrared absorption spectroscopies. The complex infrared absorption spectrum displays the NO stretching peak at $1931 \mathrm{~cm}^{-1}$ and its electronic absorption spectrum shows bands at $237 \mathrm{~nm}\left(\varepsilon=5200 \mathrm{~mol}^{-1} \mathrm{~L} \mathrm{~cm}^{-1}\right), 267\left(\varepsilon=2300 \mathrm{~mol}^{-1} \mathrm{~L} \mathrm{~cm}^{-}\right.$ $\left.{ }^{1}\right)$, and $324 \mathrm{~nm}\left(\varepsilon=160 \mathrm{~mol}^{-1} \mathrm{~L} \mathrm{~cm}^{-1}\right)$, in agreement with reported values. The Nile blue dye $\left(\lambda_{\max }=635 \mathrm{~nm}\right)$ undergoes photochemistry by irradiation with $577 \mathrm{~nm}$ light, while rhodamine-B $\left(\lambda_{\max }=524\right.$ and $\left.570 \mathrm{~nm}\right)$, sodium fluorescein $\left(\lambda_{\max }=437 \mathrm{~nm}\right)$ and tartrazine $\left(\lambda_{\max }=438 \mathrm{~nm}\right)$ do not. The photolysis of the complex in $\mathrm{pH} 3$ aqueous solution with $313 \mathrm{~nm}$ light results in NO release. Aqueous solutions of trans$\left[\mathrm{Ru}(\mathrm{NO})\left(\mathrm{NH}_{3}\right)_{4}(\mathrm{py})\right]\left(\mathrm{BF}_{4}\right)_{3}$ at $\mathrm{pH} 7,4$ (BPS) in the presence of the monomeric forms of the rhodamina-B $\left(\lambda_{\text {irr }}=570 \mathrm{~nm}\right)$, sodium fluorescein $\left(\lambda_{\text {irr }}=440\right.$ e $\left.490 \mathrm{~nm}\right)$, tartrazine $\left(\lambda_{\text {irr }}=440 \mathrm{~nm}\right)$, and acridine orange $\left(\lambda_{\text {irr }}=440 \mathrm{~nm}\right)$ dyes were irradiated at the their absorption maxima. In order to verify the NO release from the complex through sensitization by the dyes, the NO scavengers myoglobin and carboxy-PTIO were used. The results indicate that NO release does not occur under these circumstances, suggesting, thus, that there is no energy transfer from the dyes to the trans- $\left[\mathrm{Ru}(\mathrm{NO})\left(\mathrm{NH}_{3}\right)_{4}(\mathrm{py})\right]^{3+}$ complex by irradiating at the dyes absorbance maxima bands by the Förster mechanism (long distance energy transfer). For the photochemistry to occur it should be associated to a Dexter type energy transfer, in which the sensitizer is directly attached to the complex.

Keywords: nitric oxide release, dye-sensitized, ruthenium amines, ruthenium nitrosyls. 


\section{LISTA DE FIGURAS}

Figura 1 - Diagrama de orbitais moleculares do monóxido de nitrogênio.

Figura 2 - Representação da síntese biológica do óxido nítrico

Figura 3 - Estrutura do nitroprussiato de sódio (SNP).....

Figura 4 - Estrutura do complexo $\mathrm{K}[\mathrm{RuCl}($ Hedta $)]$

Figura 5 - Exemplos de doadores de NO

Figura 6 - Exemplos de nitrosilo complexos de rutênio doadores de NO

Figura 7 - Estrutura a) da ftalocianina e b) de um complexo de rutênio ligado a um sensibilizador, a resorufina

Figura 8 - Espectro Uv-vis do íon $\left[\mathrm{Ru}\left(\mathrm{NH}_{3}\right)_{5}(\mathrm{py})\right]^{2+}$ irradiado na banda de absorção eletrônica do corante rodamina-B $(520 \mathrm{~nm})$, apresentando liberação de piridina e amônia pelo complexo.

Figura 9 - Esquema dos equipamentos utilizados nos ensaios fotoquímicos....

Figura 10 - Espectro de absorção da piridina em solução aquosa

Figura 11 - Espectro de infravermelho do complexo trans$[\mathrm{Ru}(\mathrm{NO})(\mathrm{OH})(\mathrm{cyclam})]\left(\mathrm{PF}_{6}\right)_{2}$ em pastilha de $\mathrm{KBr}$

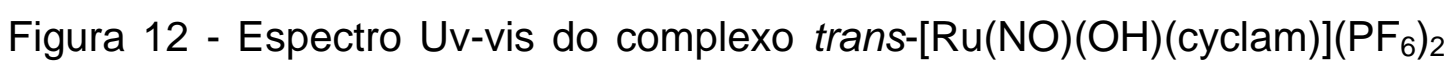
em solução de $\mathrm{HCl} 1 \mathrm{~mol} \mathrm{~L}^{-1}$.....

Figura 13 - Cromatograma do complexo trans-[Ru( $\left.\left.\mathrm{NH}_{3}\right)_{4}(\mathrm{py})(\mathrm{NO})\right]\left(\mathrm{BF}_{4}\right)_{3}$, utilizando-se como fase móvel a mistura água:metanol (70:30) acidificada 
Figura 14 - Espectro de ${ }^{1} \mathrm{H}$ NMR do complexo trans-[Ru( $\left.\left(\mathrm{NH}_{3}\right)_{4}(\mathrm{py})(\mathrm{NO})\right]^{3+}$ em $\mathrm{D}_{2} \mathrm{O}$.

Figura 15 - Representação dos desdobramentos dos sinais esperados no espectro de RMN ${ }^{1} \mathrm{H}$ para o hidrogênio $\mathrm{H}_{4}$ do ligante piridina do complexo trans-[Ru( $\left.\left(\mathrm{NH}_{3}\right)_{4}(\mathrm{py})(\mathrm{NO})\right]\left(\mathrm{BF}_{4}\right)_{3}$

Figura 16 - Espectro de absorção no infravermelho do complexo trans$\left[\mathrm{Ru}\left(\mathrm{NH}_{3}\right)_{4}(\mathrm{py})(\mathrm{NO})\right]\left(\mathrm{BF}_{4}\right)_{3}$ em $\mathrm{KBr}$

Figura 17 - Espectro eletrônico do complexo trans-[Ru(NH$\left.\left.)_{4}\right)_{4}(\mathrm{py})(\mathrm{NO})\right]\left(\mathrm{BF}_{4}\right)_{3}$ em $\mathrm{CF}_{3} \mathrm{COOH} 0,1 \mathrm{~mol} \mathrm{~L}^{-1}$

Figura 18 - Espectros de absorção eletrônica da irradiação com luz de 313 $\mathrm{nm}$ do complexo trans-[Ru($\left.\left(\mathrm{NH}_{3}\right)_{4}(\mathrm{py})(\mathrm{NO})\right]\left(\mathrm{BF}_{4}\right)_{3}$ em solução $\mathrm{CF}_{3} \mathrm{COOH} / \mathrm{CF}_{3} \mathrm{COONa} \mathrm{pH} \sim 3$, nos tempos $\mathrm{t}=0,5,10,20$ e 40 minutos.

Figura 19 - Espectros obtidos na fotólise com luz de $577 \mathrm{~nm}$ de uma solução $7,64 \times 10^{-7} \mathrm{~mol}^{-1}$ de corante Azul do Nilo em solução $\mathrm{CF}_{3} \mathrm{COOH} / \mathrm{CF}_{3} \mathrm{COONa} \mathrm{pH} \sim 3$ nos tempos $0,1,2,4,8,16,32$ e 64 minutos

Figura 20 - Espectro de emissão de uma solução 7,64 X $10^{-7} \mathrm{~mol} \mathrm{~L}^{-1}$ de corante Azul do Nilo em solução $\mathrm{CF}_{3} \mathrm{COOH} / \mathrm{CF}_{3} \mathrm{COONa} \mathrm{pH} \sim 3$ nos tempos 0 , 1, 2, 4, 8, 16, 32 e 64 minutos, com comprimentos de onda de excitação de $630 \mathrm{~nm}$ e emissão em $674 \mathrm{~nm}$.

Figura 21 - Quatro diferentes formas iônicas em que a fluoresceína pode ser encontrada em meio aquoso dependendo do $\mathrm{pH}$ do meio. 
Figura 22 - Espectro de excitação da solução de fluoresceína sódica 4,97 X $10^{-4} \mathrm{~mol} \mathrm{~L}{ }^{-1}$ em solução $\mathrm{CF}_{3} \mathrm{COOH} / \mathrm{CF}_{3} \mathrm{COONa} \mathrm{pH} \sim 3$. Pico de absorção máxima registrado em $437 \mathrm{~nm}$.

Figura 23 - Espectros Uv-vis obtidos na fotólise pela irradiação de uma solução de fluoresceína sódica $4,97 \times 10^{-4} \mathrm{~mol}^{-1}$ em solução $\mathrm{CF}_{3} \mathrm{COOH} / \mathrm{CF}_{3} \mathrm{COONa} \mathrm{pH} \sim$, com filtro de interferência de onda de $438 \mathrm{~nm}$, nos tempos $0,2,4,6$ e 26 minutos.

Figura 24 - Espectros de emissão de uma solução de $4,97 \times 10^{-4} \mathrm{~mol} \mathrm{~L}^{-1}$ de fluoresceína sódica em solução $\mathrm{CF}_{3} \mathrm{COOH} / \mathrm{CF}_{3} \mathrm{COONa} \mathrm{pH} \sim 3$, irradiada em $438 \mathrm{~nm}$, nos tempos $0,2,4,6$ e 26 minutos. A linha de menor intensidade corresponde ao tempo 0

Figura 25 - Espectros Uv-vis obtidos na irradiação de uma solução de rodamina-B $1,00 \times 10^{-5} \mathrm{~mol} \mathrm{~L}^{-1}$ em solução $\mathrm{CF}_{3} \mathrm{COOH} / \mathrm{CF}_{3} \mathrm{COONa} \mathrm{pH} \sim 3$, com luz de $524 \mathrm{~nm}$, nos tempos 0 (linha vermelha), 5 (linha verde) e 10 minutos (linha azul)

Figura 26 - Espectros Uv-vis obtidos na irradiação de uma solução de tartrazina $1,50 \times 10^{-5} \mathrm{~mol} \mathrm{~L}^{-1}$ em solução $\mathrm{CF}_{3} \mathrm{COOH} / \mathrm{CF}_{3} \mathrm{COONa} \mathrm{pH} \sim 3$, com luz de $438 \mathrm{~nm}$, nos tempos 0,5 e 10 minutos

Figura 27 - Espectros de emissão de uma solução de tartrazina 1,50 X $10^{-5}$ mol L ${ }^{-1}$ em solução $\mathrm{CF}_{3} \mathrm{COOH} / \mathrm{CF}_{3} \mathrm{COONa} \mathrm{pH} \sim 3$, irradiada com luz de 438 $\mathrm{nm}$, nos tempos 0,5 e 10 minutos.

Figura 28 - Espectros de absorção eletrônica obtidos na irradiação com luz de $438 \mathrm{~nm}$ de uma solução do complexo trans-[Ru(NH$\left.\left.)_{4}\right)_{4}(\mathrm{py})(\mathrm{NO})\right]\left(\mathrm{BF}_{4}\right)_{3}$ preparada a partir de uma solução de fluoresceína sódica $4,97 \times 10^{-4} \mathrm{~mol} \mathrm{~L}^{-1}$ em solução $\mathrm{CF}_{3} \mathrm{COOH} / \mathrm{CF}_{3} \mathrm{COONa} \mathrm{pH} \sim 3$, nos tempos $0,1,2,4,8,16$ e 60 minutos 
Figura 29 - Espectros de emissão obtidos na fotólise com luz de $438 \mathrm{~nm}$ de uma solução do complexo trans-[Ru( $\left.\left(\mathrm{NH}_{3}\right)_{4}(\mathrm{py})(\mathrm{NO})\right]\left(\mathrm{BF}_{4}\right)_{3}$ preparada a partir de uma solução de fluoresceína sódica $4,97 \times 10^{-4} \mathrm{~mol} \mathrm{~L}^{-1}$ em solução $\mathrm{CF}_{3} \mathrm{COOH} / \mathrm{CF}_{3} \mathrm{COONa} \mathrm{pH} \sim 3$, nos tempos $0,1,2,4,8,16$ e 60 minutos (Comprimento de onda de excitação foi de $450 \mathrm{~nm}$ e janela de $3 / 1,5$ ).

Figura 30 - Espectros de absorção eletrônica obtidos na irradiação com luz de $570 \mathrm{~nm}$ de uma solução do complexo trans-[Ru( $\left.\left(\mathrm{NH}_{3}\right)_{4}(\mathrm{py})(\mathrm{NO})\right]\left(\mathrm{BF}_{4}\right)_{3} 1,02$ $\times 10^{-3} \mathrm{~mol} \mathrm{~L}^{-1}$ preparada a partir de uma solução de rodamina-B $1,00 \times 10^{-5}$ mol L ${ }^{-1} \mathrm{em} \mathrm{CF}_{3} \mathrm{COOH} / \mathrm{CF}_{3} \mathrm{COONa} \mathrm{pH} \sim$, nos tempos $0,4,10,15,20,25 \mathrm{e}$ 70 minutos.

Figura 31 - Espectros de emissão obtidos na irradiação com luz de $438 \mathrm{~nm}$ de uma solução do complexo trans-[Ru(NH$\left.)_{4}(\mathrm{py})(\mathrm{NO})\right]\left(\mathrm{BF}_{4}\right)_{3} 1,02 \times 10^{-3} \mathrm{~mol}$ $\mathrm{L}^{-1}$ preparada a partir de uma solução de rodamina-B $1,00 \times 10^{-5} \mathrm{~mol} \mathrm{~L}^{-1} \mathrm{em}$ $\mathrm{CF}_{3} \mathrm{COOH} / \mathrm{CF}_{3} \mathrm{COONa} \mathrm{pH} \sim$, nos tempos $0,4,10,15,20,25$ e 70 minutos. (Comprimento de onda de excitação foi de $570 \mathrm{~nm}$ e janela de $5 / 3$ )

Figura 32 - Estrutura da tetrafenilporfirina de cobalto (Co(TPP))

Figura 33 - Espectro eletrônico do acompanhamento das irradiações com luz de $313 \mathrm{~nm}$ de uma solução de $6,8 \times 10^{-3} \mathrm{~mol} \mathrm{~L}^{-1}$ do complexo trans$\left[\mathrm{Ru}\left(\mathrm{NH}_{3}\right)_{4}(\mathrm{py})(\mathrm{NO})\right]\left(\mathrm{BF}_{4}\right)_{3}$ em tampão fosfato $(\mathrm{pH}=7,4)$ na presença de mioglobina (banda registrada em $410 \mathrm{~nm}$ ) nos tempos $0,1,2,4,8,16$ e 38 minutos

Figura 34 - Espectros de absorção eletrônica obtidos na irradiação com luz de $580 \mathrm{~nm}$ de uma solução trans-[Ru(NH$\left.)_{3}(\mathrm{py})(\mathrm{NO})\right]\left(\mathrm{BF}_{4}\right)_{3} 1,03 \times 10^{-3} \mathrm{~mol} \mathrm{~L}^{-}$ ${ }^{1}$ em solução Rodamina-B $1,00 \times 10^{-5} \mathrm{~mol} \mathrm{~L}^{-1} \mathrm{em}$ tampão fosfato $(\mathrm{pH}=7,4)$, na presença de mioglobina, nos tempos $t=0,1,2,4$ e 8 minutos

Figura 35 - Espectros de absorção eletrônica obtidos na irradiação com luz de $524 \mathrm{~nm}$ de uma solução trans-[Ru(NH$\left.)_{3}(\mathrm{py})(\mathrm{NO})\right]\left(\mathrm{BF}_{4}\right)_{3} 1,03 \times 10^{-3} \mathrm{~mol} \mathrm{~L}^{-}$ ${ }^{1}$ em solução Rodamina-B $1,00 \times 10^{-5} \mathrm{~mol} \mathrm{~L}^{-1}$ em tampão fosfato $(\mathrm{pH}=7,4)$ 
na presença de mioglobina, nos tempos $t=0,15,30,45,60,75,90$ e 105 segundos.

Figura 36 - Espectros de absorção eletrônica obtidos na irradiação com luz de $480 \mathrm{~nm}$ de uma solução trans-[Ru(NH$\left.)_{3}(\mathrm{py})(\mathrm{NO})\right]\left(\mathrm{BF}_{4}\right)_{3} 1,03 \times 10^{-3} \mathrm{~mol} \mathrm{~L}^{-}$ ${ }^{1}$ em solução fluoresceína sódica $1,05 \times 10^{-5} \mathrm{~mol} \mathrm{~L}^{-1} \mathrm{em}$ tampão fosfato $(\mathrm{pH}=$ 7,4 ), na presença de mioglobina, nos tempos $t=0,5,10$ e 15 segundos

Figura 37 - Reação do PTIO e carboxi-PTIO com NO, formando carboxi-PTI ou PTI.

Figura 38 - Espectro de EPR da solução de carboxi-PTIO (C C PTIO $=6,3 \times 10^{-3}$ mol $\left.\mathrm{L}^{-1}\right)$ em tampão fosfato $(\mathrm{pH}=7,4)$, irradiada por 10 minutos em 355 $\mathrm{nm}$.

Figura 39 - Espectro de EPR da solução trans-[Ru( $\left.\left(\mathrm{NH}_{3}\right)_{4}(\mathrm{py})(\mathrm{NO})\right]\left(\mathrm{BF}_{4}\right)_{3}\left(\mathrm{C}_{\mathrm{Ru}}\right.$ $\left.=10^{-4} \mathrm{~mol} \mathrm{~L}^{-1}\right)$ na presença de carboxi-PTIO $\left(C_{\mathrm{PTIO}}=6,3 \times 10^{-3} \mathrm{~mol} \mathrm{~L}^{-1}\right)$ irradiado por 10 minutos em $355 \mathrm{~nm}$

Figura 40 - Espectros de EPR da solução de carboxi-PTIO $\left(C_{\mathrm{PTIO}}=6,3 \times 10^{-3}\right.$ mol L $\left.{ }^{-1}\right)$ e trans- $\left[\mathrm{Ru}\left(\mathrm{NH}_{3}\right)_{4}(\mathrm{py})(\mathrm{NO})\right]\left(\mathrm{BF}_{4}\right)_{3}\left(C_{\mathrm{Ru}}=10^{-4} \mathrm{~mol} \mathrm{~L}-1\right)$ na presença de rodamina-B $\left(C_{\text {rod-B }}=5,76 \times 10^{-4} \mathrm{~mol} \mathrm{~L}^{-1}\right)$ irradiada por 15 minutos em $520 \mathrm{~nm}$ e em $570 \mathrm{~nm}$

Figura 41 - Espectro de EPR da solução de carboxi-PTIO (C CPIO $=6,3 \times 10^{-3}$ mol L-1 $)$ e trans- $\left[\mathrm{Ru}\left(\mathrm{NH}_{3}\right)_{4}(\mathrm{py})(\mathrm{NO})\right]\left(\mathrm{BF}_{4}\right)_{3}\left(C_{\mathrm{Ru}}=10^{-4} \mathrm{~mol} \mathrm{~L}-1\right)$ na presença de fluoresceína sódica $\left(\mathrm{C}_{\text {fluor. }}=5,76 \times 10^{-4} \mathrm{~mol} \mathrm{~L}^{-1}\right)$ irradiada por 15 minutos em $440 \mathrm{~nm}$ e $490 \mathrm{~nm}$

Figura 42 - Espectro de EPR da solução de carboxi-PTIO (C CPTIO $=6,3 \times 10^{-3}$ mol L-1 $)$ e trans- $\left[\mathrm{Ru}\left(\mathrm{NH}_{3}\right)_{4}(\mathrm{py})\left(\mathrm{NO}^{-}\right)\right]\left(\mathrm{BF}_{4}\right)_{3}\left(C_{\mathrm{Ru}}=10^{-4} \mathrm{~mol} \mathrm{~L}^{-1} 1\right)$ na presença de tartrazina $\left(C_{\text {tart. }}=7,6 \times 10^{-4} \mathrm{~mol} \mathrm{~L}^{-1}\right)$ irradiada por 15 minutos em $440 \mathrm{~nm} \ldots \ldots \ldots$

Figura 43 - Espectro de EPR da solução de carboxi-PTIO $\left(C_{\text {PTIO }}=6,3 \times 10^{-\varepsilon}\right.$ 
mol L $\left.{ }^{-1}\right)$ e trans- $\left[\mathrm{Ru}\left(\mathrm{NH}_{3}\right)_{4}(\mathrm{py})(\mathrm{NO})\right]\left(\mathrm{BF}_{4}\right)_{3}\left(C_{\mathrm{Ru}}=10^{-4} \mathrm{~mol} \mathrm{~L}^{-1}\right)$ na presença de alaranjado de acridina $\left(\mathrm{C}_{\text {acrid. }}=7,4 \times 10^{-4} \mathrm{~mol} \mathrm{~L}^{-1}\right)$ irradiada por 15 minutos em $440 \mathrm{~nm}$ 


\section{LISTA DE TABELAS}

Tabela 1 - Reagentes e solventes utilizados nas sínteses realizadas neste trabalho.

Tabela 2 - Dados de comprimento de onda máximo e absortividade molar encontrados nos espectros eletrônicos Uv-visível dos complexos cis-

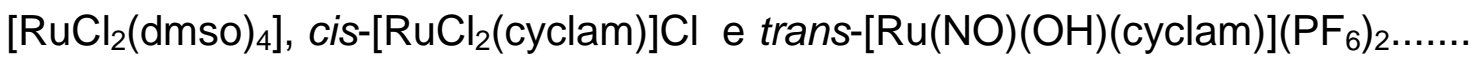

Tabela 3 - Dados de comprimento de onda máximo e absortividade molar encontrados nos espectros eletrônicos Uv-visível dos complexos $\left[\mathrm{RuCl}\left(\mathrm{NH}_{3}\right)_{5}\right] \mathrm{Cl}_{2}, \quad$ trans- $\left[\mathrm{Ru}\left(\mathrm{SO}_{4}\right)\left(\mathrm{NH}_{3}\right)_{4}(\mathrm{py})\right] \mathrm{Cl} \quad$ e $\quad$ trans$\left[\mathrm{Ru}\left(\mathrm{NH}_{3}\right)_{4}(\mathrm{py})(\mathrm{NO})\right]\left(\mathrm{BF}_{4}\right)_{3}$

Tabela 4 - Acoplamentos possíveis para os hidrogênios do benzeno, da piridina e da piridina ligada ao rutênio e suas respectivas frequências em Hertz

Tabela 5 - Atribuição das bandas do espectro de infravermelho complexo trans$\left[\mathrm{Ru}\left(\mathrm{NH}_{3}\right)_{4}(\mathrm{py})(\mathrm{NO})\right]\left(\mathrm{BF}_{4}\right)_{3}$ e os valores correspondentes encontrados na literatura.

Tabela 6 - Bandas encontradas no espectro de absorção Uv-vis do complexo trans-[Ru( $\left.\left(\mathrm{NH}_{3}\right)_{4}(\mathrm{py})(\mathrm{NO})\right]\left(\mathrm{BF}_{4}\right)_{3}$ em $\mathrm{CF}_{3} \mathrm{COOH} 0,1 \mathrm{~mol} \mathrm{~L}^{-1}$, com respectivas atribuições

Tabela 7 - Corantes escolhidos para a tentativa de sensibilização do complexo trans-[Ru( $\left.\left(\mathrm{NH}_{3}\right)_{4}(\mathrm{py})(\mathrm{NO})\right]\left(\mathrm{BF}_{4}\right)_{3}$ 


\section{SUMÁRIO}

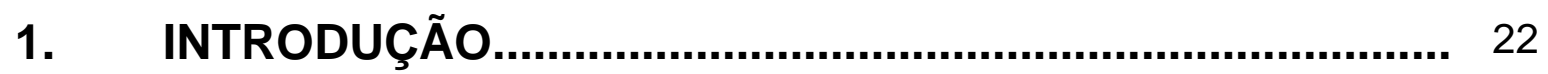

$1.1 \quad$ Aspectos químicos do óxido nítrico................................................ 22

1.2 Óxido nítrico em sistemas biológicos.............................................. 24

$1.3 \quad$ Doadores de NO........................................................................ 26

1.4 Complexos nitrosilos de metais de transição................................. 29

1.4.1 Algumas das primeitas aplicações dos compostos de rutênio na área farmacológica............................................................................ 29

1.4.2 Compostos nitrosilos de rutênio...................................................... 31

2. OBJETIVOS..................................................................... 38

3. PROCEDIMENTO EXPERIMENTAL.................................... 39

3.1 Reagentes e solventes..................................................................... 39

3.2 Purificação dos reagentes e solventes........................................... 41

3.2.1 Purificação da acetona................................................................... 41

3.2.2 Purificação do éter etílico.............................................................. 42

3.2.3 Purificação da piridina................................................................... 42

3.2.4 Amalgama de zinco................................................................... 42

3.2.5 Solução de perclorato de crômio(II) .................................................... 43

3.2.6 Sistema da linha de argônio............................................................... 43

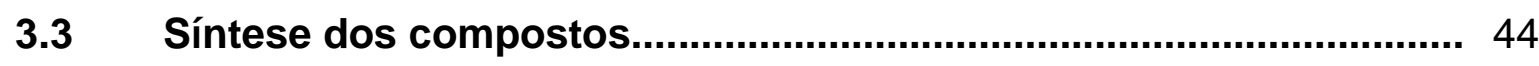

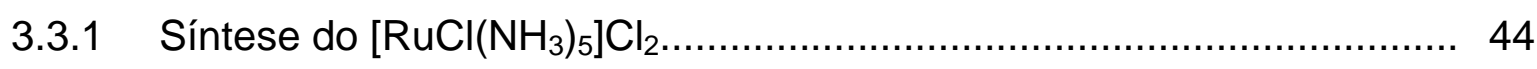

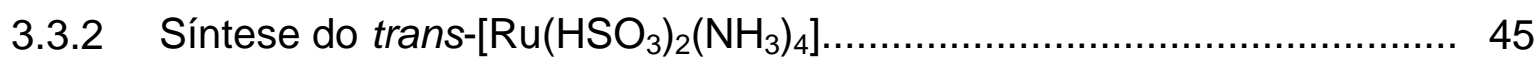

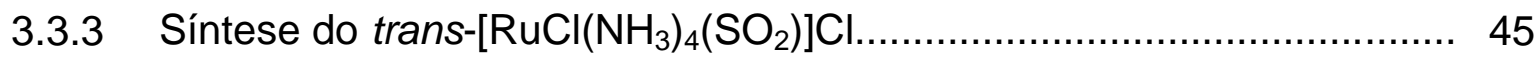




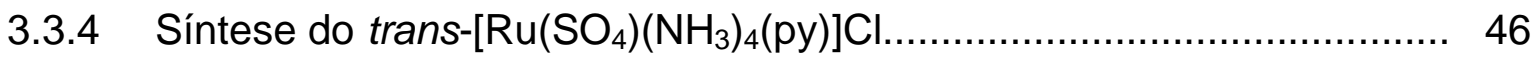

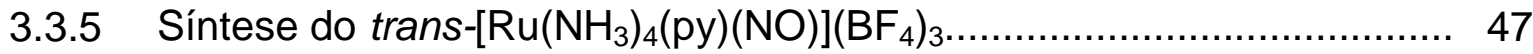

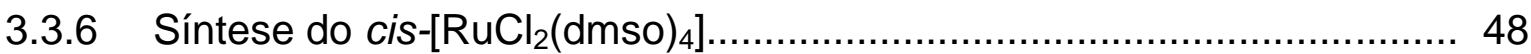

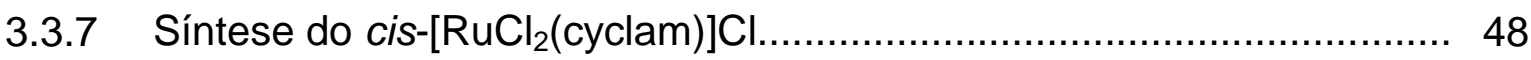

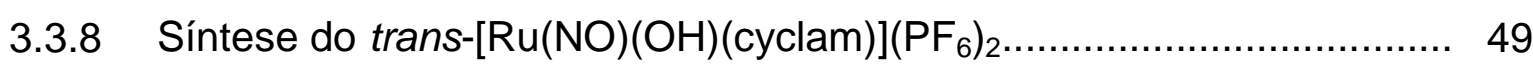

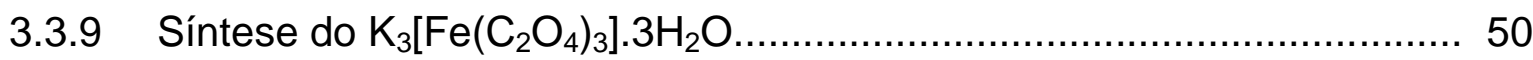

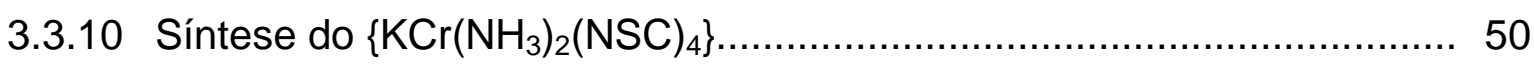

3.4 Equipamentos e métodos utilizados............................................... 51

3.4.1 Espectros eletrônicos na região do visível e ultravioleta...................... 51

3.4.2 Espectroscopia de emissão........................................................ 51

3.4.3 Espectros na região do infravermelho.............................................. 52

3.4.4 Ressonância magnética nuclear.................................................... 52

3.4.5 Ressonância paramagnética eletrônica............................................. 52

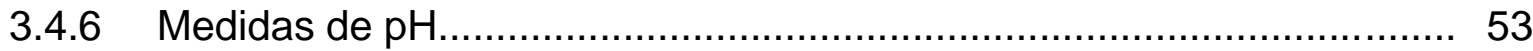

3.4.7 Cromatografia a líquido de alta eficiência - CLAE............................... 53

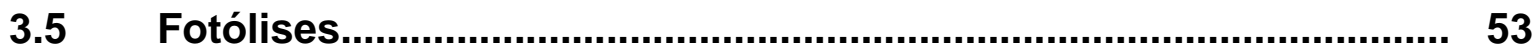

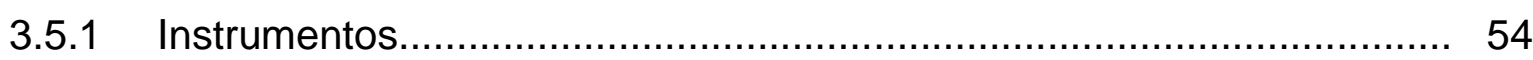

3.5.2 Filtros de interferência................................................................ 56

3.5.3 Medidas da intensidade da luz incidente......................................... 56

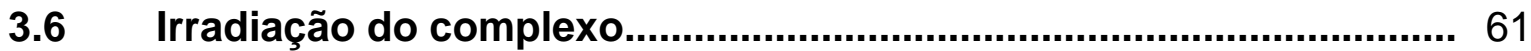

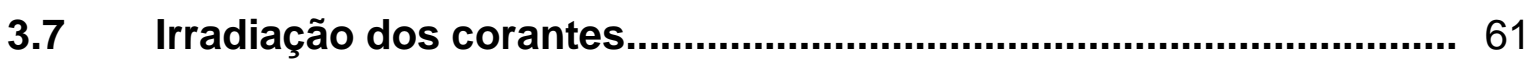

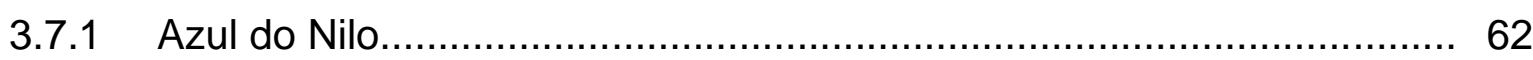

3.7.2 Fluoresceína Sódica................................................................... 62

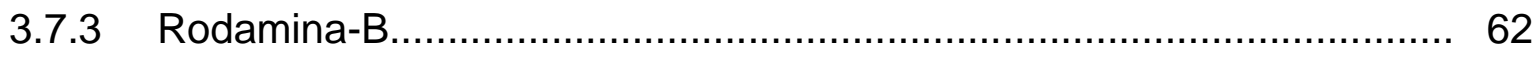

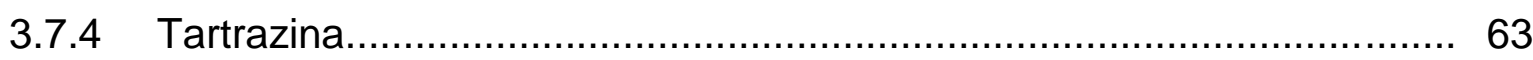

3.8 Irradiação do complexo trans-[Ru( $\left.\left(\mathrm{NH}_{3}\right)_{4}(\mathrm{py})(\mathrm{NO})\right]\left(\mathrm{BF}_{4}\right)_{3}$ na presença dos corantes................................................................. 63

3.8.1 Complexo + fluoresceína sódica..................................................... 63 
3.8.2 Complexo + Rodamina-B.

3.9 Determinação da quantidade de NO liberada.................................. 64

3.9.1 Complexo + rodamina-B + mioglobina...................................... 64

3.9.2 Complexo + fluoresceína sódica + mioglobina ................................ 65

3.9.3 Solução estoque carboxy-PTIO............................................... 65

3.9.4 Complexo + carboxy-PTIO ..................................................... 65

3.9.5 Complexo + alaranjado de acridina + carboxy-PTIO.......................... 66

3.9.6 Complexo + rodamina-B + carboxy-PTIO .................................... 66

3.9.7 Complexo + fluoresceína sódica + carboxy-PTIO............................. 67

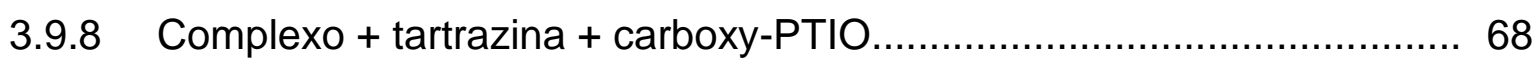

4. RESULTADOS E DISCUSSÃO............................................ 69

4.1 Purificação da Piridina......................................................................... 69

Síntese dos complexos............................................................ 69

4.3 Caracterização do complexo trans-[Ru(cyclam) $(\mathrm{NO})(\mathrm{OH})]\left(\mathrm{PF}_{6}\right)_{2} \ldots \ldots . .75$

4.4 Caracterização do complexo trans- $\left./ \mathrm{Ru}\left(\mathrm{NH}_{3}\right)_{4}(\mathrm{py})(\mathrm{NO})\right]\left(\mathrm{BF}_{4}\right)_{3} \ldots \ldots \ldots \ldots . .77$

$4.5 \quad$ Fotólise do Complexo...................................................................... 86

4.6 Corantes........................................................................................ 87

Fotólise dos corantes....................................................................... 89

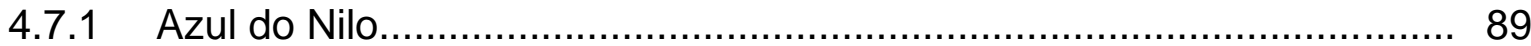

4.7.2 Fluoresceína Sódica................................................................... 91

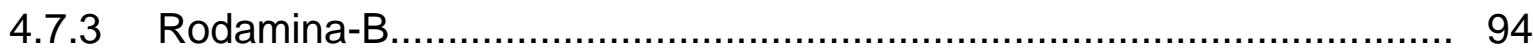

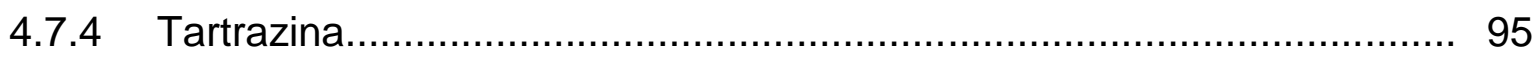

4.8 Fotólise do complexo trans- $\left[\mathrm{Ru}\left(\mathrm{NH}_{3}\right)_{4}(\mathrm{py})(\mathrm{NO})\right]\left(\mathrm{BF}_{4}\right)_{3}$ na presença 
de corantes.

4.9 Detecção do NO liberado pelo complexo trans$\left[\mathrm{Ru}\left(\mathrm{NH}_{3}\right)_{4}(\mathrm{py})(\mathrm{NO})\right]\left(\mathrm{BF}_{4}\right)_{3}$ através da sensibilização por corantes..... 102

4.9.1 Co(TPP) 102

4.9.2 Mioglobina. 104

4.10 Análise por Ressonância Paramagnética Eletrônica (EPR) através de carboxy-PTIO.

5. CONSIDERAÇÕES FINAIS 114

REFERÊNCIAS BIBLIOGRÁFICAS. 


\section{INTRODUÇÃO}

A descoberta de que o NO possui papel fundamental em sistemas biológicos, tais como regulação da pressão sanguínea, neuro-transmissão, resposta imunológica, reparação de tecidos, inibição de agregação plaquetária, relaxamento de músculo liso [1, 2] e, patologias, onde o NO exerce função relevante em doenças inflamatórias, nefrites, diabetes [3], artrite, arteriosclerose, câncer [1, 4] e doenças neurodegenerativas $[3,4]$, resultou em grande interesse em estudar seu comportamento e características. Além disso, o NO tem função como agente citoprotetor, capaz de inibir uma grande quantidade de agentes que provocam o estresse oxidativo [4].

Para entender sobre os processos fisiológicos, regulatórios e patologias, entre outros, que o NO exerce no organismo, é necessário saber um pouco sobre seus aspectos químicos.

\subsection{Aspectos Químicos do Óxido Nítrico}

O óxido nítrico é um gás incolor à temperatura ambiente (P.E. $\left.=-151,7^{\circ} \mathrm{C}\right)$, possui baixa solubilidade em água $\left(1,9 \mathrm{mmol}^{-1}\right.$ a $\left.25^{\circ} \mathrm{C}\right)$, e dissolve-se seletivamente em membranas e fases lipídicas das células.

A molécula de óxido nítrico possui 11 elétrons em sua camada de valência e sua configuração eletrônica é $(\sigma 1 s)^{2}\left(\sigma 1 s^{*}\right)^{2}(\sigma 2 s)^{2}\left(\sigma 2 s^{*}\right)^{2}(\pi 2 p)^{4}(\sigma 2 p)^{2}\left(\pi 2 p^{*}\right)^{1}$. Por apresentar um elétron desemparelhado (Figura 1), a molécula de NO é paramagnética. Esta é uma característica bastante relevante visto que a maioria dos processos biológicos que envolvem esta molécula ocorre via estabilização do elétron desemparelhado localizado no orbital $\pi$ antiligante $\left(\pi^{\star}\right)$. [5] O tempo de vida do NO 
no organismo humano é de 10 a $100 \mathrm{~ms}$ e os valores de consumo celular do NO (reações dependentes de $\mathrm{O}_{2}$ ) variam entre 0,01 a $7,5 \mathrm{~s}^{-1}[6]$.

O NO pode também se coordenar a metais, como o ferro e rutênio, por exemplo, formando inúmeros complexos. [5, 7, 8].

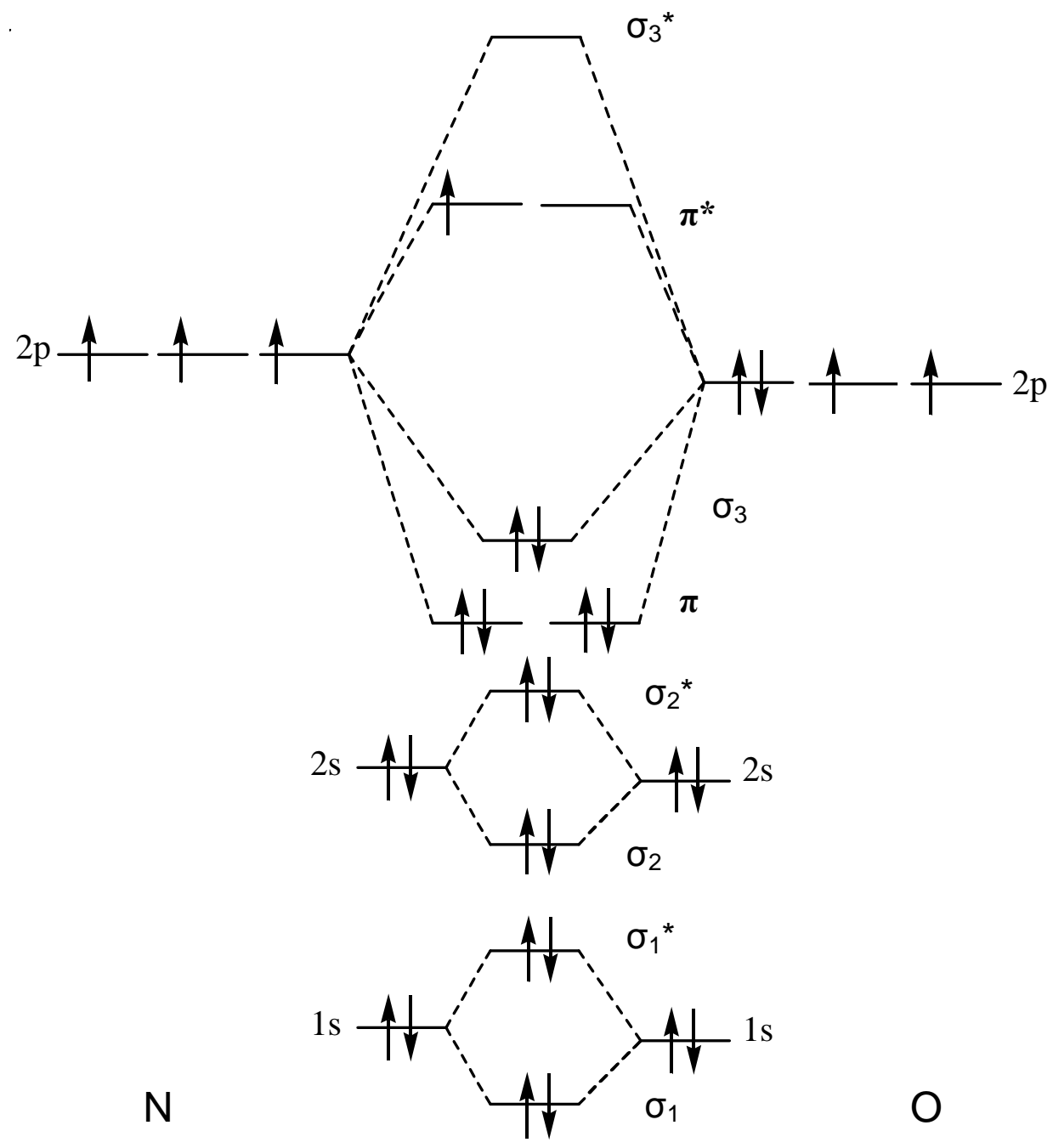

Figura 1 - Diagrama de orbitais moleculares do monóxido de nitrogênio.

Devido às diferentes eletronegatividades do nitrogênio e oxigênio, as contribuições para os orbitais moleculares também são diferentes. As funções de onda do oxigênio contribuem mais efetivamente para os orbitais moleculares ligantes, enquanto os orbitais antiligantes são formados predominantemente por 
contribuições das funções de onda do nitrogênio. O elétron desemparelhado é o que confere a seletividade da ligação via átomo de nitrogênio ao reagir com metais ou radicais, como por exemplo, $\mathrm{O}_{2}$ e $\mathrm{O}_{2}^{-}[9]$.

A reação com $\mathrm{O}_{2}^{-}$, uma das mais importantes reações do $\mathrm{NO}$ em meio biológico, gera íons peroxinitrito $\left(\mathrm{ONOO}^{-}\right)$, podendo deteriorar componentes celulares [5], como proteínas e DNA [10]. Outra reação largamente estudada é a oxidação do $\mathrm{NO}$ para $\mathrm{NO}_{2}$, reação a qual ocorre in vivo [11].

O significado químico e biológico das reações de oxidação do NO pelo oxigênio (tanto em sua forma livre quanto coordenada a metais), tem sido fonte de estudo para numerosas pesquisas, sendo certo que tais reações são importantes para a fisiologia e toxicologia do NO.

\section{2 Óxido nítrico em sistemas biológicos}

No organismo humano o NO é produzido a partir da enzima óxido nítrico sintase (NOS, do inglês Nitric Oxide Synthase). Cada unidade monomérica desta enzima possui quatro cofatores: uma molécula de flavina adenina dinucleotídeo (FAD), uma tetrahidrobiopterina $\left(\mathrm{BH}_{4}\right)$, uma flavina mononucleotídeo (FMN) e uma ferro protoporfirina IX (heme) e, pode ocorrer em três isoformas: a tipo I (óxido nítrico sintase neuronal, nNOS), tipo II (óxido nítrico sintase induzível, iNOS) e tipo III (óxido nítrico sintase endotelial, eNOS) [4].

As enzimas nNOS e eNOS, requerem o aumento na concentração de $\mathrm{Ca}^{2+}$ intracelular e consequente ativação da calmodulina para produzirem NO. Sua regulação primária é dependente do influxo de cálcio e geração de baixos níveis de NO em pequenos intervalos de tempo. Já a iNOS, necessita ser induzida por 
citocinas em praticamente todos os tipos de células, gerando NO em altas concentrações por intervalos de tempo prolongados [12].

A síntese de NO ocorre via oxidação da L-arginina, que é catalisada pela ação da enzima óxido nítrico sintase na presença da forma reduzida do fosfato de nicotinamida adenina dinucleotídeo (NADPH), que atua como doador de elétrons (Figura 2).
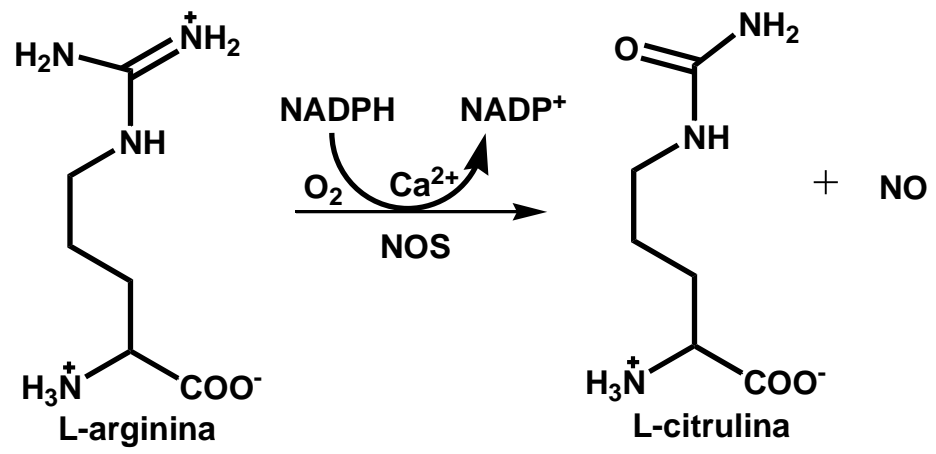

Figura 2 - Representação da síntese biológica do óxido nítrico.

Os processos que envolvem NO são categorizados em diretos ou indiretos. Os diretos geralmente ocorrem em baixas concentrações de $\mathrm{NO}$ ([NO] <50 nM) [6b], onde as reações ocorrem em tempo suficiente para que o NO consiga atingir moléculas alvo [6], sendo essencialmente funções fisiológicas de efeito protetor e regulatório [4]. Em contrapartida, os efeitos indiretos são relacionados com altas concentrações de $\mathrm{NO}([\mathrm{NO}]>300 \mathrm{nM})[6 \mathrm{~b}]$, envolvendo reações com $\mathrm{O}_{2}$ e $\mathrm{O}_{2}^{-\bullet}$ para gerar espécies reativas nitrogenadas, com subsequente reação com as moléculas alvo [6]. Altas concentrações de NO, por exemplo, podem gerar situações de choque séptico, o que gera vasodilatação, permitindo a passagem de fluídos vitais para os tecidos e, por conseguinte conduzindo ao inchaço e consequente queda de pressão sanguínea, promovendo sérios riscos à vida. Por outro lado, baixas concentrações também podem ser prejudiciais, tais como em vasoconstrição a qual resulta em 
hipertensão [13a, 13b]. Neste contexto, tornou-se considerável o interesse no estudo dos mecanismos pelos quais o $\mathrm{NO}$ atua no organismo e no desenvolvimento de compostos que ajam como doadores ou sequestradores de NO para aplicações médicas.

\subsection{Doadores e sequestradores de NO}

Os primeiros doadores de NO conhecidos, embora não como tais, foram os nitratos orgânicos, como a nitroglicerina e, o complexo metálico nitroprussiato de sódio, que embora tenha sido descoberto no final século XIX, só foi aplicado à medicina na década de 1950 [14].

O nitroprussiato de sódio (Figura 3), $\mathrm{Na}_{2}\left[\mathrm{Fe}(\mathrm{CN})_{5} \mathrm{NO}\right]$, é geralmente utilizado em casos que se necessita redução imediata de pressão sanguínea arterial (hipertensão) e para indução de hipotensão durante cirurgias [15]. No entanto, há algumas limitações em seu uso. Dependendo da concentração de cianeto presente no sangue, podem ocorrer os seguintes sintomas: taquicardia e rubor (20-30 $\mu \mathrm{mol}$ $\left.\mathrm{mL}^{-1}\right)$, níveis reduzidos de consciência $\left(48-65 \mu \mathrm{mol} \mathrm{mL}^{-1}\right)$, coma $\left(95-114 \mu \mathrm{mol} \mathrm{mL}^{-1}\right)$ e morte (acima de $114 \mu \mathrm{mol} \mathrm{mL}^{-1}$ ) [14]. Além disso, a exposição a altas doses ou uso contínuo pode acarretar em acúmulo de cianeto e seu metabólito tiocianato [16]. Para se contornar este inconveniente, alternativas podem ser utilizadas, tais como: administração de outros compostos tidos como antídotos, como hidroxocobalamina ou tiossulfato de sódio [17], ou então, o uso de outros doadores de NO. 


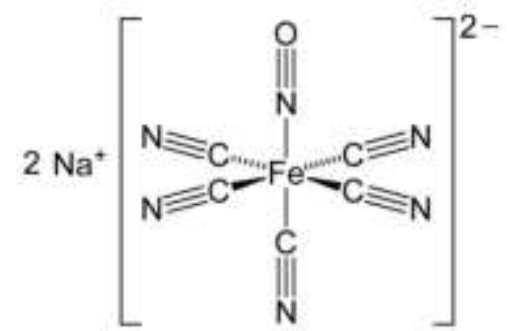

Figura 3 - Estrutura do nitroprussiato de sódio (SNP).

Mais recentemente, a partir de fins do século passado, vários doadores e capturadores de NO foram desenvolvidos. Um complexo que se apresenta como potencial e eficiente sequestrador de NO é o $\left[R u^{\prime \prime \prime}(e d t a)\left(\mathrm{H}_{2} \mathrm{O}\right)\right]^{-}$. O ligante edta (etilenodiaminotetracetato) possui 5 sítios de coordenação, ligando-se a cinco dos seis sítios de coordenação do rutênio e, deixando uma posição disponível para substituição da $\mathrm{H}_{2} \mathrm{O}$ pelo $\mathrm{NO}$, formando o $[\mathrm{Ru}(\mathrm{Hedta})(\mathrm{NO})]\left(k_{\mathrm{f}}=2,24 \times 10^{7} \mathrm{~L} \mathrm{~mol}^{-1} \mathrm{~s}^{-1}\right.$, a $\left.7,3^{\circ} \mathrm{C}, \mathrm{pH} 7,4\right)[18,19]$.

O complexo $\mathrm{K}[\mathrm{Ru}($ Hedta)Cl] (Figura 4) é solúvel em água, sendo que o íon $[\mathrm{Ru}(\mathrm{Hedta}) \mathrm{Cl}]^{-}$não possui livre passagem pelas membranas celulares. Duas vantagens desta importante característica são: por não possuir livre acesso pelas membranas celulares; o $[\mathrm{Ru}(\mathrm{Hedta}) \mathrm{Cl}]^{-}$entra em contato somente com o $\mathrm{NO}$ produzido em excesso no organismo, que se encontra na corrente sanguínea, e não, àquele encontrado em células endoteliais responsáveis pela regulação da pressão sanguínea. Além disso, devido à solubilidade, o [Ru(Hedta)Cl] é rapidamente excretado pela urina [19]. 


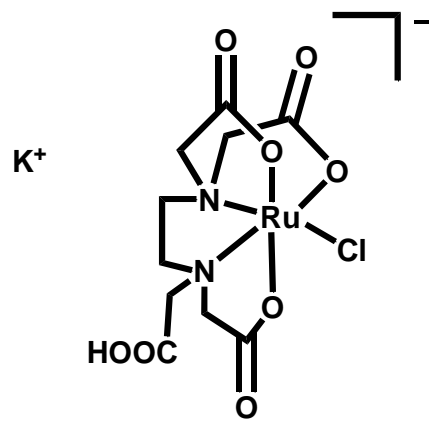

Figura 4 - Estrutura do complexo $\mathrm{K}[\mathrm{RuCl}($ Hedta $)]$.

Exemplos de doadores de NO que podem ser citados são: $N$ hidroxiguanidina [20], nitratos e nitritos orgânicos [21]; S-nitrosotióis [22, 23]; diazeniodiolatos [24, 25]; $\mathrm{N}$-nitrosaminas; $\mathrm{N}$-hidroxinitrosaminas; nitrosiminas [7] e nitrosilos de metais de transição [7, 8, 26-39] (Figura 5).

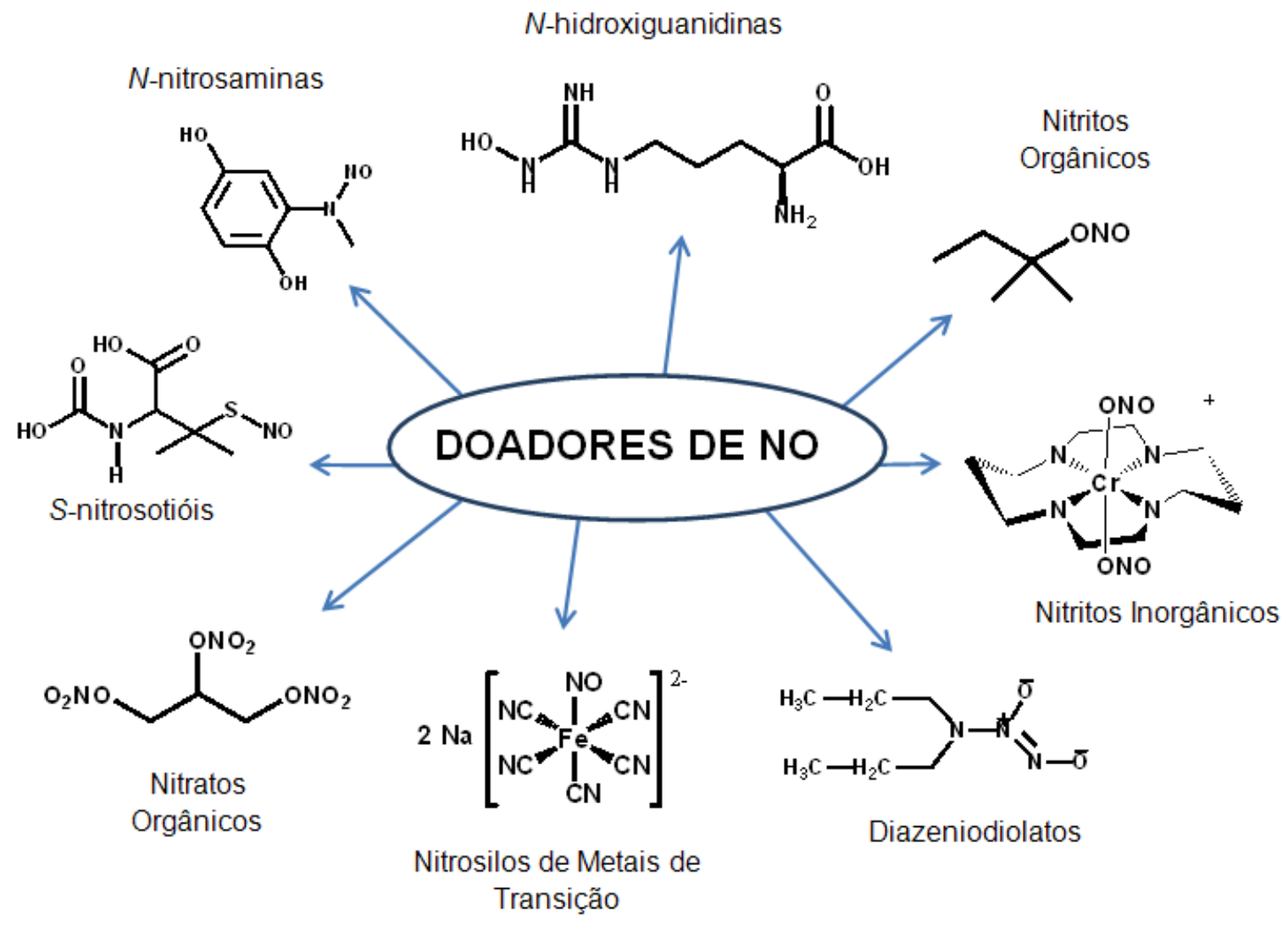

Figura 5 - Exemplos de doadores de NO. 
No contexto de nitrosilos de metais de transição como doadores de NO, os complexos de rutênio mostraram-se bastante promissores, pois o rutênio forma mais nitrosilo complexos que qualquer outro elemento e possui algumas características bastante relevantes, como: estereoquímica pseudo-octaédrica, estabilidade da ligação Ru-NO e ocorrência de processos redox do grupo em questão [19]. Devido a estas características estes compostos cada vez mais são estudados e desenvolvidos para aplicações médicas.

\subsection{Complexos de Rutênio como doadores de NO}

1.4.1 Algumas das primeiras aplicações dos compostos de rutênio na área farmacológica

Uma das aplicações mais visadas atualmente para os compostos de rutênio na área farmacológica é sua utilização como agente anticancerígeno. Alguns são muito promissores, apresentando atividade contra tumores nos quais a cisplatina é inativa ou apresenta resistência [40].

A química bem desenvolvida de complexos de rutênio, particularmente aqueles que possuem como ligantes derivados de amina e iminas, é fator de relevante importância para colocá-los como potenciais candidatos a metalofármacos. Os fatores que favorecem esta hipótese são: i) facilidade e estabilidade na obtenção de compostos com estruturas previsíveis; ii) a capacidade de troca de ligantes, transferência de elétrons e fácil obtenção de compostos com número de oxidação II e III, e iii) aumento no conhecimento da atividade biológica destes compostos. Os estados de oxidação mais comuns em solução aquosa são $R u(I I), R u(I I I)$ e $R u(I V)$, 
sendo geralmente octaédricos, e muitas vezes bastante inertes para a substituição do ligante [40].

Os complexos de rutenio com atividade antitumoral, por exemplo, possuem mecanismos diferentes daquele da cisplatina, a qual se liga diretamente à fita de DNA. [40]. As primeiras pesquisas feitas no âmbito da caracterização de complexos de rutênio e suas propriedades antitumorais foram feitas na década de $80 \mathrm{com}$ os compostos fac-[RuCl $\left.3\left(\mathrm{NH}_{3}\right)_{3}\right]$ e cis-[RuCl$\left.{ }_{2}\left(\mathrm{NH}_{3}\right)_{4}\right] \mathrm{Cl}$ [41]. Em 1987 o composto [imH][trans- $\left.\mathrm{RuCl}_{4}(\mathrm{im})_{2}\right]$ (ICR) foi relatado por Keppler apresentando atividade antitumoral [40] contra células HeLa (câncer cervical) e o fac- $\left[\mathrm{RuCl}_{3}\left(\mathrm{NH}_{3}\right)_{3}\right]$ em células P388 (leucemia) e, inspirando a síntese de compostos relacionados, como o [indH][trans- $\left.\mathrm{RuCl}_{4}(\text { ind })_{2}\right] \quad(\mathrm{KP} 1019$ ou $\mathrm{FFC14A}$; ind = indazol), completando recentemente testes clínicos de fase I [40].

O composto $(\mathrm{Na})\left[\right.$ trans- $\left.\mathrm{Ru}^{\mathrm{III}} \mathrm{Cl}_{4}(\mathrm{im})(\mathrm{DMSO})\right]$ (im = imidazol), conhecido por NAMI (New Anti-tumor Metastasis Inhibitor), foi uma das primeiras drogas anticâncer de rutênio a entrar em testes clínicos [42, 43], sendo ativo contra carcinoma de Lewis de pulmão, melanoma B16 e carcinoma mamário $\mathrm{MCa}$, possuindo um efeito anti-metastático não apresentado pela cisplatina. O NAMI-A, derivado do NAMI pela substituição do $\mathrm{Na}^{+}$por $\mathrm{imH}^{+}$como contra-íon, demonstrou atividade contra células tumorais, além de exercer efeito sobre o crescimento primário do tumor [44]. Além disso, o NAMI-A também demonstra atividade na inibição de tumores bem formados e em estágio de crescimento [45, 46a, 46b]. 


\subsubsection{Compostos nitrosilos de Rutênio}

Diversos tipos de nitrosilos de rutênio têm sido relatados [28, 30, 32-35, 3739], sendo nosso interesse focado nos complexos com aminas. Aspectos das características e da reatividade química e fotoquímica desses nitrosilos de rutênio contendo amino ligantes foram e têm sido estudados, tanto em reações nas quais estes compostos atuam como precursores de reação quanto produtos, bem como suas atividades biológicas. Nesta classe de compostos podem ser citados os de fórmula geral: trans-[Ru( $\left.\left(\mathrm{NH}_{3}\right)_{4}(\mathrm{NO}) \mathrm{L}\right] \mathrm{X}_{3}$, onde $\mathrm{L}$ pode ser piridina (py), isonicotinamida (isn), ácido isonicotínico (ina), 4-acetilpiridina (4-acpy), picolina (4pic), L-histidina (L-hist), imidazol (coordenado pelo carbono - imC, ou pelo nitrogênio - imN), nicotinamina (nic), trietilfosfito $\left(\mathrm{P}(\mathrm{OEt})_{3}\right)$, pirazina $(\mathrm{pz}), \mathrm{Cl}^{-}, \mathrm{H}_{2} \mathrm{O}$ ou $\mathrm{SO}_{3}{ }^{2-}$ ou, $\operatorname{trans}-[\mathrm{Ru}(\mathrm{NO})(\mathrm{mac}) \mathrm{L}] \mathrm{X}, \quad(\mathrm{mac} \quad($ macrociclo $)=1,4,8,11$-tetraazacyclotetradecano (cyclam), 1,4,8,12-tetraazaciclopentadecano ([15]ane $\left.\mathrm{N}_{4}\right)$, 1-(3-aminopropil)-1,4,8,11tetraazaciclotetradecano (1-(3-aminopropil)cyclam); ou $1,4,7,10$ tetraazaciclododecano (cyclen); $\mathrm{L}=\mathrm{H}_{2} \mathrm{O}, \mathrm{OH}^{-}$, ou $\mathrm{Cl}^{-}$), [34, 37-40, 47-50]. O contraíon, representado por $\mathrm{X}$, pode ser $\mathrm{PF}_{6}{ }^{-}, \mathrm{BF}_{4}^{-}, \mathrm{Cl}^{-}$, tfms se o complexo for catiônico, e $\mathrm{K}^{+}$ou $\mathrm{Na}^{+}$se o complexo for aniônico. A Figura 6 apresenta exemplos de nitrosilos de complexos de rutênio. 


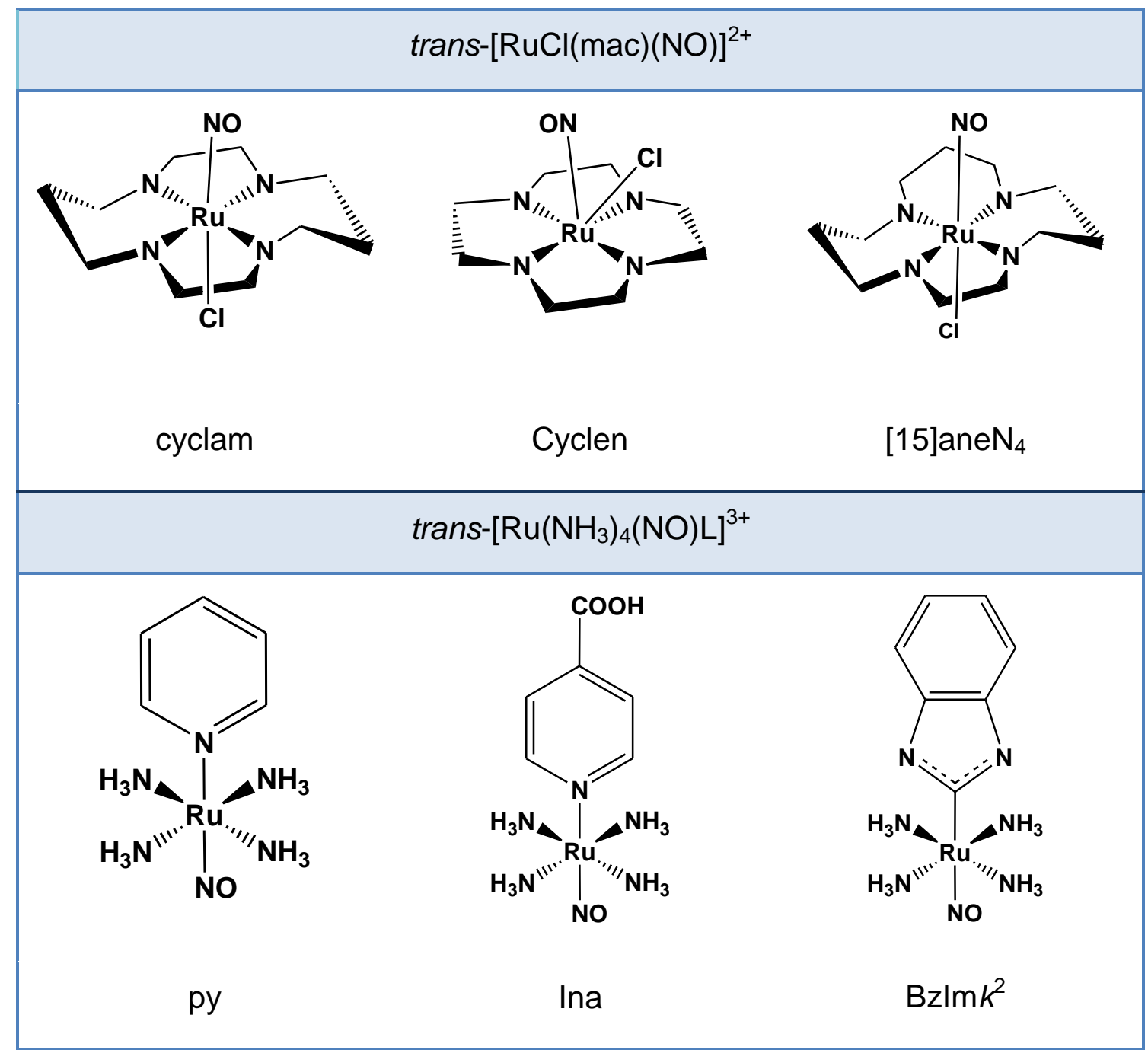

Figura 6 - Exemplos de nitrosilo complexos de rutênio doadores de NO.

Para o caso destes nitrosilo complexos de rutênio, seja com aminas de cadeia aberta ou com ligantes tetraazamacrocíclicos saturados [32,34,35,3739,47,51-54], a liberação de NO pode ser ativada quando são expostos a redução química e/ou eletroquímica, com potenciais de redução que abrangem uma faixa de 0,43 V, encontrando-se entre - 0,29 e 0,14 V (vs NHE), o que é acessível em meio biológico, visto que os potenciais de redução da cisteína, glutationa, ascorbato e $\mathrm{NADH}\left(\mathrm{E}_{\mathrm{NAD}}{ }^{+} \mathrm{NADH} \sim-0,3 \mathrm{~V}\right)$, por exemplo, estão dentro desta faixa [34, 35, 37-39]. As reações que mostram a redução destes complexos estão apresentadas nas equações $1,2,3,4$ e 5, onde se $L_{1}=\mathrm{NH}_{3}, y=4$ e se $L_{1}=$ macrociclo, $y=1, L_{2}=\mathrm{Cl}^{-}$. 
trans- $\left[\mathrm{Ru}(\mathrm{NO})\left(\mathrm{L}_{1}\right)_{\mathrm{y}}\left(\mathrm{L}_{2}\right)\right]^{\mathrm{n}+} \stackrel{+\mathrm{e}^{-}}{\underset{-\mathrm{e}^{-}}{\rightleftharpoons}} \operatorname{trans}-\left[\mathrm{Ru}(\mathrm{NO})\left(\mathrm{L}_{1}\right)_{\mathrm{y}}\left(\mathrm{L}_{2}\right)\right]^{(\mathrm{n}-1)+}$

$\operatorname{trans}-\left[\mathrm{Ru}(\mathrm{NO})\left(\mathrm{L}_{1}\right)_{\mathrm{y}}\left(\mathrm{L}_{2}\right)\right]^{(\mathrm{n}-1)+}+\mathrm{H}_{2} \mathrm{O} \underset{\mathrm{k}_{+\mathrm{NO}}}{\stackrel{\mathrm{k}_{-\mathrm{NO}}}{\rightleftharpoons}} \operatorname{trans}-\left[\mathrm{Ru}\left(\mathrm{H}_{2} \mathrm{O}\right)\left(\mathrm{L}_{1}\right)_{\mathrm{y}}\left(\mathrm{L}_{2}\right)\right]^{(\mathrm{n}-1)+}+\mathrm{NO}$

trans $-[\mathrm{Ru}(\mathrm{NO})(\mathrm{Cl})(\text { cyclam })]^{2+} \stackrel{+\mathrm{e}^{-}}{\rightleftharpoons} \operatorname{trans}-[\mathrm{Ru}(\mathrm{NO})(\mathrm{Cl})(\text { cyclam })]^{+}$

trans- $[\mathrm{Ru}(\mathrm{NO})(\mathrm{Cl})(\text { cyclam })]^{+}+\mathrm{H}_{2} \mathrm{O} \underset{\mathrm{k}_{+\mathrm{Cl}}}{\stackrel{\mathrm{k}_{-\mathrm{Cl}}}{\rightleftharpoons}}$ trans- $\left[\mathrm{Ru}(\mathrm{NO})\left(\mathrm{H}_{2} \mathrm{O}\right)(\text { cyclam })\right]^{2+}+\mathrm{Cl}^{-}$

$$
\text { trans- }\left[\mathrm{Ru}(\mathrm{NO})\left(\mathrm{H}_{2} \mathrm{O}\right)(\text { cyclam })\right]^{2+}+\mathrm{H}_{2} \mathrm{O} \underset{\mathrm{k}_{+\mathrm{NO}}}{\stackrel{\mathrm{k}_{-\mathrm{NO}}}{\rightleftharpoons}} \operatorname{trans}-\left[\mathrm{Ru}\left(\mathrm{H}_{2} \mathrm{O}\right)_{2}(\text { cyclam })\right]^{2+}+\mathrm{NO}
$$

A redução do complexo trans- $[\mathrm{Ru}(\mathrm{NO})(\text { cyclam }) \mathrm{Cl}]^{2+}$, envolve primeiramente a saída de um ligante cloreto e, em uma segunda etapa a liberação de NO. Mesmo liberando cloreto além de NO, isto não seria um obstáculo para sua utilização em meio biológico, visto que a concentração de $\mathrm{Cl}^{-}$no organismo é relativamente alta $\left(\left[\mathrm{Cl}^{-}\right]=\sim 0,1 \mathrm{~mol} \mathrm{~L}^{-1}\right.$.

Há situações em que pode ser desejável que o complexo esteja em solução e sofra redução liberando NO; exemplo disso é o decréscimo da pressão arterial em ratos hipertensos obtido com a aplicação de trans-[RuCl(cyclam)(NO)](PF $)_{2}$ [55]. Por outro lado, certamente há casos em que esta redução não é interessante, pois a liberação de NO pode se dar antes do alvo ser atingido. Assim, para evitar esta redução prematura, uma alternativa é a incorporação a matrizes, gerando um sistema de liberação controlada. O estudo dos sistemas de liberação controlada de NO se atém ao fato de que normalmente um fármaco veiculado em solução aquosa, 
ou de forma convencional, não consegue atingir locais específicos em concentrações adequadas para o efeito terapêutico específico. A incorporação em matrizes permite proteger o fármaco de reações indesejáveis ou prematuras antes de atingir o alvo. Com este propósito, a imobilização de compostos que liberam o óxido nítrico de modo controlado vêm sendo explorados por seu interesse clínico $[37,56-60]$.

Um exemplo de uma alternativa bastante viável e interessante, é a incorporação de complexos em PLGA (poli(ácido Láctico-Glicólico)) [59]. Neste caso, o complexo incorporado à matriz não pode ser reduzido e não é citotóxico. A citoxicidade desejada só ocorre com a irradiação do local, liberando NO [59].

Outra forma de ocorrer a liberação de NO, é através da irradiação de luz. Quando complexos trans-[Ru(NO) $\left.\left(\mathrm{NH}_{3}\right)_{4}(\mathrm{~L})\right]^{3+}(\mathrm{L}=$ py, isn, 4-pic) (Equação 6) são irradiados na banda de transferência de carga do metal para o ligante (TCML $R u_{d \pi}$ $\rightarrow_{\pi^{*}} \mathrm{NO}$ ), entre 300 e $350 \mathrm{~nm}$, ocorre formação do complexo trans$\left[\mathrm{Ru}\left(\mathrm{H}_{2} \mathrm{O}\right)\left(\mathrm{NH}_{3}\right)_{4}(\mathrm{~L})\right]^{3+}$ e saída do $\mathrm{NO}$ em uma reação "limpa" [28,39]. Para complexos de fórmula geral trans-[Ru(NO)(mac)L]X $\left(\right.$ mac $=$ cyclam, [15]aneN $\mathrm{N}_{4} \mathrm{e}, \mathrm{L}=\mathrm{H}_{2} \mathrm{O}, \mathrm{OH}^{-}$, $\mathrm{Cl}^{-}$), este comportamento é bastante similar (Equação 7).

trans- $\left[\mathrm{Ru}\left(\mathrm{NH}_{3}\right)_{4}(\mathrm{~L}) \mathrm{NO}\right]^{3+} \underset{\mathrm{H}_{2} \mathrm{O}}{\stackrel{\mathrm{h} v}{\rightleftharpoons}}$ trans- $\left[\mathrm{Ru}\left(\mathrm{NH}_{3}\right)_{4}(\mathrm{~L})\left(\mathrm{H}_{2} \mathrm{O}\right)\right]^{3+}+\mathrm{NO}$

trans- $\left[\mathrm{Ru}{ }^{\prime \prime} \mathrm{Cl}(\mathrm{NO})(\text { cyclam })\right]^{2+} \underset{\mathrm{H}_{2} \mathrm{O}}{\rightleftharpoons} \operatorname{hrans}-\left[\mathrm{Ru}^{\mathrm{III}} \mathrm{Cl}\left(\mathrm{H}_{2} \mathrm{O}\right)(\text { cyclam })\right]^{2+}+\mathrm{NO}$

Apesar dos complexos do tipo trans-[Ru(NO)(L$\left.\left.L_{1}\right)_{y}\left(L_{2}\right)\right]^{n+}$ apresentarem liberação de NO por irradiação de luz (300-350 nm), a energia de fotolabilização não é acessível para a terapia fotodinâmica (TFD), a qual geralmente requer irradiação 
no intervalo da "janela terapêutica" que está entre 600 e 1100 nm [61]. Para se contornar esta dificuldade, algumas estratégias estão sendo propostas visando alternativas para que a liberação de NO possa ocorrer dentro da "janela terapêutica", como, por exemplo, a utilização do processo de transferência de energia dos "Quantum-dots" para os complexos; [36, 62]; mudança dos ligantes do plano equatorial, como no complexo $\left[\mathrm{Ru}(\mathrm{NO})\left(\mathrm{NO}_{2}\right)(\mathrm{pc})\right]$ (onde $\mathrm{pc}=$ ftalocianina), que possui banda intensa $\left(\varepsilon=2,75 \times 10^{4} \mathrm{~L} \mathrm{~mol}^{-1} \mathrm{~cm}^{-1}\right)$ na região de $690 \mathrm{~nm}$ do espectro eletrônico, e quando irradiada em 660 nm, libera NO (Figura 5a) [63]; o uso de cromóforos (antena) como substituintes nos ligantes, de forma que a irradiação feita na banda do ligante (resorufina, por exemplo, que possui banda de absorção eletrônica em 600 nm) proporciona liberação de NO [64, 65] (Figura 5b) e, o uso de sensibilizadores.

a)

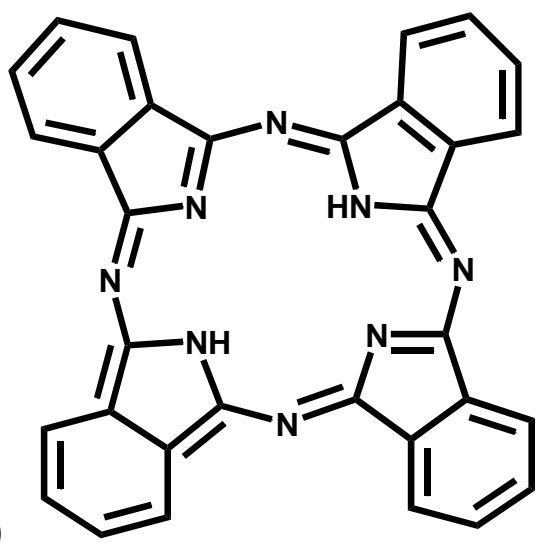

b)

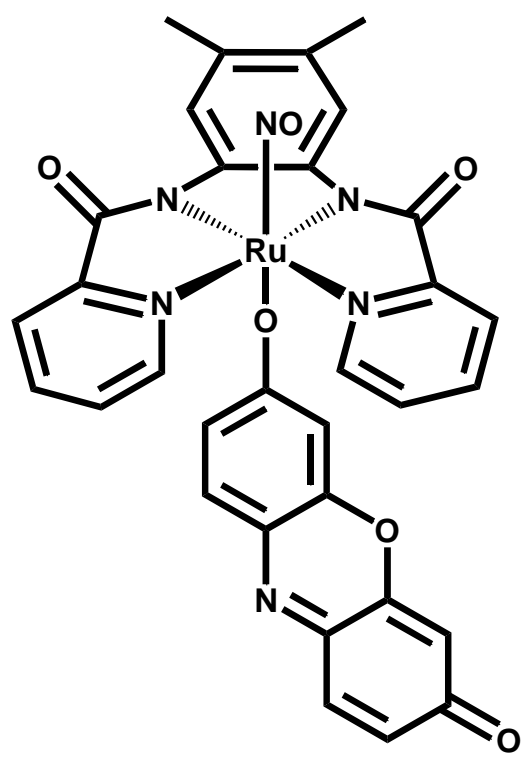

Figura 7 - Estrutura a) da ftalocianina e b) de um complexo de rutênio ligado a um sensibilizador, a resorufina.

O complexo $\left[\mathrm{Ru}\left(\mathrm{NH}_{3}\right)_{5}(\mathrm{py})\right]^{2+}$ libera piridina e amônia quando irradiado em comprimentos de onda próximos de $405 \mathrm{~nm}$. Porém, na presença de rodamina-B (corante) também ocorre atividade fotoquímica irradiando-se na região de $520 \mathrm{~nm}$ 
(região de absorção do corante), na qual o complexo sozinho não apresenta atividade fotoquímica [66] (Gráfico 1). Neste sistema foi possível determinar a energia do estado excitado responsável pela fotoquímica usando-se diversos corantes como sensibilizadores. Desse modo a utilização de sensibilizadores para complexos nitrosilos de rutênio contendo tetraminas e macrociclos é bastante interessante, de forma que o corante pode ocasionar a liberação de NO irradiandose em comprimentos de onda dentro da janela terapêutica, e, além disso, pode permitir a determinação da energia do estado excitado responsável pela liberação de NO.

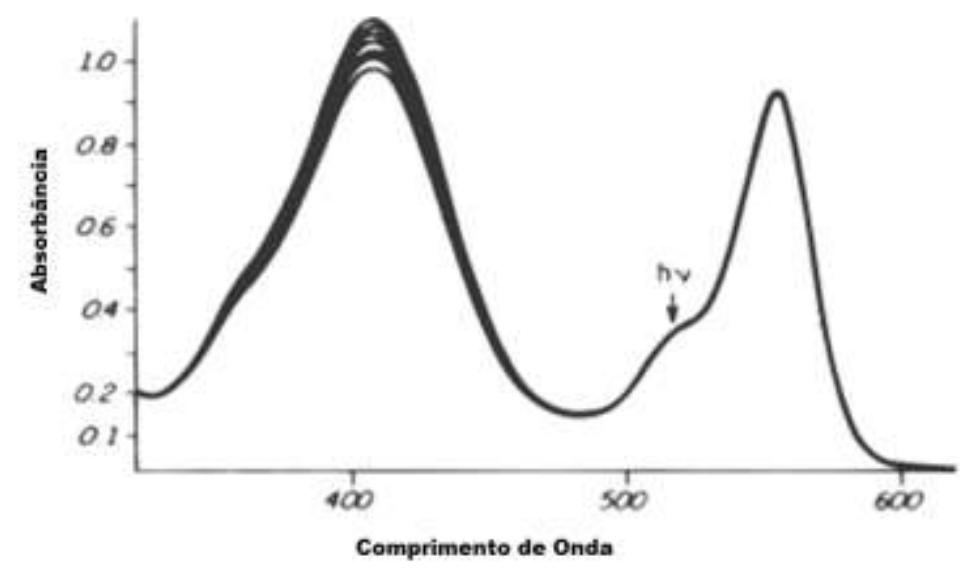

Figura 8 - Espectro Uv-vis do íon $\left[\mathrm{Ru}\left(\mathrm{NH}_{3}\right)_{5}(\mathrm{py})\right]^{2+}$ irradiado na banda de absorção eletrônica do corante rodamina-B (520 nm), apresentando liberação de piridina e amônia pelo complexo [66].

Outra possibilidade ainda é a utilização de compostos binucleares de rutênio, que quando irradiados na região do visível, liberam NO, como ocorre no complexo $\left[\mathrm{Ru}\left(\mathrm{NH}_{3}\right)_{5}(\mathrm{pz}) \mathrm{Ru}(\mathrm{bpy})_{2}(\mathrm{NO})\right]^{5+}$, o qual possui banda de absorção eletrônica na região do visível $(\lambda=523 \mathrm{~nm})$ que quando irradiada induz à liberação de NO [67]. Neste caso o fragmento $\mathrm{Ru}\left(\mathrm{NH}_{3}\right)_{5}(\mathrm{pz})$ funciona como sensibilizador. 
Assim, seria interessante estudar a possibilidade de obter a liberação de NO fotoquimicamente irradiando com luz de comprimento de onda dentro da janela terapêutica, utilizando sensibilizadores no meio reacional. O uso de sensibilizadores no meio reacional ao invés de coordenados ao rutênio permitiria eliminar rotas sintéticas e tornar mais fácil a investigação de diversos sensibilizadores e complexos. Além da fotoquímica desejada, este estudo, se bem sucedido, permitiria determinar a energia do estado excitado responsável pela fotoquímica de liberação de NO. Como um estudo deste tipo foi feito para o complexo $\left[\mathrm{Ru}\left(\mathrm{NH}_{3}\right)_{5}(\mathrm{py})\right]^{2+}$, a

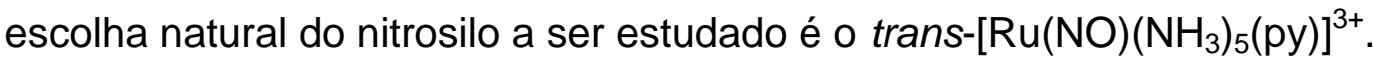




\section{OJETIVOS}

Embora o complexo nitrosilo de rutênio do tipo trans-[Ru(NO) $\left.\left(\mathrm{NH}_{3}\right)_{4}(\mathrm{py})\right]^{3+}$ apresente liberação de NO por irradiação de luz entre 300 e 370 nm, esta faixa de comprimentos de onda não está dentro da janela terapêutica. Para contornar esta dificuldade, uma alternativa seria a sensibilização deste complexo por corantes que absorvam na faixa de comprimento de onda do visível, tais como a rodamina-B e azul do Nilo.

O uso de sensibilizadores no meio reacional ao invés de coordenados ao rutênio possibilita a eliminação de rotas sintéticas e torna mais fácil a investigação de diversos sensibilizadores e complexos. Além do estudo da atividade fotoquímica pela sensibilização, este trabalho, se bem sucedido, permitiria determinar a energia do estado excitado responsável pela fotoquímica de liberação de NO.

Assim, este trabalho visou fazer o estudo da possível liberação de óxido

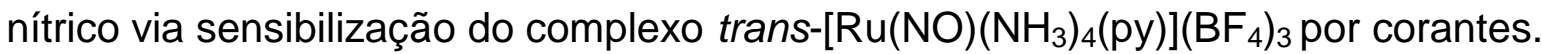




\section{PROCEDIMENTO EXPERIMENTAL}

\subsection{Reagentes e Solventes}

Os reagentes e solventes utilizados nos experimentos deste trabalho foram adquiridos comercialmente e, quando necessário foram purificados previamente. $\mathrm{Na}$ tabela abaixo (Tabela 1) encontra-se a lista de reagentes e solventes, utilizados nas sínteses e análises deste trabalho e, suas respectivas pureza e procedência.

Tabela 1 - Reagentes e solventes utilizados nas sínteses realizadas neste trabalho.

\begin{tabular}{ccc} 
Reagente ou Solvente & Pureza & Marca \\
\hline Acetona & $99,5 \%$ & Synth \\
Ácido clorídrico & $36,5-38 \%$ em massa & Synth \\
Ácido hexafluorofosfórico & $\sim 65 \%$ & Sigma-Aldrich \\
Ácido nítrico & $65 \%$ em massa & Synth \\
Ácido perclórico & --- & Cinética Química \\
Ácido tetrafluorobórico & $48 \%$ & Strem \\
Ácido trifluoracético & $99 \%$ & Acros \\
Água deuterada & $99,9 \%$ & Aldrich \\
Alaranjado de acridina & --- & Vetec \\
Argônio & $99,998 \%$ & White Martins \\
Azul do Nilo & --- & Sigma
\end{tabular}




\begin{tabular}{|c|c|c|}
\hline Bicarbonato de sódio & $99,5 \%$ & Merck \\
\hline Bissulfito de sódio & $98 \%$ & Merck \\
\hline Carbonato de sódio & $99,5 \%$ & Merck \\
\hline Carboxy-PTIO (potassium salt) & --- & Sigma-RBI \\
\hline $\begin{array}{l}\text { Cloreto de ferro(III) } \\
\text { hexahidratado }\end{array}$ & $97 \%$ & Sigma-Aldrich \\
\hline Cloreto de mercúrio(II) & $99,50 \%$ & Acros \\
\hline Cloreto de rutênio(III) & $40-43 \%$ em massa de $\mathrm{Ru}$ & Strem \\
\hline Cloreto de sódio & $99,9 \%$ & Nuclear (CAQ) \\
\hline $\begin{array}{l}\text { Cyclam }(1,4,8,11 \text { - } \\
\text { tetraazaciclotetradecano) }\end{array}$ & $98 \%$ & Fluka \\
\hline Dicromato de potássio & $99,5 \%$ & Carlo Erba \\
\hline Dimetilsulfóxido (DMSO) & $99,7 \%$ & Vetec \\
\hline Dióxido de enxofre 3.0 & $99.9 \%$ & White Martins \\
\hline Etanol & $99,5 \%$ & Synth \\
\hline Éter etílico & --- & Vetec \\
\hline Fluoresceína sódica & --- & Sigma-Aldrich \\
\hline Fosfato de sódio bibásico & $98 \%$ & Qeel \\
\hline Fosfato de sódio monobásico & $98 \%$ & Hopkin \& Williams \\
\hline Hexafluorofosfato de amônio & $99 \%$ & Strem \\
\hline Hexafluorofosfato de hidrogênio & $65 \%$ & Sigma-Aldrich \\
\hline
\end{tabular}




\begin{tabular}{ccc} 
Hidrazina monohidratada & $98 \%$ & Aldrich \\
Hidróxido de sódio & $97 \%$ & Vetec \\
Metanol & $99 \%$ & Vetec \\
Nitrito de sódio & $99,4 \%$ & J. T. Baker \\
Pentóxido de fósforo & $97 \%$ & Aldrich \\
Peróxido de hidrogênio & $29,0 \%$ & Vetec \\
Piridina & $99 \%$ & Vetec \\
Rodamina-B & --- & Sigma \\
Zinco & $99,99995 \%$ & Reagen \\
\hline
\end{tabular}

\subsection{Purificação dos reagentes e solventes}

3.2.1 Purificação da Acetona

A acetona utilizada na síntese do complexo trans-[Ru( $\left.\left(\mathrm{SO}_{4}\right)\left(\mathrm{NH}_{3}\right)_{4}(\mathrm{py})\right] \mathrm{Cl}$ foi previamente tratada da seguinte forma: a um balão de três bocas de 2 litros foram adicionados 1,5 $\mathrm{L}$ de acetona e $40 \mathrm{~g}$ de $\mathrm{P}_{2} \mathrm{O}_{5}$ (obs: este composto é muito higroscópico, então foi necessário pesar com certa agilidade). Deixou-se sob refluxo por 20 minutos e, então retirou-se a cabeça de destilação. Descartando-se a cauda da destilação, a acetona destilada foi armazenada em frasco de vidro contendo peneira molecular previamente deixada em estufa $\left(100^{\circ} \mathrm{C}\right)$ por três dias. 


\subsubsection{Purificação do Éter Etílico}

A um balão de três bocas de 2 litros foram adicionados $1,5 \mathrm{~L}$ de éter etílico que foram submetidos a refluxo com hidróxido de sódio por 3 horas e, em seguida, destilados. Este procedimento foi repetido 3 vezes. O armazenamento do éter destilado foi feito em recipiente de vidro na presença de sódio metálico $\left(\mathrm{Na}^{0}\right)$ para eliminação de água e peróxidos.

\subsubsection{Purificação da Piridina}

A um balão de 3 bocas de $50 \mathrm{~mL}$ foram adicionados $30 \mathrm{~mL}$ de piridina. A temperatura para a destilação foi de $65^{\circ} \mathrm{C}$. Separou-se $6 \mathrm{~mL}$ da cabeça de destilação e $6 \mathrm{~mL}$ da cauda de destilação. Os $28 \mathrm{~mL}$ de piridina obtidos (transparente) foram armazenados em frasco de vidro em refrigerador.

\subsubsection{Amálgama de zinco}

O zinco granulado foi lavado com ácido nítrico $50 \%$, gota a gota e sob agitação, para se realizar a limpeza de sua superfície. Após, lavou-se com água desionizada e então, e foi adicionada uma solução de $\mathrm{HCl} 0,1 \mathrm{~mol} \mathrm{~L}^{-1}$ apenas para recobrir o zinco. Adicionou-se aproximadamente $2 \mathrm{mg} \mathrm{de} \mathrm{HgCl}_{2}$ e deixou-se reagir por 10 minutos. Lavou-se novamente com água desionizada e secou-se com papel toalha. Obs.: o amálgama de zinco não pode ser manuseado com instrumentos metálicos. 


\subsubsection{Solução de Perclorato de Crômio(II)}

Foi feita uma suspensão de $18,5 \mathrm{~g}$ de dicromato de potássio em $150 \mathrm{~mL}$ de ácido perclórico 50\%. Resfriou-se essa solução em banho de gelo e adicionou-se gota a gota, $125 \mathrm{~mL}$ de $\mathrm{H}_{2} \mathrm{O}_{2} 30 \%$ sob agitação. Aqueceu-se a solução a $60^{\circ} \mathrm{C}$ durante 3 horas para eliminar o excesso de $\mathrm{H}_{2} \mathrm{O}_{2}$. A solução foi deixada em geladeira durante a noite e, então, o sólido formado $\left(\mathrm{KClO}_{4}\right)$ foi retirado por filtração. Após a filtração em funil de placa sinterizada, o filtrado foi diluído a $500 \mathrm{~mL}$, produzindo uma solução de perclorato de crômio(III) aproximadamente igual a 0,25 mol $L^{-1}$. Através da redução desta solução com amálgama de zinco, em atmosfera de argônio, obtém-se uma solução de perclorato de crômio(II).

\subsubsection{Sistema da linha de Argônio}

Quando foi necessária a utilização de atmosfera inerte no meio reacional, utilizou-se argônio. O gás foi borbulhado em um frasco lavador contendo uma solução de perclorato de crômio(II) e amálgama de zinco, passando em seguida por um frasco lavador contendo água desionizada, para evitar que gotículas acidas da solução de crômio chegassem até a reação.

O complexo de crômio(II) apresenta coloração azul claro e pode ser obtida a partir da redução da solução de $\left[\mathrm{Cr}\left(\mathrm{H}_{2} \mathrm{O}\right)_{6}\right]^{3+}$ de cor azul escura. O íon complexo $\left[\mathrm{Cr}\left(\mathrm{H}_{2} \mathrm{O}\right)_{6}\right]^{2+}$ é um forte agente redutor e é utilizado para consumir o oxigênio que vem juntamente ao argônio como impureza.

$$
\left[\mathrm{Cr}\left(\mathrm{H}_{2} \mathrm{O}\right)_{6}\right]^{2+}{ }_{(\mathrm{aq})}+\mathrm{O}_{2(\mathrm{~g})}+4 \mathrm{H}^{+}{ }_{(\mathrm{aq})} \rightarrow\left[\mathrm{Cr}\left(\mathrm{H}_{2} \mathrm{O}\right)_{6}\right]^{3+}{ }_{(\mathrm{aq})}+2 \mathrm{H}_{2} \mathrm{O}_{(\mathrm{l})}
$$




\subsection{Síntese dos Compostos}

\subsubsection{Síntese do $\left[\mathrm{RuCl}\left(\mathrm{NH}_{3}\right)_{5}\right] \mathrm{Cl}_{2}$}

Este composto foi sintetizado de acordo com o método descrito na literatura [69], com algumas modificações. Em um balão de três bocas de $500 \mathrm{~mL}$ foram dissolvidos $5,00 \mathrm{~g}$ de $\mathrm{RuCl}_{3} \cdot \mathrm{nH}_{2} \mathrm{O}$ (40 - 43\% de $\mathrm{Ru}, 0,0210$ a 0,0190 mol) em $67 \mathrm{~mL}$ de $\mathrm{H}_{2} \mathrm{O}$ desionizada. Adicionou-se, sob agitação magnética constante, $47 \mathrm{~mL}$ de hidrato de hidrazina $98 \%$ gota a gota durante aproximadamente 1 hora. Conforme a reação foi ocorrendo, a mistura reacional passou de marrom escuro para vinho. Deixou-se reagir durante 4 horas. Após as 4 horas de reação, resfriou-se o sistema em banho de gelo até a temperatura atingir $5{ }^{\circ} \mathrm{C}$ (aprox. 40 minutos). Adicionou-se, então, $125 \mathrm{~mL}$ de $\mathrm{HCl}$ concentrado $\left(12 \mathrm{~mol} \mathrm{~L}^{-1}\right)$ gota a gota ( 30 minutos) sob agitação. A mistura de cor vermelha intensa foi refluxada por 2 horas, com posterior formação de precipitado amarelo. Após resfriamento em banho de gelo, a solução foi filtrada e o precipitado lavado com $\mathrm{HCl} 1,5 \mathrm{~mol}^{-1} \mathrm{~L}^{-1}$ para remoção de cloreto de amônio formado e, pequenas porções de acetona e posteriormente éter etílico.

A recristalização foi feita em aproximadamente $300 \mathrm{~mL}$ de ácido clorídrico $0,1 \mathrm{~mol} \mathrm{~L}^{-1}$ a quente $\left(\sim 85^{\circ} \mathrm{C}\right)$. Após a dissolução do sólido amarelo, fez-se a filtração a quente rapidamente, pois o sólido começa a precipitar no fundo do kitassato. Adicionou-se $100 \mathrm{~mL}$ de $\mathrm{HCl}$ concentrado. A mistura foi colocada em banho de gelo até o sobrenadante adquirir temperatura de $5{ }^{\circ} \mathrm{C}$ (40 minutos). $\mathrm{O}$ sólido foi coletado por filtração, lavado com éter e então, secado em dessecador a vácuo. Rendimento: $60,0-64,6 \%, 3,75 \mathrm{~g}\left(1,28 \times 10^{-2} \mathrm{~mol}\right)$. 


\subsubsection{Síntese do trans- $\left[\mathrm{Ru}\left(\mathrm{HSO}_{3}\right)_{2}\left(\mathrm{NH}_{3}\right)_{4}\right]$}

Esta síntese foi feita conforme métodos descritos por K. Gleu [71], com algumas modificações. Em um balão de 3 bocas de $500 \mathrm{~mL}$ foram dissolvidos 2,00 $\mathrm{g}$ (6,84 mmol) de $\left[\mathrm{RuCl}\left(\mathrm{NH}_{3}\right)_{5}\right] \mathrm{Cl}_{2}$ em $75,0 \mathrm{~mL}$ de água desionizada sob agitação constante. Aqueceu-se a mistura a temperatura até $80 \stackrel{\circ}{ } \mathrm{C}$. Adicionou-se $2,84 \mathrm{~g}(27,3$ mmol) de bissulfito de sódio $\left(\mathrm{NaHSO}_{3}\right)$ e a mistura resultante foi mantida a $75{ }^{\circ} \mathrm{C}$, com auxilio de um banho de silicone, e foi borbulhado dióxido de enxofre $\left(\mathrm{SO}_{2}\right)$ na solução durante a reação. Depois de alguns minutos houve a formação de um sólido creme. A reação continuou por duas horas sob refluxo e, então foi resfriada em banho de gelo com borbulhamento contínuo de $\mathrm{SO}_{2}$ até o sobrenadante atingir a temperatura de $5{ }^{\circ} \mathrm{C}$ (40 minutos). $\mathrm{O}$ sólido creme foi coletado por filtração em trompa de vácuo devido à solução ser bastante ácida (pode danificar a bomba). Para esta filtração utilizou-se máscara de proteção devido ao desprendimento de gás. O filtrado foi lavado com etanol e, então, secado sob vácuo. Rendimento:77,8\%, 1,74 g $(5,25 \mathrm{mmol})$.

Como este composto é instável, não podendo ser armazenado, partiu-se diretamente para a reação seguinte.

\subsubsection{Síntese do trans-[RuCl $\left.\left(\mathrm{NH}_{3}\right)_{4}\left(\mathrm{SO}_{2}\right)\right] \mathrm{Cl}$}

Esta síntese foi feita conforme métodos descritos por K. Gleu [71], com algumas modificações. Sob condições de ausência de luz (papel alumínio), adicionou-se $2,04 \mathrm{~g}(6,15 \mathrm{mmol})$ de trans-[Ru( $\left.\left(\mathrm{HSO}_{3}\right)_{2}\left(\mathrm{NH}_{3}\right)_{4}\right]$ a um balão de 3 bocas de $500 \mathrm{~mL}$ juntamente a $220 \mathrm{~mL}$ de $\mathrm{HCl} 6 \mathrm{~mol} \mathrm{~L}^{-1}$. Aqueceu-se a suspensão até 108 
${ }^{\circ} \mathrm{C}$ e deixou-se sob refluxo por 20 minutos. $\mathrm{O}$ composto solubilizou-se, formando uma solução vermelha escura. A solução foi filtrada a quente para retirar impurezas. O filtrado, no kitassato mesmo, foi deixado na capela até atingir temperatura ambiente (30 minutos) e, então, deixado em refrigerador por 30 minutos para que ocorresse precipitação. Obteve-se cristais vermelhos brilhantes, que foram coletados por filtração a vácuo, em trompa d'água, e lavados com pequenas porções de $\mathrm{HCl} 6$ mol L-1. Rendimento: $55 \%$, 0,55 g (1,81 mmol).

\subsubsection{Síntese do trans-[Ru( $\left.\left(\mathrm{SO}_{4}\right)\left(\mathrm{NH}_{3}\right)_{4}(\mathrm{py})\right] \mathrm{Cl}$}

Esta síntese foi feita com base em métodos descritos na literatura [71], com algumas modificações.

Sob atmosfera de argônio, adicionou-se uma suspensão de 0,600 g (1,97 mmol) de trans-[RuCl$\left.\left(\mathrm{NH}_{3}\right)_{4}\left(\mathrm{SO}_{2}\right)\right] \mathrm{Cl}$ em $8 \mathrm{~mL}$ de água desionizada previamente desaerada (30 minutos) a um balão de 3 bocas de $250 \mathrm{~mL}$. Após 5 minutos de reação foi adicionado bicarbonato de sódio $\left(\mathrm{NaHCO}_{3}\right)$ em pequenas porções até cessar a efervescência. Observou-se mudança de coloração da solução de vermelho para amarelo. Decorridos mais 5 minutos de reação adicionou-se $2 \mathrm{~mL}$ de piridina (excesso de cerca de 20 vezes). Deixou-se em reação por 15 minutos e observou-se

o escurecimento da solução, passando de amarelo para marrom. A solução foi filtrada para eliminar impurezas em um béquer de $20 \mathrm{~mL}$. Adicionou-se $\mathrm{HCl}$ concentrado até ocorrer precipitação e um pouco mais para se ter excesso. Observou-se desprendimento de gás e formação de precipitado vermelho tijolo. Deixou-se em geladeira por 30 minutos. Filtrou-se em filtro de placa sinterizada fina e lavou-se com metanol, para retirar o excesso de piridina, e, posteriormente, 
acetona. Secou-se o sólido sob vácuo por 10 minutos. O sólido vermelho claro obtido foi transferido para um béquer de $100 \mathrm{~mL}$. Adicionou-se algumas gotas de $\mathrm{HCl} 1,5 \mathrm{~mol} \mathrm{~L}^{-1}$ apenas para umedecer o sólido e, então, $2 \mathrm{~mL}$ de $\mathrm{H}_{2} \mathrm{O}_{2} 30 \%$. Observou-se dissolução do sólido e mudança de cor, de vermelho tijolo para marrom e solução amarela clara. Adicionou-se $60 \mathrm{~mL}$ de acetona tratada à solução e ocorreu precipitação de sólido amarelo. Deixou-se em geladeira por 1 hora. O sólido formado foi coletado por filtração em filtro de placa sinterizada fina e lavado com acetona.

A recristalização foi feita da seguinte forma: aqueceu-se $50 \mathrm{~mL}$ de $\mathrm{HCl} 1,5$ mol L-1 até temperatura de $70{ }^{\circ} \mathrm{C}$ e adicionou-se ao composto amarelo obtido na etapa anterior. Este se solubilizou formando uma solução amarelo ouro. Diminuiu-se o volume até o ponto que começasse a ocorrer turbidez e, então foi deixado em banho de gelo. O sólido resultante apresentou cor amarelo claro. Rendimento: 19\%, $0,16 \mathrm{~g}(0,37 \mathrm{mmol})$.

\subsubsection{Síntese do trans-[Ru( $\left.\left(\mathrm{NH}_{3}\right)_{4}(\mathrm{py})(\mathrm{NO})\right]\left(\mathrm{BF}_{4}\right)_{3}$}

Esta síntese foi feita com base em métodos descritos na literatura [72], com algumas modificações.

Solubilizou-se $100 \mathrm{mg}(0,23 \mathrm{mmol})$ de trans-[Ru($\left.\left(\mathrm{SO}_{4}\right)\left(\mathrm{NH}_{3}\right)_{4}(\mathrm{py})\right] \mathrm{Cl}$ em $4 \mathrm{~mL}$ de $\mathrm{CF}_{3} \mathrm{COOH} \mathrm{pH}=2$ previamente desaerado e, reduziu-se com amálgama de zinco durante 1 hora para gerar o íon trans-[Ru( $\left.\left(\mathrm{NH}_{3}\right)_{4}\left(\mathrm{H}_{2} \mathrm{O}\right)(\mathrm{py})\right]^{2+}$. A solução passou de coloração amarela translúcida para vermelha escura, a qual foi então adicionada por meio de uma canícula a uma solução de $100 \mathrm{mg}(1,45 \mathrm{mmol})$ de $\mathrm{NaNO}_{2} \mathrm{em} 3 \mathrm{~mL}$ de solução de $\mathrm{HBF}_{4} 1 \mathrm{~mol} \mathrm{~L}^{-1}$, previamente desaerada, num balão de três bocas. À solução amarela resultante foram adicionados $20 \mathrm{~mL}$ de etanol tratado e, a seguir, a 
mistura foi deixada em geladeira por 1 hora. O complexo foi coletado por filtração, lavado com etanol e, em seguida com acetona e secado a vácuo. Rendimento: $30 \%$, 0,040 g (0,0067 mmol). O complexo foi recristalizado utilizando-se o mínimo volume de $\mathrm{HBF}_{4}$ 1,0 mol L-1 , coletado por filtração e reprecipitado com o mínimo volume de etanol tratado. Rendimento: $38 \%, 0,051 \mathrm{~g}(0,0086 \mathrm{mmol})$.

\subsubsection{Síntese do cis-[RuCl $\left.2(\mathrm{dmso})_{4}\right]$}

Este complexo foi sintetizado conforme descrito na literatura [73] com algumas modificações.

$1,00 \mathrm{~g}(3,96-4,45 \mathrm{mmol})$ de $\mathrm{RuCl}_{3} \cdot \mathrm{nH}_{2} \mathrm{O}$ foi dissolvido em $10 \mathrm{~mL}$ de dimetilsulfóxido (dmso). A solução foi aquecida a $160^{\circ} \mathrm{C}$ e deixada sob refluxo em atmosfera inerte de argônio, sob condições de escuro por exatamente 5 minutos (a fim de evitar isomerização para a forma trans). Esperou-se que a solução adquirisse temperatura ambiente e deixou-se em banho de gelo por $\sim 30$ minutos. O precipitado amarelo formado foi filtrado e lavado com etanol. Foram adicionados $50 \mathrm{~mL}$ de etanol ao filtrado e o volume diminuído a 1/5 por rotaevaporador. Rendimento: 73$82 \%, 1,60 \mathrm{~g}(3,3 \mathrm{mmol})$.

\subsubsection{Síntese do cis-[RuCl $($ cyclam)]Cl}

$1,00 \mathrm{~g}(2,06 \mathrm{mmol})$ de cis-[RuCl $\left.2(\mathrm{dmso})_{4}\right]$ foram adicionados a um balão de $250 \mathrm{~mL}$, onde havia $100 \mathrm{~mL}$ de etanol tratado. A mistura foi aquecida a $50^{\circ} \mathrm{C}$ (sob atmosfera de argônio) para dissolver o complexo. Adicionou-se lentamente com auxílio de um funil gotejador de $125 \mathrm{~mL}, 0,420 \mathrm{~g}(2,09 \mathrm{mmol})$ de cyclam em $20 \mathrm{~mL}$ 
de etanol. Subiu-se a temperatura para $70^{\circ} \mathrm{C}$ e deixou-se sob refluxo por 2 horas. Então, foram adicionados $20 \mathrm{~mL}$ de $\mathrm{HCl}$ concentrado gota a gota e, ar foi borbulhado na reação por 30 minutos para oxidar o $R u(I I)$ para $R u(I I I)$. A mistura foi então refluxada por 4 horas. Os cristais amarelo dourados formados foram coletados por filtração, lavados com acetona e secados sob vácuo. Rendimento: 75\% (635 mg $1,56 \mathrm{mmol})$.

\subsubsection{Síntese do trans-[Ru(NO)(OH)(cyclam)](PF $)_{2}$}

Este complexo foi sintetizado conforme descrito na literatura [73], com algumas modificações.

Em um balão de três bocas $100 \mathrm{mg}(0,245 \mathrm{mmol})$ de cis-[RuCl $2(\mathrm{cyclam})] \mathrm{Cl}$ foram dissolvidos em solução água/etanol/clorofórmio (10:5:5 v/v) previamente desaerada. Sob atmosfera de argônio, e após completa dissolução do complexo, foi adicionado amálgama de zinco $(\mathrm{Zn}(\mathrm{Hg}))$. Após 1 hora, o amálgama de zinco foi separado da solução e a solução transferida para um balão que já continha 130 mg (1,88 mmol) de $\mathrm{NaNO}_{2}$ dissolvidos em um mínimo volume de água previamente desaerada. A solução resultante foi aquecida a $55^{\circ} \mathrm{C}$ por 1 hora. Em seguida, $1 \mathrm{~mL}$ de $0,1 \mathrm{~mol} \mathrm{~L}^{-1} \mathrm{HPF}_{6}$ foi adicionado, e a solução deixada para reagir por 1 hora. Adicionou-se $1,3 \times 10^{-3} \mathrm{mg}(0,78 \mathrm{mmol})$ de $\mathrm{NH}_{4} \mathrm{PF}_{6}$, e deixou-se reagir por 1 hora. Concentrou-se a solução com auxílio de um rotaevaporador. O sólido amarelo formado foi coletado por filtração e lavado com éter etílico. Rendimento: 50\% (50 mg $78,6 \mu \mathrm{mol})$. 
O ferrioxalato de potássio foi preparado pela mistura de solução de cloreto férrico $1,5 \mathrm{~mol} \mathrm{~L}^{-1}$ com solução de oxalato de potássio $1,5 \mathrm{~mol} \mathrm{~L}^{-1}$, na proporção 1:3. Sua precipitação foi imediata. O sal complexo de tonalidade verde esmeralda foi recolhido em funil de Büchner e lavado com água quente $\left(60^{\circ} \mathrm{C}\right)$.

Recristalizou-se com água quente 3 vezes. Foi deixado secar em dessecador a vácuo, ao abrigo de luz. É imprescindível que o ferrioxalato de potássio fique ao abrigo de qualquer radiação ultravioleta e visível incidente.

\subsubsection{Síntese do $\left\{\mathrm{KCr}\left(\mathrm{NH}_{3}\right)_{2}(\mathrm{NSC})_{4}\right\}[75]$}

O sal de Reinecke é comprado como sal amoniacal $\left(\mathrm{NH}_{4}\right)\left[\mathrm{Cr}\left(\mathrm{NH}_{3}\right)_{2}(\mathrm{NCS})_{4}\right] \mathrm{H}_{2} \mathrm{O}$, sendo convertido para um sal de potássio da seguinte forma: dissolveu-se o sal em água desionizada a $50{ }^{\circ} \mathrm{C}$ sob agitação constante. Essa solução foi filtrada a quente e ao filtrado foi adicionado nitrato de potássio $\left(\mathrm{KNO}_{3}\right)$. A solução foi resfriada com banho de gelo por aproximadamente 20 minutos. Formou-se precipitado azul claro, que foi recolhido por filtração e lavado 4 vezes com água gelada e etanol. O sólido foi seco sobre vácuo. 


\subsection{Equipamentos e Métodos Utilizados}

3.4.1 Espectros eletrônicos na região do visível e ultravioleta

- Laboratório de Fotoquímica Inorgânica (Prof. Dr. Elia Tfouni-DQ-FFCLRPUSP): os espectros de absorção foram obtidos através de um espectrofotômetro Uvvis Hewlett-Packard de modelo 8452A. A faixa deste equipamento abrange o intervalo de 200 a $800 \mathrm{~nm}$.

- Laboratório de Química Inorgânica (Prof. Dra. Rose Maria Carlos - DQUFSCar): os espectros de absorção foram obtidos através de umespectrofotômetro Uv-vis Agilent de modelo 8453. A faixa deste equipamento abrange o intervalo de 190 a $1100 \mathrm{~nm}$.

- Laboratório de Física (Prof. Dr. louri Borissevitch - DF-FFCLRP-USP): os espectros de absorção foram obtidos através de um espectrofotômetro Uv-vis Beckman Coulter de modelo DU 640. A faixa deste equipamento abrange o intervalo de 190 a $1100 \mathrm{~nm}$.

\subsubsection{Espectroscopia de Emissão}

- Laboratório de Química Inorgânica (Prof. Dra. Rose Maria Carlos - DQ UFSCar): os espectros de emissão foram obtidos em um Espectrômetro de Fluorescência de modelo RF-5301PC da Shimadzu. 
- Laboratório de Física (Prof. Dr. louri Borissevitch - DF-FFCLRP-USP): os espectros de emissão foram obtidos em um Espectrômetro de Fluorescência de modelo F-7000 da Hitachi High-Technologies.

\subsubsection{Espectros na região do infravermelho}

Espectros vibracionais na região do infravermelho foram obtidos no espectrômetro com transformada de Fourier (FTIR) Bomem MB 102 utilizando pastilhas de $\mathrm{KBr}$ ou nujol na faixa de $4000-400 \mathrm{~cm}^{-1}$.

\subsubsection{Ressonância Magnética Nuclear}

Os espectros de RMN em solução foram obtidos através do equipamento Bruker DRX300, na Faculdade de Filosofia, Ciências e Letras de Ribeirão Preto. Foram utilizados tubos de $5 \mathrm{~mm}$. O solvente utilizado foi $\mathrm{D}_{2} \mathrm{O}$.

\subsubsection{Ressonância Paramagnética Eletrônica}

As medidas de ressonância paramagnética nuclear foram realizados no Instituto de Química da USP de São Carlos. Utilizou-se um espectrômetro da Bruker modelo EMX Plus operando na banda X (9 a $10 \mathrm{GHz}$ ), à temperatura de $293 \mathrm{~K}$. 


\subsubsection{Medidas de $\mathrm{pH}$}

As medidas de $\mathrm{pH}$ foram feitas em um pHmetro de bancada da Quimis Aparelhos Científicos, modelo Q400AS, faixa de medição de $\mathrm{pH}$ 0,00 a 14,00, variação de 94 a 240 Volts, potência de 10 Watts e, sensor de temperatura Pt 100 operando na faixa de 0 a $100{ }^{\circ} \mathrm{C}$. Sua calibração foi feita diariamenteatravés de tampões $\mathrm{pH} 9,18,6,86$ e 4,01.

\subsubsection{Cromatografia a Líquido de Alta Eficiência - HPLC}

As análises cromatográficas foram realizadas no laboratório de Fotoquímica Inorgânica do Departamento de Química da Faculdade de Filosofia, Ciências e Letras de Ribeirão Preto - USP, utilizando-se um equipamento de Cromatografia a Líquido de Alta Eficiência da marca Shimadzu, com coluna ODS (C18) de 4,6 x 250 $\mathrm{mm}$, diâmetro da partícula igual a 5,0 $\mu \mathrm{m}$, alça de $10 \mu \mathrm{L}$ e detector de arranjo de diodo, modelo LC-10AD.

\subsection{Fotólises}

Para avaliar a contribuição da temperatura, em todos os sistemas foram mantidas em condições de escuro, soluções das mesmas amostras a serem fotolisadas. Foram registrados espectros antes e ao final do tempo de irradiação e possíveis reações dessas amostras foram descontadas das amostras fotolisadas. Todas as fotólises foram feitas em soluções desaeradas com nitrogênio ou argônio e somente luz vermelha foi utilizada como fonte de iluminação no ambiente. 


\subsubsection{Instrumentos}

- Laboratório de Fotoquímica Inorgânica (Prof. Dr. Elia Tfouni - DQ-FFCLRPUSP): as irradiações monocromáticas foram geradas utilizando-se fonte de 150 Watts, com lâmpada de Xenônio, em um trem ótico da Oriel modelo 8500, com fonte de alimentação universal.

- Laboratório de Química Inorgânica (Prof. Dra. Rose Maria Carlos - DQUFSCar): as irradiações monocromáticas foram geradas utilizando-se fonte de 200 Watts, com lâmpada de Xenônio, em um trem ótico da Oriel modelo 69911, com fonte de alimentação universal.

- Laboratório de Química (Prof. Dr. Douglas Wagner Franco - IQSC-USP): as irradiações a laser foram feitas usando o equipamento Continuum Surelite OPO PII10), operando no terceiro harmônico (355 nm) e, $2 \mathrm{~mJ} /$ pulso ou $5 \mathrm{~mJ} /$ pulso como fonte de excitação. Este sistema possuía ajuste no intervalo de 440 a 700 nm.

\section{- Ensaios Fotoquímicos}

Os ensaios fotoquímicos foram efetuados em um trem ótico da Oriel, com lâmpada de xenônio de pressão média de 150, 200 e 500 Watts. O sistema possuía compartimento para manter a cela termostatizada e sob agitação constante (Figura 9). 


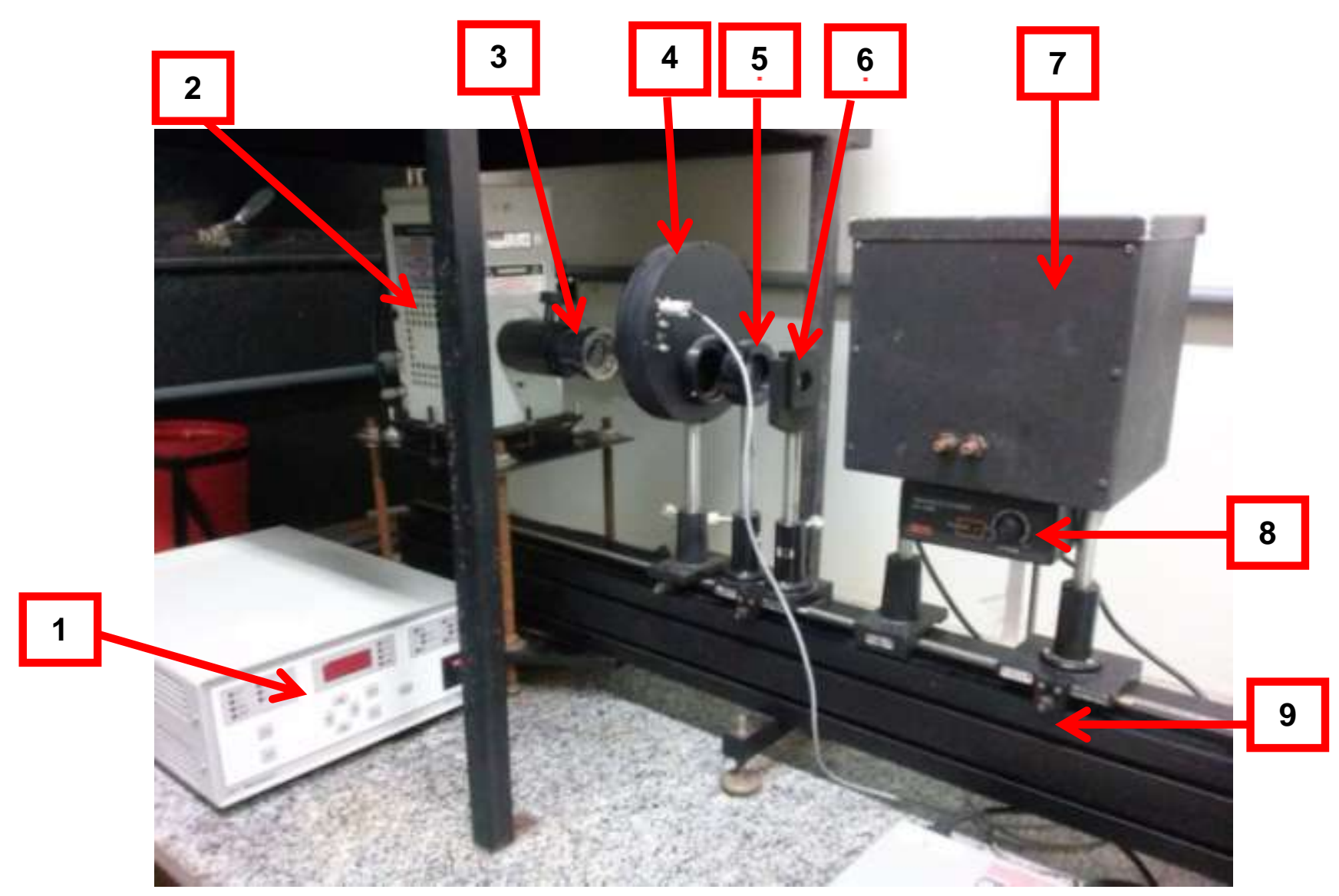

Figura 9 - Equipamento utilizado nos ensaios fotoquímicos.

As atribuições para cada componente do sistema utilizado são listadas a seguir:

1 - Fonte Universal Oriel.

2 - Caixa contendo lâmpada de xenônio provida de (3) lente acoplada juntamente com filtro de infravermelho (IV) na saída da luz.

4 - "Shutter", utilizado para bloqueio da luz incidente.

5 - Lente colimadora.

6 - Suporte para filtro ótico.

7 - Compartimento para amostras com tampa.

8 - Agitador magnético.

9 - Trilho para adaptação e sustentação dos equipamentos. 


\subsubsection{Filtros de Interferência}

Antes da utilização de cada filtro de interferência, foram obtidos espectros Uv-vis de cada um e comparados aos espectros fornecidos pelo fabricante com a finalidade de ver se estavam em boas condições para serem utilizados.

\subsubsection{Medidas da Intensidade da luz incidente}

A determinação da intensidade da luz é fundamental para se calcular o rendimento quântico. A intensidade da luz é calculada através de actinometria.

Um actinômetro químico é um sistema químico que sofre uma reação induzida pela luz (a um determinado comprimento de onda, $\lambda$ ) no qual o rendimento quântico, $\Phi(\lambda)$, é conhecido com precisão [76].

Em princípio, um bom actinômetro deve satisfazer as seguintes características: não ser muito sensível à variação de concentração dos reagentes, temperatura, intensidade de luz, comprimento de onda de excitação, vestígios de impurezas e oxigênio [77]. Muitos actinômetros são baseados em reações redox de compostos de coordenação, tais como o ferrioxalato de potássio e o sal de

Reinecke. O ferrioxalato de potássio, por exemplo, em soluções ácidas, é muito sensível no intervalo de 250 a 500 nm [76]. Já o sal de Reinecke, é excelente para comprimentos de onda maiores, no intervalo de 316 a $750 \mathrm{~nm}$.

\section{Actinometria com ferrioxalato de potássio [74]}

O ferrioxalato de potássio quando irradiadona faixa de 250-500 nm [76], sofre a seguinte reação (Equação 9) [78]: 


$$
\begin{aligned}
& {\left[\mathrm{Fe}^{\prime \prime \prime}\left(\mathrm{C}_{2} \mathrm{O}_{4}\right)_{3}\right]^{3-} \stackrel{\mathrm{hv}}{\rightarrow}\left[\left(\mathrm{C}_{2} \mathrm{O}_{4}\right)_{2} \mathrm{Fe}^{\prime \prime}-\mathrm{OCO}-\mathrm{COO}^{3-} \rightarrow \mathrm{Fe}^{2+}+2 \mathrm{CO}_{2}+3 \mathrm{C}_{2} \mathrm{O}_{4}{ }^{2-}\right.} \\
& \mathrm{Fe}^{2+}{ }_{(\text {aq })}+3 \mathrm{fen}_{(\mathrm{aq})} \rightarrow\left[\mathrm{Fe}(\mathrm{fen})_{3}\right]^{2+}{ }_{(\mathrm{aq})}
\end{aligned}
$$

Os íons $\mathrm{Fe}^{2+}$ podem ser determinados espectrofotometricamente dispondose da utilização de um reagente bastante seletivo, a 1,10-fenantrolina (fen), que em meio ácido forma um complexo de cor avermelhada com o Fe ${ }^{2+}$ (Equação 10), cuja formação pode ser acompanhada por Uv-visível, pois o complexo $\left[\mathrm{Fe}(\text { phen })_{3}\right]^{2+}$ tem absortividade molar $(\varepsilon)$ alta $\left(1,11 \times 10^{4} \mathrm{~L} \mathrm{~mol}^{-1} \mathrm{~cm}^{-1} \mathrm{em} 510 \mathrm{~nm}\right)$.

Portanto, este actinômetro foi utilizado para medir a intensidade da luz nos comprimentos de onda de 313, 350, 400 e $438 \mathrm{~nm}$. Foram preparadas as seguintes soluções:

Solução A: Ferrioxalato de potássio $\mathrm{K}_{3}\left[\mathrm{Fe}\left(\mathrm{C}_{2} \mathrm{O}_{4}\right)_{3} \cdot 3 \mathrm{H}_{2} \mathrm{O} 6 \times 10^{-3} \mathrm{~mol} \mathrm{~L}^{-1}\right.$; preparada pela mistura de uma solução de $\mathrm{FeCl}_{3} \cdot 6 \mathrm{H}_{2} \mathrm{O} 1,5 \mathrm{~mol} \mathrm{~L}^{-1}$ com uma solução de $\mathrm{K}_{2} \mathrm{C}_{2} \mathrm{O}_{4}$ $1,5 \mathrm{~mol} \mathrm{~L}^{-1}$, na proporção de 1:3, respectivamente.

Solução B: Preparada pela mistura de $600 \mathrm{~mL}$ de solução de acetato de sódio $1 \mathrm{~mol}$ $\mathrm{L}^{-1}$ e $360 \mathrm{~mL}$ de $\mathrm{H}_{2} \mathrm{SO}_{4} 1 \mathrm{~mol} \mathrm{~L}^{-1}$, e diluída para $1 \mathrm{~L}$.

Solução C: 1,10-fenantrolina 0,1\% (m/v): dissolveu-se $0,1 \mathrm{~g}$ de 1,10-fenantrolina em $100 \mathrm{~mL}$ de água destilada à quente $\left(\sim 70^{\circ} \mathrm{C}\right)$.

Somente luz vermelha foi mantida acesa no local onde a actinometria e as irradiações foram realizadas. Foram transferidos $3 \mathrm{~mL}\left(\mathrm{~V}_{1}\right)$ da solução $A$ para uma cela de quartzo de caminho ótico de $1 \mathrm{~cm}$ e, $2 \mathrm{~mL}$ para um balão volumétrico de 10 
$\mathrm{mL}$ (controle).A solução da cubeta foi irradiada (com agitação) durante determinado tempo (1 a 3 minutos), no comprimento de onda em que foram irradiadas as amostras. Desta solução irradiada foram transferidos $2 \mathrm{~mL}\left(\mathrm{~V}_{2}\right)$ para um balão volumétrico de $10 \mathrm{~mL}\left(\mathrm{~V}_{3}\right)$. À solução irradiada, assim como ao controle foram adicionados $2,5 \mathrm{~mL}$ de solução $\mathbf{B}$ e $1 \mathrm{~mL}$ da solução $\mathbf{C}$. Os volumes dos balões foram completados com água desionizada para $10 \mathrm{~mL}$. As soluções foram agitadas e mantidas em escuro por uma hora. Mediu-se a absorbância da solução irradiada e do controle em $510 \mathrm{~nm}$.

A intensidade da luz emitida pela lâmpada utilizada foi calculada por [77]:

$$
I=\frac{\left(6.10^{23}\right) \mathrm{V}_{1} \mathrm{~V}_{3} \Delta \mathrm{A}}{\emptyset_{\mathrm{Fe}} \mathrm{t} \mathrm{V}_{2} \mathrm{l} \varepsilon_{\mathrm{Fe}}\left(1-10^{-\mathrm{Abs}}\right)}
$$

Onde:

- $\mathrm{V}_{1}$ é o volume da solução de actinômetro irradiada $(\mathrm{mL})$;

- $\quad V_{2}$ é o volume de solução da alíquota irradiada na análise (mL);

- $\quad V_{3}$ é o volume do balão volumétrico no qual $V_{2}$ foi diluído $(\mathrm{mL})$;

- $\Delta \mathrm{A}$ é a diferença da absorbância em $510 \mathrm{~nm}$ entre o controle e a solução irradiada;

- $\varnothing_{\mathrm{Fe}}$ é o rendimento quântico de formação de $\mathrm{Fe}^{2+}$ no comprimento de luz irradiada;

- $\quad$ é o tempo de irradiação (s);

- $\quad$ é o caminho ótico da cela fotolisada $(\mathrm{cm})$;

- $\varepsilon_{\mathrm{Fe}}$ é o coeficiente de absortividade molar do íon complexo $\left[\mathrm{Fe}(\text { phen })_{3}\right]^{2+}$ a 510 $\mathrm{nm}\left(1,11 \times 10^{4} \mathrm{~L} \mathrm{~cm}^{-1} \mathrm{~mol}^{-1}\right)$; 
- I é a intensidade da luz incidente (einstein $\mathrm{s}^{-1}$ ).

- Abs = absorbância da solução controle no comprimento de onda de excitação;

\section{Actinometria com sal de Reinecke [75]}

$\mathrm{O}$ sal de Reinecke, $\mathrm{K}\left[\mathrm{Cr}\left(\mathrm{NH}_{3}\right)_{2}(\mathrm{NCS})_{4}\right]$, em solução aquosa, quando irradiado principalmente na faixa de 316 a $750 \mathrm{~nm}$, sofre substituição de um ligante NCS` por uma água (Equação 12).

$\left[\mathrm{Cr}\left(\mathrm{NH}_{3}\right)_{2}(\mathrm{NCS})_{4}\right]^{-}+\mathrm{H}_{2} \mathrm{O} \stackrel{\mathrm{hv}}{\longrightarrow}\left[\mathrm{Cr}\left(\mathrm{NH}_{3}\right)_{2}(\mathrm{NCS})_{3}\left(\mathrm{H}_{2} \mathrm{O}\right)\right]^{-}+\mathrm{NCS}^{-}$

Os íons NCS são quantificados adicionando-se nitrato de ferro(III) à solução, pois o complexo formado com o $\mathrm{Fe}(\mathrm{III})$ (Equação 13), é vermelho e possui coeficiente de absortividade molar $(\varepsilon)$ alto $\left(4300 \mathrm{~L} \mathrm{~mol}^{-1} \mathrm{~cm}^{-1}\right)$, sendo possível fazer a sua determinação por espectrofotometria Uv-visível.

$\left[\mathrm{Fe}\left(\mathrm{H}_{2} \mathrm{O}\right)_{6}\right]^{3+}+\mathrm{SCN}^{-} \longrightarrow\left[\mathrm{Fe}(\mathrm{SCN})\left(\mathrm{H}_{2} \mathrm{O}\right)_{5}\right]^{2+}+\mathrm{H}_{2} \mathrm{O}$

Este actinômetro foi utilizado nas irradiações nos comprimentos de onda de 520 e $577 \mathrm{~nm}$. Foram preparadas as seguintes soluções:

Solução A: Sal de Reinecke, $\mathrm{KCr}\left(\mathrm{NH}_{3}\right)_{2}(\mathrm{NCS})_{4}, 5 \times 10^{-4} \mathrm{~mol} \mathrm{~L}^{-1}$; preparada pela dissolução de $0,055 \mathrm{~g}$ de $\operatorname{KCr}\left(\mathrm{NH}_{3}\right)_{2}(\mathrm{NCS})_{4} \mathrm{em} 20 \mathrm{~mL}$ de água. Esta solução foi mantida em escuro e sob agitação constante por 1 hora. 
Solução B: Nitrato de ferro(III) $0,1 \mathrm{~mol} \mathrm{~L}^{-1}$, preparada pela dissolução de $12,1 \mathrm{~g}$ de $\mathrm{Fe}\left(\mathrm{NO}_{3}\right)_{3} .9 \mathrm{H}_{2} \mathrm{O}$ em $14 \mathrm{~mL}$ de solução $\mathrm{HClO}_{4} 70 \%$ e completado o volume com água desionizada para $300 \mathrm{~mL}$.

Somente luz vermelha foi mantida acesa no local onde a actinometria e as irradiações foram realizadas. Foram transferidos $3 \mathrm{~mL}\left(\mathrm{~V}_{1}\right)$ da solução $\mathrm{A}$ para uma cela de quartzo de caminho ótico de $1 \mathrm{~cm} \mathrm{e,} 2 \mathrm{~mL}$ para um balão volumétrico de 25 $\mathrm{mL}$ (controle). A solução da cela de quartzo foi irradiada (com agitação) durante 10 minutos, com luz de $524 \mathrm{~nm}$. Desta solução irradiada foram transferidos $2 \mathrm{~mL}\left(\mathrm{~V}_{2}\right)$ para um balão volumétrico de $25 \mathrm{~mL}\left(\mathrm{~V}_{3}\right)$. O balão de $25 \mathrm{~mL}$ contendo a solução irradiada assim como o controle foram completados com a solução B. As soluções foram agitadas e mantidas em escuro por uma hora. Mediu-se a absorbância da solução irradiada e do controle em $450 \mathrm{~nm}$. Este procedimento foi repetido para os tempos (t) 10, 15, 30 e 60 segundos.

A intensidade da luz emitida pela lâmpada utilizada foi calculada por [77]:

$$
I=\frac{\left(6.10^{20}\right) \mathrm{V}_{1} \mathrm{~V}_{3} \Delta \mathrm{A}}{\emptyset_{\mathrm{SCN}^{-}} \mathrm{t}_{2} \mathrm{l} \varepsilon_{\left[\mathrm{Fe}(\mathrm{SCN})\left(\mathrm{H}_{2} \mathrm{O}\right)_{5}\right]^{2+}}\left(1-10^{-\mathrm{Abs}}\right)}
$$

Onde:

- $\quad V_{1}$ é o volume da solução de actinômetro irradiada $(\mathrm{mL})$;

- $\quad V_{2}$ é o volume da alíquota da solução irradiada a ser analisada (mL);

- $\mathrm{V}_{3}$ é o volume do balão volumétrico no qual $\mathrm{V}_{2}$ foi diluído $(\mathrm{mL})$;

- $\Delta$ A é a diferença da absorbância em 450 nm entre o controle e a solução irradiada; 


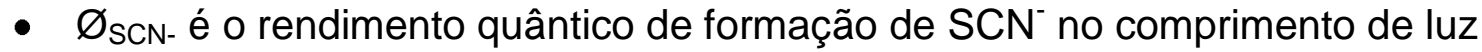
irradiada $(0,28$ em $520 \mathrm{~nm}$ e 0,27 em $577 \mathrm{~nm})$;

- Abs = absorbância da solução controle no comprimento de onda de excitação;

- t é o tempo de irradiação (s);

- $\quad$ é o caminho ótico da cela fotolisada $(\mathrm{cm})$;

- $\quad$ é o coeficiente de absortividade molar do íon complexo a 450 $\mathrm{nm}\left(4,30 \times 10^{3} \mathrm{~L} \mathrm{~cm}^{-1} \mathrm{~mol}^{-1}\right)$

- I é a intensidade da luz incidente (einstein $\mathrm{s}^{-1}$ ).

\subsection{Irradiação do complexo}

Sob atmosfera de argônio, foi preparada uma solução de $1,0 \times 10^{-4} \mathrm{~mol} \mathrm{~L}^{-1}$ do complexo trans-[Ru( $\left.\left.\mathrm{NH}_{3}\right)_{4}(\mathrm{py})(\mathrm{NO})\right]\left(\mathrm{BF}_{4}\right)_{3}$ em $\mathrm{HCF}_{3} \mathrm{COO} / \mathrm{NaCF}_{3} \mathrm{COO} \mathrm{pH} \sim 3$. Desta solução, foram adicionados $3 \mathrm{~mL}$ a uma cela de quartzo de caminho ótico de 1 $\mathrm{cm}$ e irradiada com luz de $313 \mathrm{~nm}$. A cada irradiação foram registrados espectros eletrônicos de Uv-vis, sendo os intervalos de tempo entre cada irradiação de 0,5, 10,20 e 40 minutos.

\subsection{Irradiação dos corantes}

Todas as soluções foram preparadas e mantidas sob atmosfera inerte de argônio ou nitrogênio. 


\subsubsection{Azul do Nilo}

Preparou-se uma solução $7,64 \times 10^{-7} \mathrm{~mol} \mathrm{~L}^{-1}$ do corante azul do Nilo em solução aquosa de $\mathrm{HCF}_{3} \mathrm{COO} / \mathrm{NaCF}_{3} \mathrm{COO} \mathrm{pH} \sim 3$. Uma alíquota de $3 \mathrm{~mL}$ desta solução foi adicionada a uma cela de quartzo de caminho ótico de $1 \mathrm{~cm}$ e irradiada com filtro de interferência de onda de $577 \mathrm{~nm}$. A cada irradiação foram registrados espectros eletrônicos de Uv-vis e de emissão, sendo os intervalos de tempo entre cada irradiação de 1, 2, 4, 8, 16, 32 e 64 minutos.

\subsubsection{Fluoresceína sódica}

Preparou-se uma solução de $4,97 \times 10^{-4} \mathrm{~mol} \mathrm{~L}^{-1}$ do corante fluoresceína sódica em solução $\mathrm{CF}_{3} \mathrm{COOH} / \mathrm{CF}_{3} \mathrm{COONa} \mathrm{pH} \sim 3$. Uma alíquota de $3 \mathrm{~mL}$ desta solução foi adicionada a uma cela de quartzo de caminho ótico de $1 \mathrm{~cm}$ e irradiada, com filtro de interferência de onda de $438 \mathrm{~nm}$. A cada irradiação foram registrados espectros eletrônicos de Uv-vis e de emissão, sendo os tempos de irradiação $t=0$, 2, 4, 6 e 26 minutos.

\subsubsection{Rodamina-B}

Preparou-se uma solução $1,00 \times 10^{-5} \mathrm{~mol} \mathrm{~L}^{-1}$ do corante rodamina-B em solução $\mathrm{HCF}_{3} \mathrm{COO} / \mathrm{NaCF}_{3} \mathrm{COO} \mathrm{pH} \sim 3$. Uma alíquota de $2,5 \mathrm{~mL}$ desta solução foi adicionada a uma cela de quartzo de caminho ótico de $1 \mathrm{~cm}$ e irradiada com luz de 524 nm. A cada irradiação foram registrados espectros eletrônicos de Uv-vis de 
absorção e de emissão, sendo os tempos de cada irradiação de 4, 10, 15, 20, 25 e 70 minutos.

\subsubsection{Tartrazina}

Preparou-se uma solução de $1,50 \times 10^{-5} \mathrm{~mol} \mathrm{~L}^{-1}$ do corante tartrazina em solução $\mathrm{HCF}_{3} \mathrm{COO} / \mathrm{NaCF}_{3} \mathrm{COO} \mathrm{pH} \sim 3$. Uma alíquota de $2,5 \mathrm{~mL}$ desta solução foi adicionada a uma cela de quartzo de caminho ótico de $1 \mathrm{~cm}$ e irradiada com luz de $438 \mathrm{~nm}$. A cada irradiação foram registrados espectros eletrônicos de Uv-vis de absorção e de emissão, sendo os tempos de cada irradiação de $t=0,5$ e 10 minutos.

\subsection{Irradiação do complexo trans-[Ru(NH$\left.\left.)_{3}\right)_{4}(\mathrm{py})(\mathrm{NO})\right]\left(\mathrm{BF}_{4}\right)_{3}$ na presença dos corantes}

Todas as soluções foram preparadas e mantidas sob atmosfera inerte de argônio ou nitrogênio.

\subsubsection{Complexo + fluoresceína sódica}

A partir de uma solução de fluoresceína sódica $4,97 \times 10^{-4} \mathrm{~mol} \mathrm{~L}^{-1} \mathrm{em}$ solução $\mathrm{CF}_{3} \mathrm{COOH} / \mathrm{CF}_{3} \mathrm{COONa} \mathrm{pH} \sim 3$, preparou-se uma solução de $8,15 \times 10^{-4} \mathrm{~mol}$ $\mathrm{L}^{-1}$ do complexo trans-[Ru($\left.\left(\mathrm{NH}_{3}\right)_{4}(\mathrm{py})(\mathrm{NO})\right]\left(\mathrm{BF}_{4}\right)_{3}$. Uma alíquota de $2,5 \mathrm{~mL}$ desta solução foi adicionada a uma cela de quartzo de caminho ótico de $1 \mathrm{~cm}$ e irradiada, com filtro de interferência de onda de $438 \mathrm{~nm}$. A cada irradiação foram registrados 
espectros eletrônicos de Uv-vis e de emissão, sendo os tempos de irradiação $t=0$, $1,2,4,8,16$ e 60 minutos.

\subsubsection{Complexo + rodamina-B}

Pesou-se $3,8 \mathrm{mg}$ do complexo trans-[Ru( $\left.\left(\mathrm{NH}_{3}\right)_{4}(\mathrm{py})(\mathrm{NO})\right]\left(\mathrm{BF}_{4}\right)_{3}$ e adicionouse a um balão volumétrico de $10 \mathrm{~mL}$. Completou-se o volume comuma solução 1,00 $\mathrm{X} 10^{-5} \mathrm{~mol} \mathrm{~L}^{-1}$ de rodamina-B em $\mathrm{CF}_{3} \mathrm{COOH} / \mathrm{CF}_{3} \mathrm{COONa} \mathrm{pH} \sim 3$. Uma alíquota de 2,5 $\mathrm{mL}$ desta solução foi adicionada a uma cela de quartzo de caminho ótico de $1 \mathrm{~cm}$ e irradiada, com filtro de interferência de onda de $570 \mathrm{~nm}$. A cada irradiação foram registrados espectros eletrônicos de Uv-vis e de emissão, sendo os tempos de irradiação $\mathrm{t}=0,4,10,15,20,25$ e 70 minutos.

\subsection{Determinação da quantidade de NO liberada}

Todas as soluções foram preparadas e mantidas sob atmosfera inerte de argônio ou nitrogênio.

3.9.1 Complexo + rodamina-B + mioglobina

Pesou-se 4,4 mg do complexo trans-[Ru( $\left.\left(\mathrm{NH}_{3}\right)_{4}(\mathrm{py})(\mathrm{NO})\right]\left(\mathrm{BF}_{4}\right)_{3}$ e adicionou-se a um balão volumétrico de $10 \mathrm{~mL}$. Completou-se o volume com uma solução 1,00 X $10^{-5} \mathrm{~mol} \mathrm{~L}^{-1}$ de rodamina-B em tampão fosfato $(\mathrm{pH}=7,4)$. Desta solução, transferiuse $3 \mathrm{~mL}$ para uma cela de quartzo, e 0,6 $\mathrm{mg}$ de mioglobina foi introduzida ao recipiente de fundo redondo acoplado a uma cela de quartzo de caminho ótico $1 \mathrm{~cm}$. 
Deixou-se desaerar por 15 minutos. Irradiou-se a amostra com luz de 580 e $524 \mathrm{~nm}$. Foram obtidos espectros de absorção da amostra sem misturar a mioglobina e após a mistura. A cada irradiação foram registrados espectros eletrônicos de Uv-vis e de emissão.

\subsubsection{Complexo + fluoresceína sódica + mioglobina}

Pesou-se 4,0 mg do complexo trans-[Ru( $\left.\left(\mathrm{NH}_{3}\right)_{4}(\mathrm{py})(\mathrm{NO})\right]\left(\mathrm{BF}_{4}\right)_{3}$ e adicionou-se a um balão volumétrico de $10 \mathrm{~mL}$. Completou-se o volume com uma solução 1,08 X $10^{-5} \mathrm{~mol} \mathrm{~L}^{-1}$ de fluoresceína sódica em tampão fosfato $(\mathrm{pH}=7,4)$. Desta solução transferiu-se $3 \mathrm{~mL}$ para uma cela de quartzo e, 0,5 mg da mioglobina foi introduzida ao recipiente de fundo redondo acoplado a uma cela de quartzo de caminho ótico 1 $\mathrm{cm}$. Foram obtidos espectros de absorção da amostra sem misturar a mioglobina e após a mistura Irradiou-se a amostra com luz de $479 \mathrm{~nm}$. A cada irradiação foram registrados espectros eletrônicos de Uv-vis e de emissão.

\subsubsection{Solução estoque carboxy-PTIO - Solução F}

Pesou-se $2 \mathrm{mg}$ de carboxy-PTIO $\left(6,3 \times 10^{-6} \mathrm{~mol}\right)$ e adicionou-se a um microtubo de $2 \mathrm{~mL}$. Adicionou-se $1 \mathrm{~mL}$ de tampão fosfato $(\mathrm{pH}=7,4)$.

3.9.4 Complexo + carboxy-PTIO

A um balão de $5 \mathrm{~mL}$ adicionou-se $2 \mathrm{mg}$ do complexo trans$\left[\mathrm{Ru}\left(\mathrm{NH}_{3}\right)_{4}(\mathrm{py})(\mathrm{NO})\right]\left(\mathrm{BF}_{4}\right)$ e completou-se o volume com tampão fosfato $(\mathrm{C}=7,4 \mathrm{X}$ 
$\left.10^{-4} \mathrm{~mol} \mathrm{~L}^{-1}\right)$. Foi adicionado $1 \mathrm{~mL}$ desta solução a uma cela de quartzo de caminho ótico $0,5 \mathrm{~cm}$, juntamente a $50 \mu \mathrm{L}$ da solução estoque de carboxy-PTIO. Irradiou-se com laser no comprimento de onda de $355 \mathrm{~nm}, 5 \mathrm{~mJ} /$ pulso, durante 5 , 10 e 15 minutos.

3.9.5 Complexo + alaranjado de acridina + carboxy-PTIO

Pesou-se 15 mg do corante alaranjado de acridina e adicionou-se a um balão volumétrico de $10 \mathrm{~mL}$. Completou-se o volume com tampão fosfato $(\mathrm{pH}=7,4)-$ solução do corante de concentração $5,7 \times 10^{-3} \mathrm{~mol} \mathrm{~L}^{-1}$.

A um balão de $5 \mathrm{~mL}$ adicionou-se $2 \mathrm{mg}$ do complexo trans$\left[\mathrm{Ru}\left(\mathrm{NH}_{3}\right)_{4}(\mathrm{py})(\mathrm{NO})\right]\left(\mathrm{BF}_{4}\right)_{3}$ e $650 \mu \mathrm{L}$ da solução de alaranjado de acridina de concentração $5,7 \times 10^{-3} \mathrm{~mol} \mathrm{~L}^{-1}$. Completou-se o volume com tampão fosfato (solução do complexo $7,4 \times 10^{-4} \mathrm{~mol} \mathrm{~L}^{-1}+$ corante).

A uma cela de quartzo de caminho ótico de $0,5 \mathrm{~cm}$ e volume de $1 \mathrm{~mL}$, adicionou-se $1 \mathrm{~mL}$ da solução do complexo + corante, $50 \mu \mathrm{L}$ da solução estoque de carboxy-PTIO $\left(6,3 \times 10^{-3} \mathrm{~mol}\right)$. Irradiou-se no comprimento de onda de $440 \mathrm{~nm}, 2$ $\mathrm{mJ} /$ pulso, nos intervalos de tempo de 5, 10 e 20 minutos.

3.9.6 Complexo + rodamina-B + carboxy-PTIO

Pesou-se $23 \mathrm{mg}$ do corante rodamina-B e adicionou-se a um balão volumétrico de $10 \mathrm{~mL}$. Completou-se o volume com tampão fosfato $(\mathrm{pH}=7,4)-$ solução do corante de concentração $4,8 \times 10^{-3} \mathrm{~mol} \mathrm{~L}^{-1}$. 
A um balão de $10 \mathrm{~mL}$ adicionou-se $3,3 \mathrm{mg}$ do complexo trans$\left[\mathrm{Ru}\left(\mathrm{NH}_{3}\right)_{4}(\mathrm{py})(\mathrm{NO})\right]\left(\mathrm{BF}_{4}\right)_{3}$ e 1,2 $\mathrm{mL}$ da solução de rodamina-B de concentração 4,8 $\mathrm{X}$ $10^{-3} \mathrm{~mol} \mathrm{~L}^{-1}$. Completou-se o volume com tampão fosfato (solução de complexo 7,4 $\mathrm{X} 10^{-4} \mathrm{~mol} \mathrm{~L}^{-1}+$ corante). A uma cubeta de caminho ótico de $0,5 \mathrm{~cm}$ e volume de 1 $\mathrm{mL}$, adicionou-se $1 \mathrm{~mL}$ da desta solução e $50 \mu \mathrm{L}$ da solução estoque de carboxyPTIO. Irradiou-se nos comprimentos de onda de 520 e 570 nm, 2 mJ/pulso, nos intervalos de tempo de 5, 10 e 15 minutos.

\subsubsection{Complexo + fluoresceína sódica + carboxy-PTIO}

Pesou-se $9 \mathrm{mg}$ do corante fluoresceína sódica e adicionou-se a um balão volumétrico de $10 \mathrm{~mL}$. Completou-se o volume com tampão fosfato $(\mathrm{pH}=7,4)-$ solução do corante de concentração $2,4 \times 10^{-3} \mathrm{~mol} \mathrm{~L}^{-1}$.

A um balão de $10 \mathrm{~mL}$ adicionou-se $1,7 \mathrm{mg}$ do complexo trans$\left[\mathrm{Ru}\left(\mathrm{NH}_{3}\right)_{4}(\mathrm{py})(\mathrm{NO})\right]\left(\mathrm{BF}_{4}\right)_{3}$ e $1,3 \mathrm{~mL}$ da solução de fluoresceína sódica de concentração $2,4 \times 10^{-3} \mathrm{~mol} \mathrm{~L}^{-1}$. Completou-se o volume com tampão fosfato (solução de complexo $3,2 \times 10^{-4} \mathrm{~mol} \mathrm{~L}^{-1}+$ corante). A uma cubeta de caminho ótico de $0,5 \mathrm{~cm}$ e volume de $1 \mathrm{~mL}$, adicionou-se $1 \mathrm{~mL}$ da solução desta solução e, $50 \mu \mathrm{L}$ da solução estoque de Carboxy-PTIO $\left(6,3 \times 10^{-3} \mathrm{~mol} \mathrm{~L}^{-1}\right)$. Irradiou-se nos comprimentos de onda de 440 e $490 \mathrm{~nm}, 2 \mathrm{~mJ} /$ pulso, nos intervalos de tempo de 5, 10 e 15 minutos. 


\subsubsection{Complexo + tartrazina + carboxy-PTIO}

Pesou-se $15 \mathrm{mg}$ do corante tartrazina e adicionou-se a um balão volumétrico de $10 \mathrm{~mL}$. Completou-se o volume com tampão fosfato $(\mathrm{pH}=7,4)$ - solução do corante de concentração $1,9 \times 10^{-3} \mathrm{~mol} \mathrm{~L}^{-1}$.

A um balão de $5 \mathrm{~mL}$ adicionou-se $2 \mathrm{mg}$ do complexo trans$\left[\mathrm{Ru}\left(\mathrm{NH}_{3}\right)_{4}(\mathrm{py})(\mathrm{NO})\right]\left(\mathrm{BF}_{4}\right)_{3}$ e $2 \mathrm{~mL}$ da solução de tartrazina de concentração $1,9 \times 10$ ${ }^{3} \mathrm{~mol} \mathrm{~L}^{-1}$. Completou-se o volume com tampão fosfato (solução do complexo $3,7 \mathrm{X}$ $10^{-4} \mathrm{~mol} \mathrm{~L}^{-1}+$ corante). A uma cela de quartzo de caminho ótico de $0,5 \mathrm{~cm}$ e volume de $1 \mathrm{~mL}$, adicionou-se $1 \mathrm{~mL}$ desta solução e $50 \mu \mathrm{L}$ da solução estoque de carboxyPTIO $\left(6,3 \times 10^{-3} \mathrm{~mol}\right)$. Irradiou-se no comprimento de onda de $440 \mathrm{~nm}, 2 \mathrm{~mJ} /$ pulso, nos intervalos de tempo de 5, 10 e 20 minutos. 


\section{RESULTADOS E DISCUSSÃO}

\subsection{Purificação da piridina}

A piridina utilizada como ligante para 0 complexo trans$\left[\mathrm{Ru}\left(\mathrm{SO}_{4}\right)\left(\mathrm{NH}_{3}\right)_{4}(\mathrm{py})\right] \mathrm{Cl}$ foi previamente tratada, pois seu espectro eletrônico de absorção não era coincidente com o espectro eletrônico de absorção da piridina pura encontrado [68]. Optou-se então por fazer destilação a vácuo. O espectro de absorção da piridina tratada (Figura 10) foi coincidente com o da piridina pura [68].

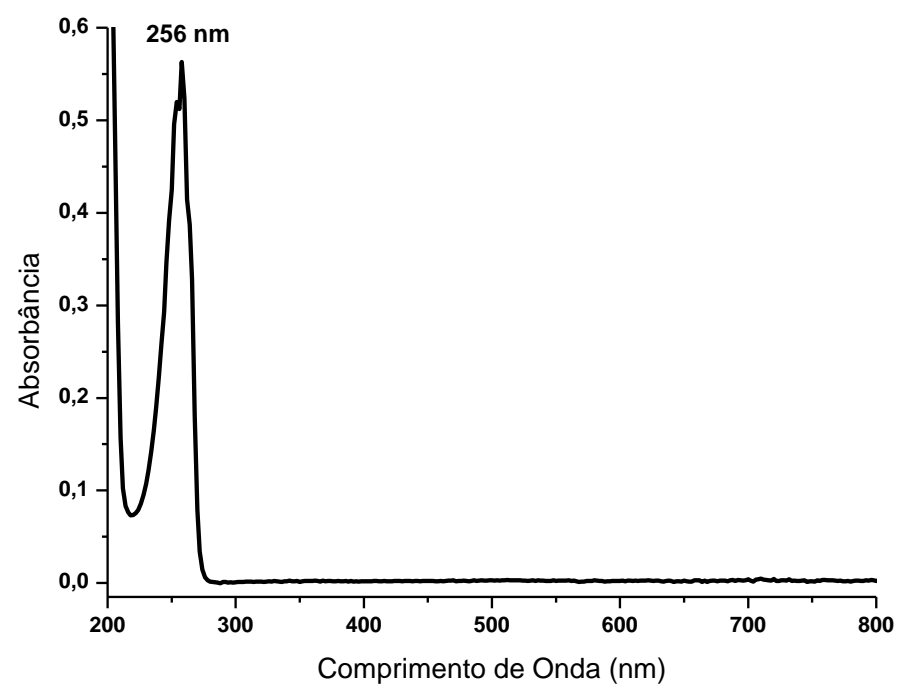

Figura 10 - Espectro de absorção da piridina em solução aquosa.

\subsection{Síntese dos complexos}

- Síntese do complexo trans-[Ru(NO)(OH)(cyclam)]($\left(\mathrm{PF}_{6}\right)_{2}$

As sínteses dos compostos cis-[RuCl $\left.2(\mathrm{dmso})_{4}\right], \quad c i s-\left[\mathrm{RuCl}_{2}(\operatorname{cyclam})\right] \mathrm{Cl}$ e

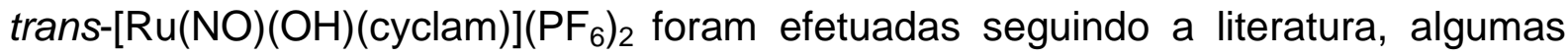


com pequenas modificações (vide parte experimental). Elas foram realizadas mais de uma vez, visto que apenas uma síntese não era suficiente para a obtenção das quantidades necessárias.

Para a obtenção do complexo cis- $\left[\mathrm{RuCl}_{2}(\mathrm{dmso})_{4}\right]$ de coloração amarela, foi adicionado o precursor $\mathrm{RuCl}_{3} \cdot \mathrm{nH}_{2} \mathrm{O}$ ao solvente dimetilsulfóxido, o qual é líquido a temperatura ambiente. O complexo formado, o cis-[RuCl$\left(\mathrm{dmso}_{4}\right]$, é estável frente a temperaturas mais altas, enquanto o complexo na forma trans- sofre isomerização frente ao aumento de temperatura [100]. Por isso, esta reação foi realizada com refluxo à temperatura de $160^{\circ} \mathrm{C}$. Além disso, a reação foi feita em condições de escuro a fim de se evitar a mínima formação do complexo trans-[RuCl$\left(\mathrm{dmso}_{4}\right]$ pela interferência da luz, conforme indicado na reação abaixo [100]

$\operatorname{cis}-\left[\mathrm{RuCl}_{2}(\mathrm{dmso})_{4}\right] \stackrel{\mathrm{hv}}{\rightleftharpoons} \underset{\Delta}{\rightleftharpoons}$ trans $\left[\mathrm{RuCl}_{2}(\mathrm{dmso})_{4}\right]$

O complexo cis-[RuCl 2 (cyclam)]Cl foi preparado a partir da reação do complexo cis-[RuCl $\left.2(\mathrm{dmso})_{4}\right]$ com uma solução etanólica do ligante cyclam, a $70 \stackrel{\circ}{\circ}$. A formação do complexo cis- foi preferencial visto que este complexo apresenta reações de substituição muito mais rápidas do que as reações de substituição do complexo na forma trans- [38].

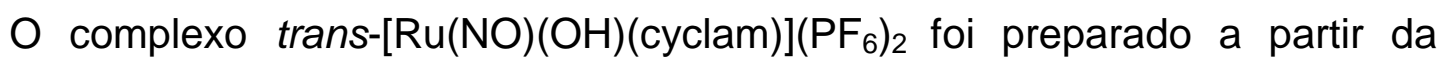
redução do cis-[RuCl $\mathrm{R}_{2}($ cyclam $\left.)\right] \mathrm{Cl}$ com amálgama de zinco em uma solução água/etanol/clorofórmio (10:5:5 v/v), passando de $\mathrm{Ru}(\mathrm{III})$ para $\mathrm{Ru}(\mathrm{II})$. A redução foi necessária visto que o $\mathrm{NO}^{+}$que será produzido na etapa posterior, possui maior afinidade pelo $\mathrm{Ru}(\mathrm{II})$ do que pelo $\mathrm{Ru}(\mathrm{III})$. Posteriormente, foi adicionado o complexo a uma solução de $\mathrm{NaNO}_{2}$ previamente desaerada, para ocorrer troca dos dois 
ligantes $\mathrm{Cl}^{-}$em posição trans-, por um ligante $\mathrm{OH}^{-}$e um ligante $\mathrm{NO}^{+}$. A precipitação do complexo foi feita através do contra-íon $\mathrm{PF}_{6}$.

Os dados dos espectros eletrônicos Uv-vis obtidos no decorrer das reações se encontram na Tabela 2.

Tabela 2 - Dados de comprimento de onda máximo e absortividade molar encontrados nos espectros eletrônicos Uv-visível dos complexos cis-[RuCl$\left(\mathrm{dmso}_{4}\right]$, cis-[RuCl 2 (cyclam)]Cl e trans-[Ru(NO)(OH)(cyclam)]($\left(\mathrm{PF}_{6}\right)_{2}$.

\begin{tabular}{|l|c|c|c|c|}
\cline { 2 - 5 } \multicolumn{1}{c|}{} & \multicolumn{2}{c|}{$\begin{array}{c}\text { Uv-vis: } \lambda_{\text {máx }} \\
(\mathrm{nm})\end{array}$} & \multicolumn{2}{c|}{$\begin{array}{c}\text { Absortividade Molar }(\varepsilon) \\
\left(10^{3} \mathrm{~mol} \mathrm{~L}^{-1} \mathrm{~cm}^{-1}\right)\end{array}$} \\
\cline { 2 - 5 } & Encontrado & Literatura & Encontrado & Literatura \\
\hline cis-[RuCl & $\left.(\mathrm{dmso})_{4}\right]$ \\
& 314 & $314^{\mathrm{a}}$ & 0,352 & $0,370^{\mathrm{a}}$ \\
\hline $\begin{array}{l}\text { trans- } \\
{[\mathrm{Ru}(\mathrm{NO})(\mathrm{OH})(\mathrm{cyclam})]\left(\mathrm{PF}_{6}\right)_{2}}\end{array}$ & 340 & $360^{\mathrm{a}}$ & 0,530 & $0,544^{\mathrm{a}}$ \\
\hline
\end{tabular}

*Ainda não reportado.

${ }^{a}$ Referência 100.

O complexo trans-[Ru(NO)(OH)(cyclam)]($\left(\mathrm{PF}_{6}\right)_{2}$ foi analisado e caracterizado por espectroscopia de absorção no infravermelho e eletrônica no UV-vis.

- Síntese do trans-[Ru(NH$\left.)_{4}(\mathrm{py})(\mathrm{NO})\right]\left(\mathrm{BF}_{4}\right)_{3}$

As sínteses dos compostos $\left[\mathrm{RuCl}\left(\mathrm{NH}_{3}\right)_{5}\right] \mathrm{Cl} \mathrm{Cl}_{2}$, trans-[Ru($\left.\left(\mathrm{HSO}_{3}\right)_{2}\left(\mathrm{NH}_{3}\right)_{4}\right]$, trans-

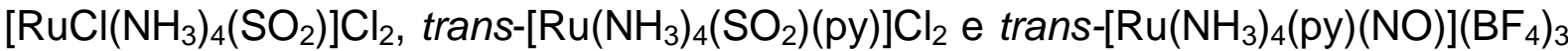
foram efetuadas seguindo a literatura, algumas com pequenas modificações (vide parte experimental). Elas foram realizadas mais de uma vez, visto que apenas uma 
síntese não era suficiente para a obtenção das quantidades necessárias. As sínteses foram repetidas sempre que necessário, pois foi observado que às vezes a síntese a partir de uma quantidade maior de reagentes não resulta em um rendimento satisfatório.

Para a obtenção do composto $\left[\mathrm{RuCl}\left(\mathrm{NH}_{3}\right)_{5}\right] \mathrm{Cl}_{2}$ (sólido de coloração amarelo claro), reagiu-se uma solução do precursor $\mathrm{RuCl}_{3} \cdot \mathrm{xH}_{2} \mathrm{O}$ com hidrato de hidrazina $98 \%$. Esta foi adicionada lentamente, pois foi observado que quanto mais lenta a adição, melhor o rendimento, ocorrendo um desprendimento menor de amônia gasosa. Primeiramente é formado o complexo $\left[\mathrm{Ru}\left(\mathrm{NH}_{3}\right)_{5}\left(\mathrm{~N}_{2}\right)\right]^{2+}$. Com a adição de $\mathrm{HCl}$ concentrado ocorre a saída do $\mathrm{N}_{2}$ e a entrada de um $\mathrm{Cl}^{-}$, obtendo-se, então, o complexo $\left[\mathrm{RuCl}\left(\mathrm{NH}_{3}\right)_{5}\right]^{2+}$, como mostrado abaixo [79], o qual precipita na forma de cloreto.

$\mathrm{RuCl}_{3}+4 \mathrm{H}_{2} \mathrm{NNH}_{2} \stackrel{\mathrm{H}_{2} \mathrm{O}}{\longrightarrow}\left[\mathrm{Ru}\left(\mathrm{NH}_{3}\right)_{5} \mathrm{~N}_{2}\right]^{2+}+\ldots$

$\left[\mathrm{Ru}\left(\mathrm{NH}_{3}\right)_{5} \mathrm{~N}_{2}\right]^{2+}+\mathrm{HCl}_{(\text {conc. })} \underset{\Delta}{\stackrel{\mathrm{H}_{2} \mathrm{O}}{\longrightarrow}}\left[\mathrm{Ru}\left(\mathrm{NH}_{3}\right)_{5} \mathrm{Cl}\right] \mathrm{Cl}_{2(\mathrm{~s})}+\ldots$

Ao reagir uma solução do complexo $\left[\mathrm{RuCl}\left(\mathrm{NH}_{3}\right)_{5}\right] \mathrm{Cl}_{2}$ com bissulfito de sódio e dióxido de enxofre ocorreu a saída do cloreto, ligado à primeira esfera de coordenação do metal, e entrada da espécie $\mathrm{HSO}_{3}{ }^{-}$, que é trans-labilizante. Houve assim, o favorecimento da saída de um grupo $\mathrm{NH}_{3}$ em posição trans- e a coordenação de outro grupo $\mathrm{HSO}_{3}{ }^{-}$, formando o complexo trans- $\left[\mathrm{Ru}\left(\mathrm{HSO}_{3}\right)_{2}\left(\mathrm{NH}_{3}\right)_{4}\right]$, que é um sólido de coloração creme.

Ao refluxar a $108^{\circ} \mathrm{C}$ uma suspensão do complexo trans-[Ru( $\left.\left(\mathrm{HSO}_{3}\right)_{2}\left(\mathrm{NH}_{3}\right)_{4}\right]$, em $\mathrm{HCl} 6$ mol L-1, ocorreu a saída de um dos ligantes $\mathrm{HSO}_{3}{ }^{-}$e entrada de um ligante 
$\mathrm{Cl}^{-}$, com a formação de trans-[RuCl$\left.\left(\mathrm{SO}_{2}\right)\left(\mathrm{NH}_{3}\right)_{4}\right]^{+}$. O rutênio até aqui permaneceu na forma de $\mathrm{Ru}(\mathrm{II})$.

$\mathrm{Na}$ etapa seguinte, adicionou-se a piridina. Nesta etapa ocorreu a saída do $\mathrm{Cl}^{-}$e entrada da piridina, para formar o complexo trans-[Ru($\left.\left(\mathrm{NH}_{3}\right)_{4}\left(\mathrm{SO}_{2}\right)(\mathrm{py})\right]^{2+}$, que foi precipitado na forma de cloreto com $\mathrm{HCl}$ concentrado.

A fim de se obter o nitrosilo complexo, foi necessário trocar o $\mathrm{SO}_{2}$ pelo $\mathrm{NO}$ no complexo trans-[Ru( $\left.\left.\mathrm{NH}_{3}\right)_{4}\left(\mathrm{SO}_{2}\right)(\mathrm{py})\right]^{2+}$. Com a adição de $\mathrm{H}_{2} \mathrm{O}_{2}$, o $\mathrm{Ru}(\mathrm{II})$ e o $\mathrm{SO}_{2}$ foram oxidados a $\mathrm{Ru}(\mathrm{III})$ e sulfato, formando o complexo trans-[Ru($\left.\left(\mathrm{SO}_{4}\right)\left(\mathrm{NH}_{3}\right)_{4}(\mathrm{py})\right]^{+}$, o qual foi precipitado na forma de cloreto.

$\mathrm{Na}$ última etapa, o complexo trans-[Ru($\left.\left(\mathrm{NH}_{3}\right)_{4}\left(\mathrm{SO}_{4}\right)(\mathrm{py})\right] \mathrm{Cl}$ foi dissolvido em uma solução de $\mathrm{CF}_{3} \mathrm{COOH} / \mathrm{CF}_{3} \mathrm{COONa} \mathrm{pH}$ 3. Este $\mathrm{pH}$ foi escolhido, pois neste $\mathrm{pH} \mathrm{o}$ $R u(I I I)$ é estável. O $R u(I I I)$ foi reduzido a $R u(I I)$ e o sulfato, que não foi reduzido e se tornou lábil, foi trocado pela água em uma reação rápida [101] (Equação 18), formando o íon complexo trans-[Ru( $\left.\left(\mathrm{NH}_{3}\right)_{4}\left(\mathrm{H}_{2} \mathrm{O}\right)(\mathrm{py})\right]^{2+}$.

trans- $\left[\mathrm{Ru}^{\prime \prime} \mathrm{SO}_{4}\left(\mathrm{NH}_{3}\right)_{4}(\mathrm{py})\right]+\mathrm{H}_{2} \mathrm{O} \rightarrow$ trans- $\left[\mathrm{Ru}^{\prime \prime}\left(\mathrm{NH}_{4}\right)_{3}(\mathrm{py})\left(\mathrm{H}_{2} \mathrm{O}\right)\right]^{2+}+\mathrm{SO}_{4}{ }^{2-}$

$\mathrm{O}$ aquacomplexo, ainda em solução reagiu com $\circ \mathrm{NO}^{+}$, que foi gerado através da reação do nitrito de sódio e do ácido tetrafluorobórico $\left(\mathrm{HBF}_{4} 4,9 \mathrm{~mol} \mathrm{~L}^{-1}\right)$. Foi adicionado nitrito em excesso, pois logo que formado, o NO gasoso começa a recombinar-se com o $\mathrm{O}_{2}$ do meio e gerar $\mathrm{NO}_{2(\mathrm{~g})}$, diminuindo a concentração do $\mathrm{NO}$ na solução. O complexo foi precipitado através da adição de etanol.

A recristalização do complexo trans- $\left[\mathrm{Ru}\left(\mathrm{NH}_{3}\right)_{4}(\mathrm{py})(\mathrm{NO})\right]\left(\mathrm{BF}_{4}\right)_{3}$ foi realizada através da solubilização em o mínimo possível de uma solução $\mathrm{HBF}_{4} 4,9 \mathrm{~mol} \mathrm{~L}^{-1}$. Deixou-se em refrigerador por 1 hora. Devido à necessidade de sucessivas 
recristalizações, a massa final era tão pequena que houve a necessidade de sintetizar o complexo novamente. Assim, sua obtenção apresentou algumas dificuldades experimentais, como reações com baixíssimos rendimentos (12\%) e produtos altamente impuros. Para aprimoramento desta síntese foram modificadas algumas condições, tais como: tempos de reação, marcas de reagentes e solventes, quantidades de solventes e, procedimentos de filtração e secagem. Após estas modificações, o complexo de interesse foi gerado com rendimento um pouco maior ( 38\%).

A cada síntese realizada foi obtido um espectro eletrônico Uv-vis. O resumo destes dados se encontra na Tabela 3.

Tabela 3 - Dados de comprimento de onda máximo e absortividade molar encontrados nos espectros eletrônicos Uv-visível dos complexos $\left[\mathrm{RuCl}\left(\mathrm{NH}_{3}\right)_{5}\right] \mathrm{Cl}_{2}$, trans-[Ru(SO 4$\left.)\left(\mathrm{NH}_{3}\right)_{4}(\mathrm{py})\right] \mathrm{Cl}$ e trans-[Ru(NH$\left.)_{4}(\mathrm{py})(\mathrm{NO})\right]\left(\mathrm{BF}_{4}\right)_{3}$.

\begin{tabular}{|c|c|c|c|c|}
\hline & \multicolumn{2}{|c|}{$\begin{array}{l}\text { Uv-vis: } \lambda_{\text {máx }} \\
(\mathrm{nm})\end{array}$} & \multicolumn{2}{|c|}{$\begin{array}{c}\text { Absortividade Molar }(\varepsilon) \\
\qquad\left(10^{3} \mathrm{~mol} \mathrm{~L}^{-1} \mathrm{~cm}^{-1}\right)\end{array}$} \\
\hline & Encontrado & Literatura & Encontrado & Literatura \\
\hline$\left[\mathrm{RuCl}\left(\mathrm{NH}_{3}\right)_{5}\right] \mathrm{Cl}_{2}$ & 328 & $328^{a}$ & 2,0 & $1,9^{d}$ \\
\hline \multirow{2}{*}{$\begin{array}{l}\text { trans- } \\
{\left[\mathrm{Ru}\left(\mathrm{NH}_{3}\right)_{4}(\mathrm{py})\left(\mathrm{SO}_{4}\right)\right] \mathrm{Cl}}\end{array}$} & 259 & $259^{b}$ & 4,9 & $4,9^{e}$ \\
\hline & 330 & $330^{b}$ & 3,3 & $3,1^{\mathrm{e}}$ \\
\hline \multirow{4}{*}{$\begin{array}{l}\text { trans- } \\
{\left[\mathrm{Ru}\left(\mathrm{NH}_{3}\right)_{4}(\mathrm{py})(\mathrm{NO})\right]\left(\mathrm{BF}_{4}\right)_{3}}\end{array}$} & 238 & $237^{c}$ & 4,9 & $5,2^{c}$ \\
\hline & 267 & $267^{c}$ & 2,4 & $2,3^{c}$ \\
\hline & 324 & $324^{c}$ & 0,15 & $0,16^{\mathrm{c}}$ \\
\hline & 480 & $474^{c}$ & 0,027 & $0,023^{c}$ \\
\hline
\end{tabular}

a. Referência 70 - Os dados foram obtidos em solução de $\mathrm{HCl} 0,1 \mathrm{~mol} \mathrm{~L}^{-1}$.

b. Referência 72 - Os dados foram obtidos em solução $\mathrm{CF}_{3} \mathrm{COOH}-\mathrm{CF}_{3} \mathrm{COONa} \mathrm{pH} \sim 3$.

c. Referência 72 - Os dados foram obtidos em solução de $\mathrm{CF}_{3} \mathrm{COOH} 0,1 \mathrm{~mol} \mathrm{~L}^{-1}$.

d. Referência 102.

e. Referência 102. 
O complexo trans-[Ru( $\left.\left(\mathrm{NH}_{3}\right)_{4}(\mathrm{py})(\mathrm{NO})\right]\left(\mathrm{BF}_{4}\right)_{3}$ foi analisado e caracterizado por CLAE e espectroscopias de RMN, de absorção no infravermelho e eletrônica no UVvis.

4.3 Caracterização do complexo trans-[Ru(cyclam) $(\mathrm{NO})(\mathrm{OH})]\left(\mathrm{PF}_{6}\right)_{2}$

- Espectroscopia de Infravermelho

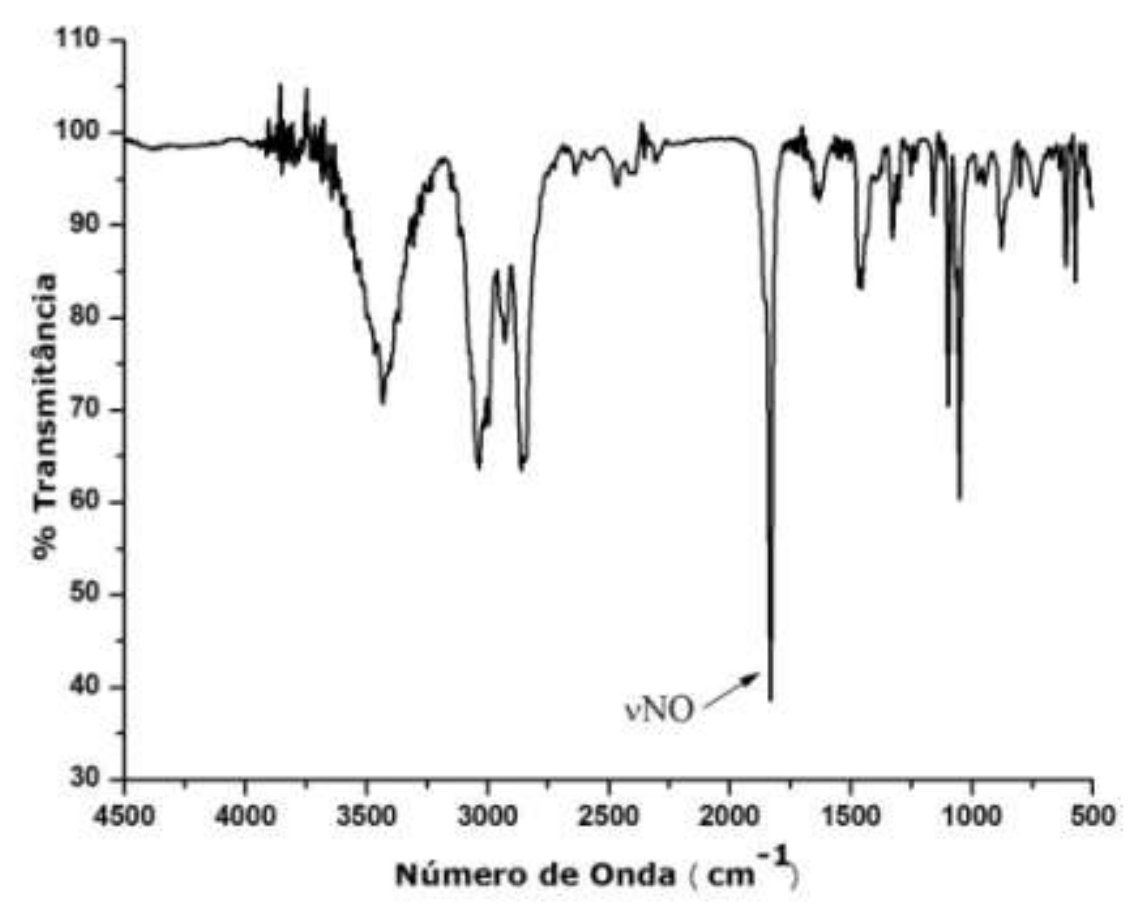

Figura 11 - Espectro de infravermelho do complexo trans$[\mathrm{Ru}(\mathrm{NO})(\mathrm{OH})(\mathrm{cyclam})]\left(\mathrm{PF}_{6}\right)_{2}$ em pastilha de $\mathrm{KBr}$.

O pico observado em $1830 \mathrm{~cm}^{-1}$ é atribuído ao estiramento vNO. Os valores observados entre 2750 e $3750 \mathrm{~cm}^{-1}$ são referentes ao ligante cyclam coordenado [73], o qual apresenta um leve deslocamento comparando-se ao ligante livre (2500 - 


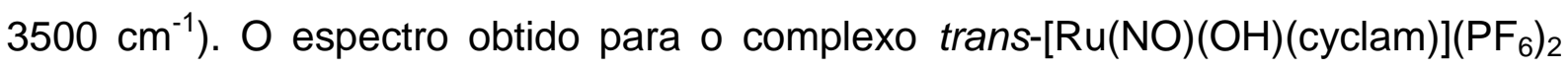
apresentou-se bastante próximo ao relatado [73].

- Espectroscopia Eletrônica de Uv-vis

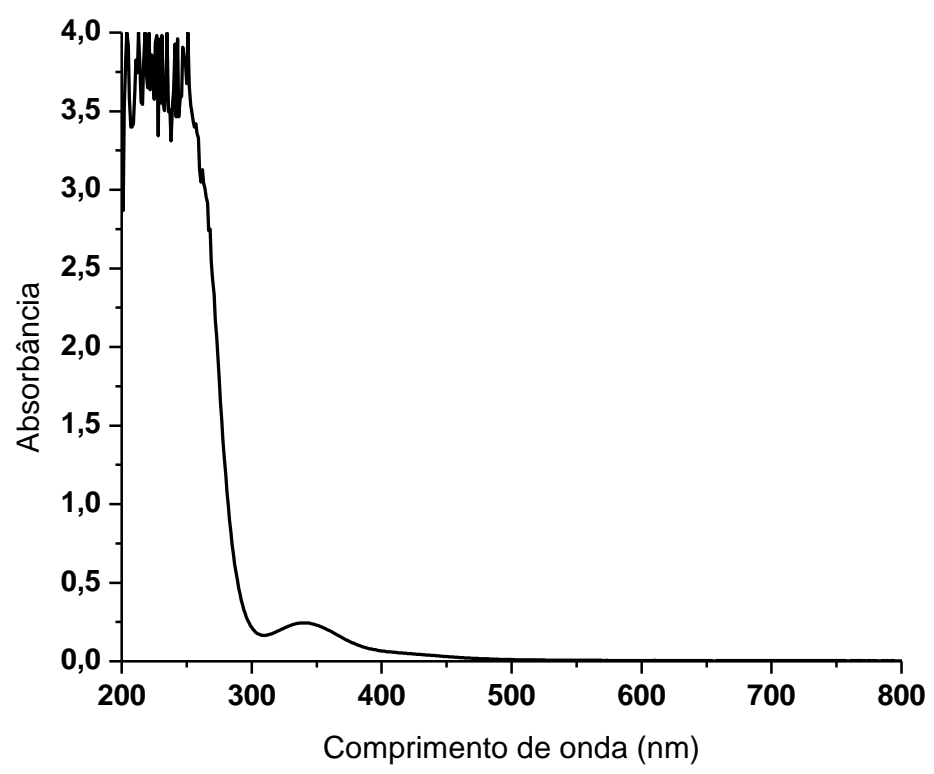

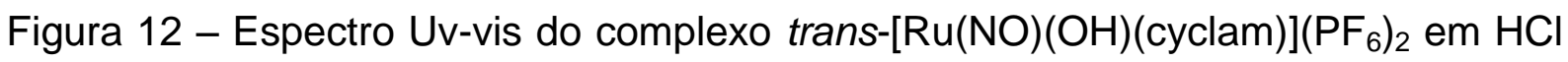
$1 \mathrm{~mol} \mathrm{~L}^{-1}$.

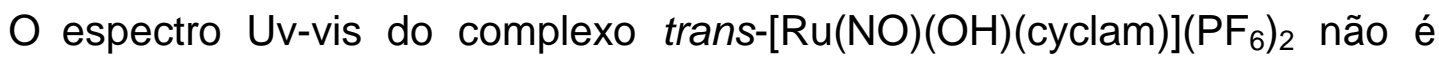
reportado na literatura. No entanto, este complexo é bastante similar ao complexo trans-[RuCl(cyclam)(NO)$]^{2+}$, podendo-se fazer as atribuições de bandas por comparação. O complexo trans-[RuCl(cyclam)(NO)$]^{2+}$ possui 4 bandas no espectro eletrônico Uv-vis. A banda localizada em região de alta energia, por volta de 260 $280 \mathrm{~nm}$, é atribuída a transições de transferência de carga do ligante para o metal TCLM, $\pi_{\mathrm{p}}(\mathrm{Cl}) \rightarrow \mathrm{e}_{\mathrm{g}}(\mathrm{Ru})$. A segunda banda, localizada em $334 \mathrm{~nm}$ é atribuída a transições $d$-d permitidas por spin ${ }^{1} A_{1} \rightarrow{ }^{1} T_{1}$. As duas pequenas bandas localizadas por volta de $430-460 \mathrm{~nm}$ são atribuídas a transições proibidas por spin, ${ }^{1} \mathrm{~A}_{1} \rightarrow{ }^{3} \mathrm{~T}_{1} \mathrm{e}$ 
${ }^{1} A_{1} \rightarrow{ }^{3} T_{2}$, que são características de compostos que possuem orbitais $4 d$ e $5 d$, os quais podem ter a retrodoação $t_{2 g}(R u) \rightarrow \pi^{*}(N O)$ [103]. Assim, pode-se atribuir à banda encontrada em $340 \mathrm{~nm}$ à transições $d$-d permitidas por spin ${ }^{1} \mathrm{~A}_{1} \rightarrow{ }^{1} \mathrm{~T}_{1}$, e o pequeno ombro observado na região de 430 - $460 \mathrm{~nm}$, a transições proibidas por spin, ${ }^{1} \mathrm{~A}_{1} \rightarrow{ }^{3} \mathrm{~T}_{1}$ e ${ }^{1} \mathrm{~A}_{1} \rightarrow{ }^{3} \mathrm{~T}_{2}$.

\subsection{Caracterização do complexo trans-[Ru(NH$\left.)_{4}(\mathrm{py})(\mathrm{NO})\right]\left(\mathrm{BF}_{4}\right)_{3}$}

- Cromatografia a Líquido de Alta Eficiência (CLAE)

A fim de se caracterizar um composto e estudar as reações de interesse, é necessário que ele esteja puro. Assim, antes da espectroscopia verificou-se a pureza do complexo trans-[Ru( $\left.\left(\mathrm{NH}_{3}\right)_{4}(\mathrm{py})(\mathrm{NO})\right]\left(\mathrm{BF}_{4}\right)_{3}$ por CLAE. Utilizou-se como fase móvel a mistura água:metanol acidificada com TFA. Esta fase móvel foi utilizada com base no conhecimento do grupo, que já utilizava esta fase móvel para compostos similares. Para a escolha do melhor pH para a corrida cromatográfica, foram testados $3 \mathrm{pHs}$ diferentes: 4,0; 3,0 e 2,5. Observou-se que os cromatogramas cuja fase móvel era composta de soluções mais ácidas ficavam mais bem definidos, com picos mais finos. A partir desta observação, passou-se a utilizar pH $\sim 2,5$. As amostras utilizadas foram todas de $1 \mathrm{mg}$ do complexo dissolvido em $0,5 \mathrm{~mL}$ de solução água:metanol acidificada com TFA 0,1\% (pH 2,5).

O cromatograma abaixo (Figura 13) indica que o complexo está puro suficiente para os ensaios fotoquímicos realizados neste trabalho, sendo o pico

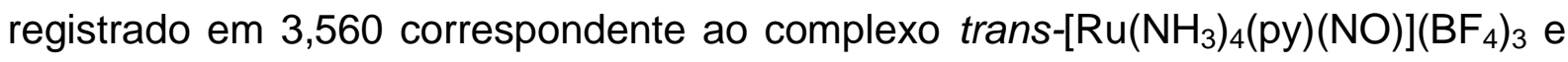
o menor pico, registrado em 3,185 , possivelmente seja correspondente ao íon trans- 
$\left[\mathrm{Ru}\left(\mathrm{NH}_{3}\right)_{4}\left(\mathrm{H}_{2} \mathrm{O}\right)(\mathrm{py})\right]^{2+}$,impureza da reação de formação do nitrosilo, do qual o aquo complexo é precursor.

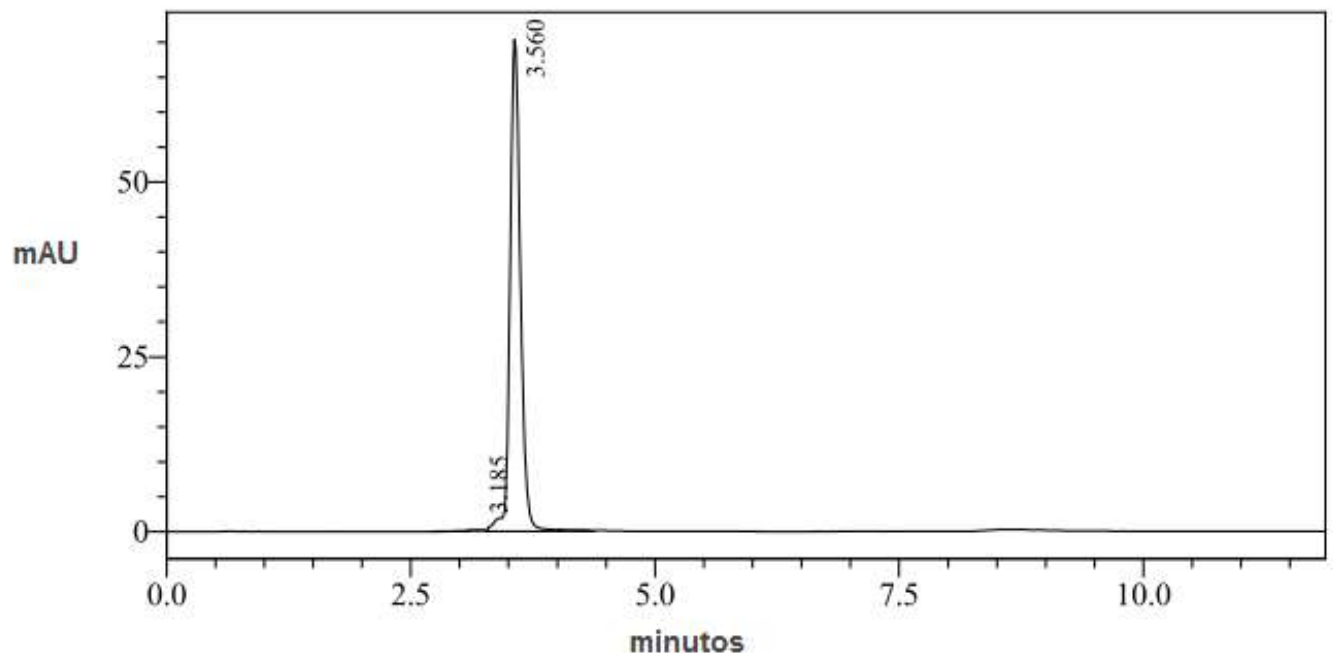

Figura 13 - Cromatograma do complexo trans-[Ru( $\left.\left(\mathrm{NH}_{3}\right)_{4}(\mathrm{py})(\mathrm{NO})\right]\left(\mathrm{BF}_{4}\right)_{3}$, utilizandose como fase móvel a mistura água:metanol (70:30) acidificada com TFA $0,1 \%(\mathrm{pH}=2,5)$.

\section{- Ressonância Magnética Nuclear de Próton}

O complexo trans-[Ru( $\left.\left.\mathrm{NH}_{3}\right)_{4}(\mathrm{py})(\mathrm{NO})\right]\left(\mathrm{BF}_{4}\right)_{3}$ apresentou o seguinte espectro de RMN de próton em água deuterada (Figura 14). 


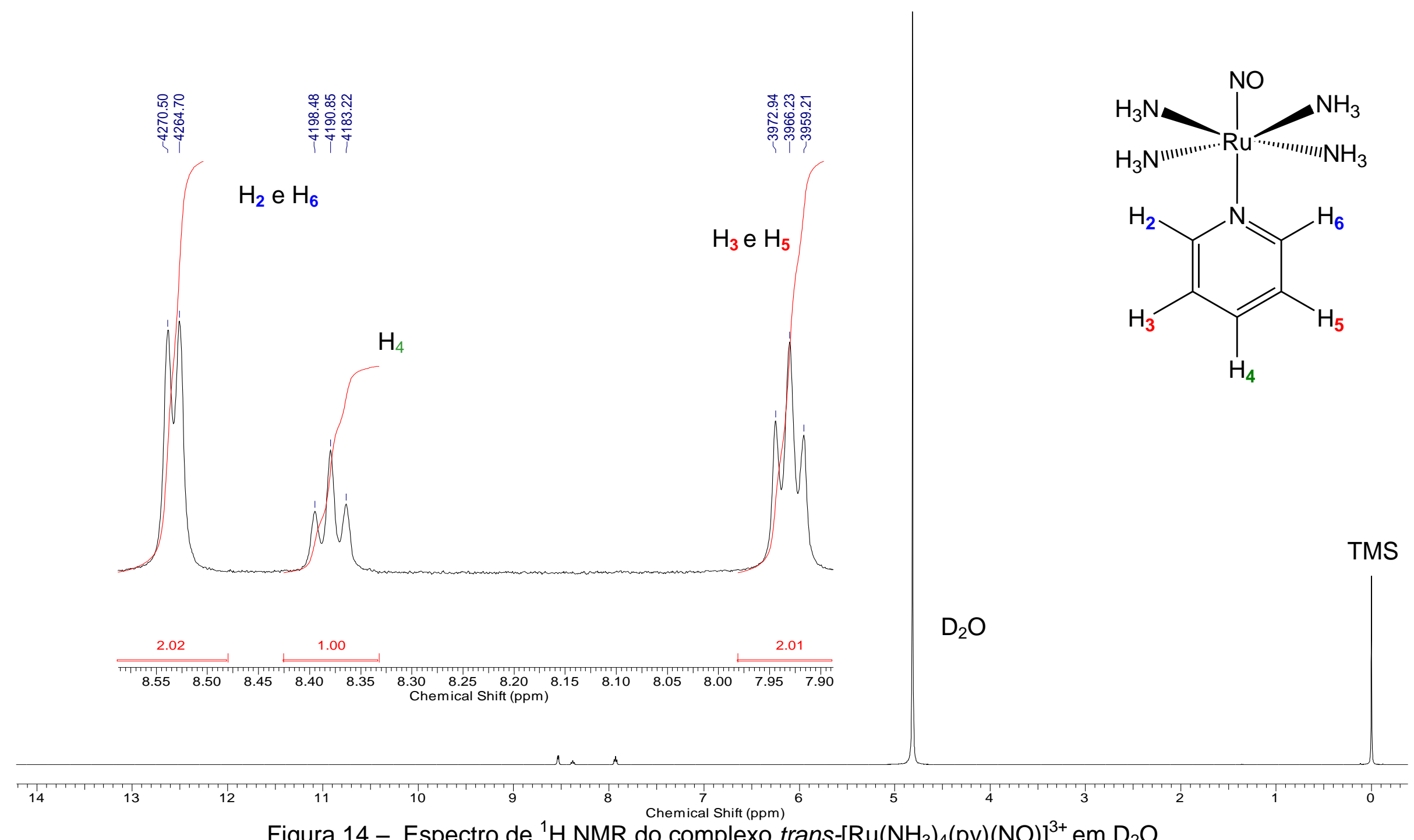


As constantes de acoplamento em anéis piridínicos são menores que as constantes de acoplamento em anéis que com

As constantes de acoplamento em anéis piridínicos são menores que as constantes de acoplamento em anéis que contêm somente carbono [80], assim, no complexo trans- $\left[\mathrm{Ru}\left(\mathrm{NH}_{3}\right)_{4}(\mathrm{py})(\mathrm{NO})\right]\left(\mathrm{BF}_{4}\right)_{3}$, as constantes de acoplamento para hidrogênios em posição -orto na piridina são $\mathrm{J}_{2,3}=5,8 \mathrm{~Hz}$ e $\mathrm{J}_{3,4}=7,6 \mathrm{~Hz}$ (Tabela 4). Já as constantes de acoplamento para os hidrogênios em posição meta são tão pequenas que não permitiram a visualização dos desdobramentos dos sinais.

Tabela 4 - Acoplamentos possíveis para os hidrogênios do benzeno, da piridina e da piridina ligada ao rutênio e suas respectivas frequências em Hertz

\begin{tabular}{|c|c|c|c|}
\cline { 2 - 4 } & \multicolumn{3}{|c|}{ Frequências em Hz } \\
\hline Acoplamentos & Benzeno $^{[80]}$ & Piridina $^{[80]}$ & $\begin{array}{c}\text { Piridina ligada ao } \\
\text { Ru }\end{array}$ \\
\hline$J_{2,3}$ & $6-10(9)$ & $5-6(5)$ & 5,8 \\
$J_{3,4}$ & $6-10(9)$ & $7-9(8)$ & 7,6 \\
$J_{2,4}$ & $1-3(3)$ & $1-2(1,5)$ & --- \\
$J_{3,5}$ & $1-3(3)$ & $1-2(1,5)$ & --- \\
$J_{2,5}$ & $0-1(\sim 0)$ & $0-1(\sim 0)$ & --- \\
$J_{2,6}$ & $1-3(3)$ & $0-1(\sim 0)$ & - \\
\hline
\end{tabular}

Os valores em parênteses nas colunas da piridina e do benzeno são valores geralmente encontrados dentro do intervalo de frequências para os acoplamentos listados na primeira coluna.

Para o hidrogênio vizinho ao nitrogênio $\left(\mathrm{H}_{2}\right.$ e $\left.\mathrm{H}_{6}\right)$, vê-se somente o primeiro desdobramento, que é do acoplamento em orto $\left(J_{2,3}\right.$ e $\left.J_{6,5}\right)$. Já o segundo desdobramento, que seria o acoplamento dos hidrogênios em posição meta $\left(J_{2,4}\right.$; $\left.J_{3,5} \mathrm{e} J_{2,6}\right)$, não é observado. Portanto, para os hidrogênios $H_{2}$ e $H_{6}$, não se vê um duplo dupleto como é esperado através da análise binomial, vê-se apenas um 
dupleto. $\mathrm{O}$ mesmo ocorre para o hidrogênio $\mathrm{H}_{4}$, que deveria gerar um triplo tripleto (ver Figura 15) no espectro, mas vê-se apenas um tripleto.

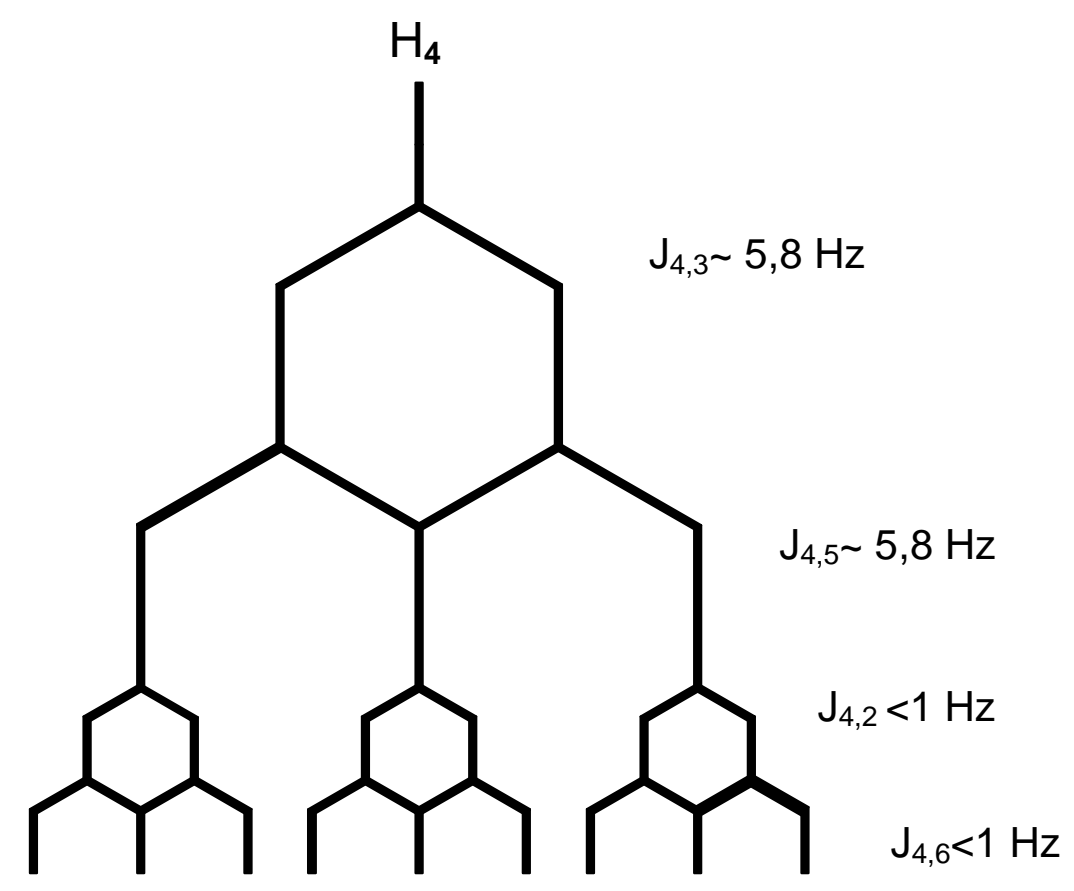

Figura 15 - Representação dos desdobramentos dos sinais esperados no espectro de $\mathrm{RMN}{ }^{1} \mathrm{H}$ para $\mathrm{O}$ hidrogênio $\mathrm{H}_{4}$ do ligante piridina do complexo trans$\left[\mathrm{Ru}\left(\mathrm{NH}_{3}\right)_{4}(\mathrm{py})(\mathrm{NO})\right]\left(\mathrm{BF}_{4}\right)_{3}$.

\section{-Espectroscopia de Infravermelho}

A Figura 16 apresenta o espectro de absorção vibracional no infravermelho do complexo trans-[Ru( $\left.\left(\mathrm{NH}_{3}\right)_{4}(\mathrm{py})(\mathrm{NO})\right]\left(\mathrm{BF}_{4}\right)_{3}$ em pastilha de $\mathrm{KBr}$.

$\mathrm{Na}$ Tabela 5 estão apresentados valores encontrados para as principais bandas e as respectivas bandas descritas na literatura com suas atribuições. A presença dos picos em 1928 e $619 \mathrm{~cm}^{-1}$, atribuídos aos estiramentos NO e Ru-NO, além dos demais picos com valores praticamente iguais aos da literatura, indicam a formação do complexo. 


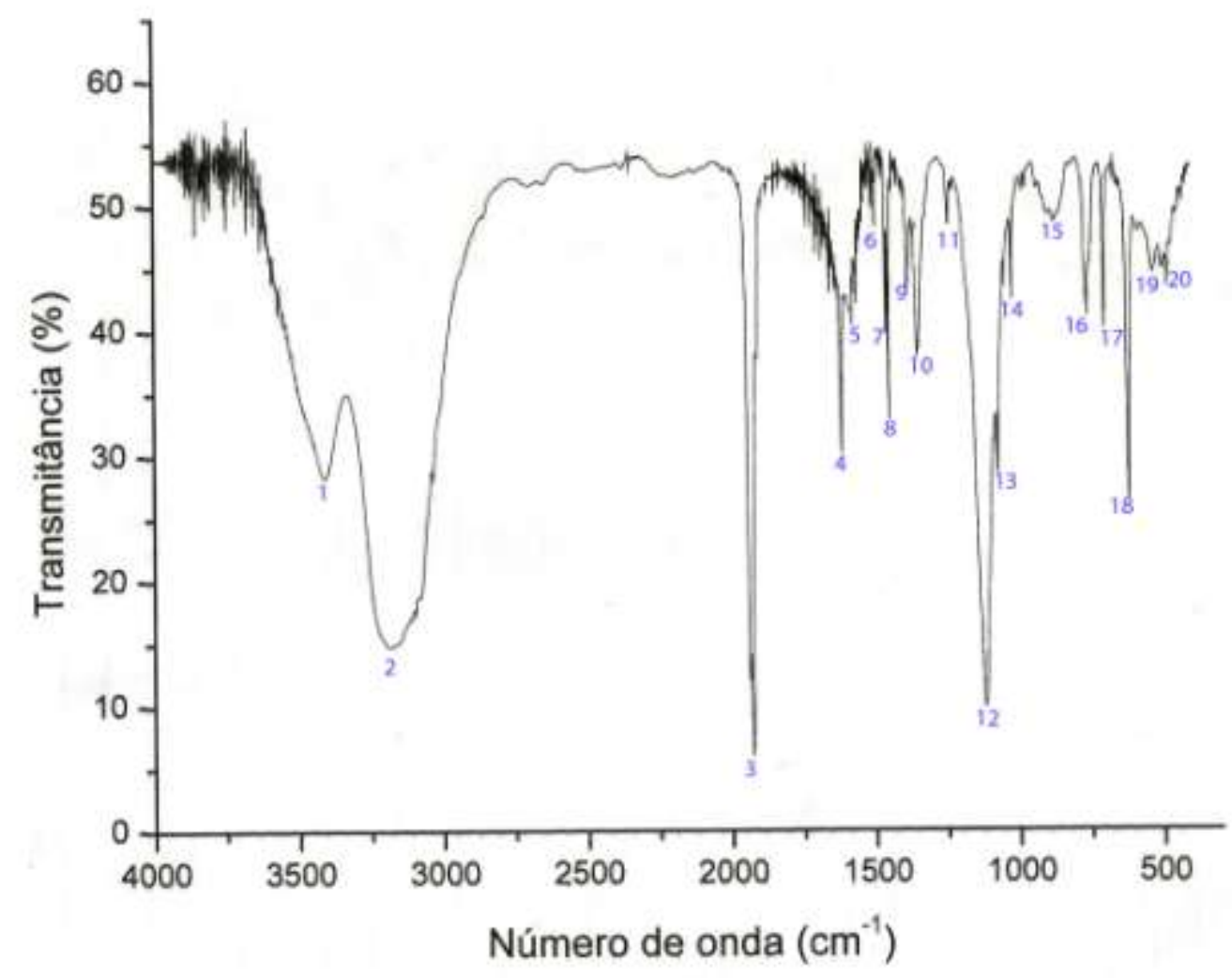

Figura 16 - Espectro de absorção no infravermelho do complexo trans$\left[\mathrm{Ru}\left(\mathrm{NH}_{3}\right)_{4}(\mathrm{py})(\mathrm{NO})\right]\left(\mathrm{BF}_{4}\right)_{3}$ em KBr.

O espectro apresenta um pico em $1928 \mathrm{~cm}^{-1}$ acompanhado de um ombro em $1931 \mathrm{~cm}^{-1}$ atribuído a um de estiramento do NO, v(NO) [72]. Este desdobramento é atribuído a efeitos de estado sólido e não ocorre em solução aquosa [38, 72]. Pequenas diferenças com outros valores relatados também podem ser atribuídas a consequências dos espectros terem sido obtidos em pastilhas de $\mathrm{KBr}$. 
Tabela 5 - Atribuição das bandas do espectro de infravermelho complexo trans$\left[\mathrm{Ru}\left(\mathrm{NH}_{3}\right)_{4}(\mathrm{py})(\mathrm{NO})\right]\left(\mathrm{BF}_{4}\right)_{3}$ e os valores correspondentes encontrados na literatura.

\begin{tabular}{|c|c|c|}
\hline ATRIBUIÇÃO & ENCONTRADAS $^{\mathrm{a}}$ & LITERATURA $^{\mathrm{b}}$ \\
\hline$v(\mathrm{NH})$ & $1(3407)$ & 3404 \\
\hline$v(\mathrm{CH})$ & $2(3182)$ & 3188 \\
\hline$v(\mathrm{NO})$ & $3(1928)$ & 1931 \\
\hline$\delta(\mathrm{NH})$, bandas do anel, $\delta(\mathrm{CH})$ e $v(\mathrm{NH})$ & $4(1613)$ & 1614 \\
\cline { 2 - 3 } & $5(1575)$ & 1582 \\
\hline$v\left(\mathrm{BF}_{4}{ }^{-}\right)$ & $13(1074)$ & 1089 \\
\hline$\rho(\mathrm{NH} 3)$, bandas do anel, $\delta(\mathrm{CH})$, e $\delta(\mathrm{NH})$ & $15(872)$ & 874 \\
\cline { 2 - 3 } fora do plano & $16(760)$ & 742 \\
\hline$v\left(\mathrm{RuNO}^{2}\right)$ & $18(619)$ & 619 \\
\hline$\delta\left(\mathrm{RuNO}^{\prime}\right)$ & $19(531)$ & 532 \\
\hline$v\left(\mathrm{RuNH}_{3}\right)$ & $20(483)$ & 484 \\
\hline
\end{tabular}

a) Bandas encontradas no espectro de infravermelho do complexo trans-[Ru( $\left.\left(\mathrm{NH}_{3}\right)_{4}(\mathrm{py})(\mathrm{NO})\right]\left(\mathrm{BF}_{4}\right)_{3}$ em pastilhas de $\mathrm{KBr}$. Ver figura 14 para numeração das bandas.

b) Referência 72 .

\section{- Espectroscopia Eletrônica de Uv-vis}

Os espectros eletrônicos de absorção das aminas de rutênio de fórmula geral trans- $\left[R u\left(N_{3}\right)_{4} L_{1} L_{2}\right]^{2+}\left(L_{1}\right.$ e $L_{2}=$ azinas, pirazina) apresentam bandas $T C M L$ de alta intensidade na região do visível, o que já não é observado em complexos similares com o ligante NO, nem mesmo quando um dos ligantes $L_{1}$ ou $L_{2}$ é uma azina ou piridina, tal como é o caso do complexo trans-[Ru( $\left.\left(\mathrm{NH}_{3}\right)_{4}(\mathrm{py})(\mathrm{NO})\right]^{3+}[28]$, cujo espectro feito em $\mathrm{CF}_{3} \mathrm{COOH}$ 0,1 $\mathrm{mol} \mathrm{L}^{-1}$, está na Figura 17. 


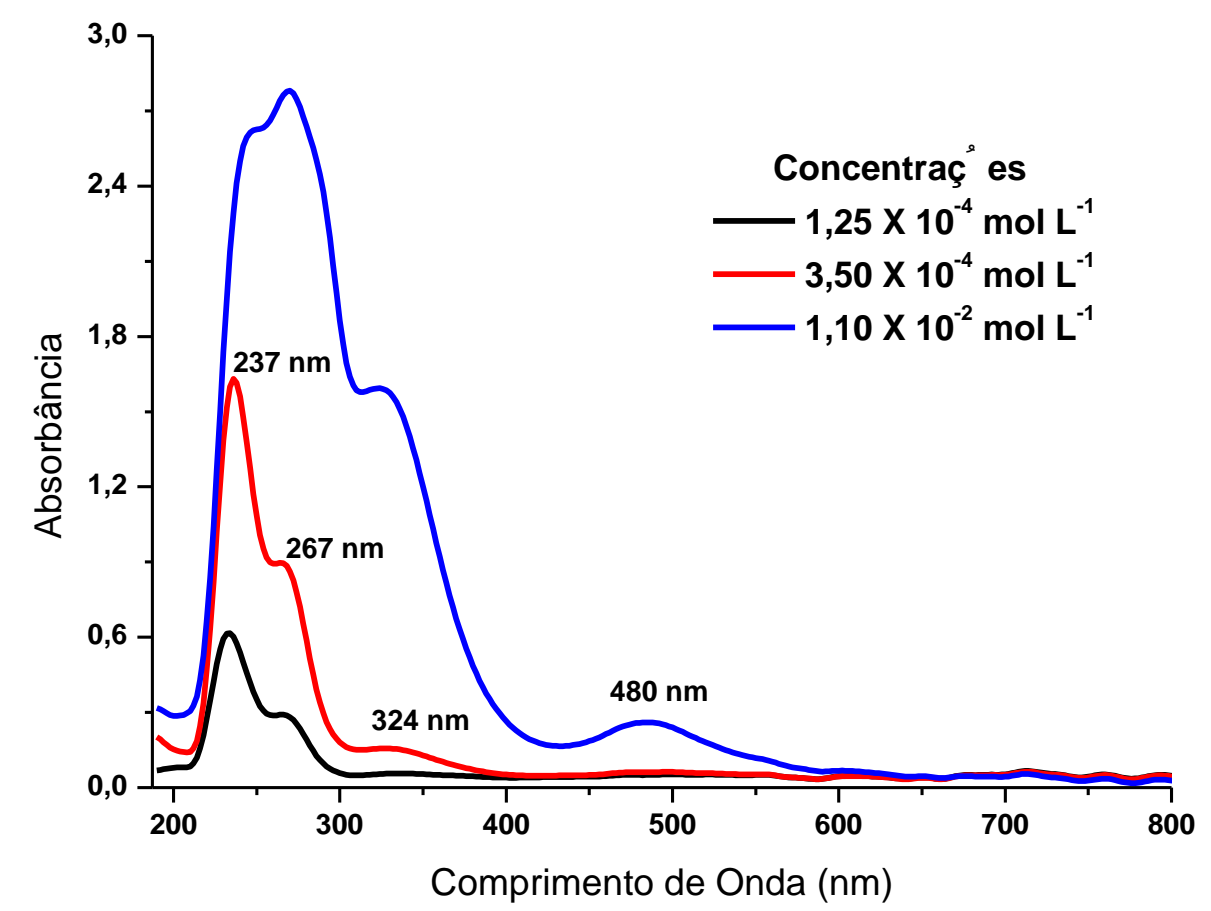

Figura 17 - Espectro eletrônico do complexo trans-[Ru(NH$\left.)_{4}(\mathrm{py})(\mathrm{NO})\right]\left(\mathrm{BF}_{4}\right)_{3}$ em $\mathrm{CF}_{3} \mathrm{COOH} 0,1 \mathrm{~mol} \mathrm{~L}^{-1}$.

O espectro de absorção eletrônica do complexo trans$\left[\mathrm{Ru}\left(\mathrm{NH}_{3}\right)_{4}(\mathrm{py})(\mathrm{NO})\right]\left(\mathrm{BF}_{4}\right)_{3}$ (Figura 17) é semelhante ao relatado e foram observadas quatro bandas, cujos dados estão na Tabela 6. A banda de menor energia, localizada em 480 nm, é atribuída à combinação de duas transições: transferência de carga ligante-ligante (TCLL) $\pi$ (piridina) $\rightarrow \pi^{\star}$ (NO) e transferência de carga do metal para o ligante (TCML) $t_{2} \rightarrow \pi^{*}(\mathrm{NO})$. A segunda banda observada, entre $300 \mathrm{e}$ $350 \mathrm{~nm}$, é atribuída principalmente a uma transição de transferência de carga do metal para o ligante (TCML) $\operatorname{Rud}_{\pi} \rightarrow \pi^{*}(\mathrm{NO})$ com contribuições de duas transições, uma d-d ${ }^{1} A_{1} \rightarrow{ }^{1} A_{1},{ }^{1} E$, e outra de transferência de carga do ligante py para o metal $(T C L M) p(p y) \rightarrow d(R u)[28,72,81]$. As bandas na região de maior energia do espectro (<300 nm) são de mais difícil atribuição uma vez que ocorrem diversas transições. A banda localizada em $267 \mathrm{~nm}$ pode ser atribuída a uma transição de 
TCML $d_{\pi}(R u) \rightarrow \pi^{*}(N O)$ de acordo com cálculos teóricos de TD-DFT que preveem esta banda ao redor de $261 \mathrm{~nm}$ [81]. De acordo com estes mesmos cálculos, são esperadas duas bandas em 226 e $224 \mathrm{~nm}$ atribuídas a transições $\pi(p y) \rightarrow d \sigma(R u)$ e IL. Assim, a banda observada em $237 \mathrm{~nm}$ deve ser composta por estas diversas transições.

Além das bandas observadas no espectro absorção Uv-vis do complexo trans-[Ru(NH$\left.)_{4}(\mathrm{py})(\mathrm{NO})\right]\left(\mathrm{BF}_{4}\right)_{3}$, uma outra banda que não foi observada é prevista na região de 500-600 nm, atribuída a transição de transferência de carga do ligante para o metal px,py(piridina) $\rightarrow_{\mathrm{d} z}{ }^{2}, \mathrm{~d} x y(\mathrm{Ru})$ ainda de acordo com os cálculos de TDDFT[81]).

Tabela 6 - Bandas encontradas no espectro de absorção Uv-vis do complexo trans$\left[\mathrm{Ru}\left(\mathrm{NH}_{3}\right)_{4}(\mathrm{py})(\mathrm{NO})\right]\left(\mathrm{BF}_{4}\right)_{3}$ em $\mathrm{CF}_{3} \mathrm{COOH} 0,1 \mathrm{~mol} \mathrm{~L}^{-1}$, com respectivas atribuições.

\begin{tabular}{|c|c|}
\hline BANDAS $(\mathrm{nm})$ & ATRIBUIÇÕES ${ }^{\mathrm{a}, \mathrm{b}}$ \\
\hline 237 & $\mathrm{TCLM} \pi(\mathrm{py}) \rightarrow \mathrm{d} \sigma(\mathrm{Ru}) ;$ \\
& $\mathrm{IL} \pi(\mathrm{py}) \rightarrow \pi^{*}(\mathrm{py})$ \\
\hline 267 & $\mathrm{TCML} \mathrm{d}_{\pi}(\mathrm{Ru}) \rightarrow \pi^{*}(\mathrm{NO})$ \\
\hline \multirow{2}{*}{324} & $\mathrm{TCML}\left(\mathrm{Ru} \mathrm{d}_{\pi} \rightarrow \pi^{*}(\mathrm{NO})\right)$ \\
& $\mathrm{d}-\mathrm{d}\left({ }^{1} \mathrm{~A}_{1} \rightarrow{ }^{1} \mathrm{~A}_{1},{ }^{1} \mathrm{E}\right)$ \\
& $\mathrm{TCLM}(\mathrm{p}(\mathrm{py}) \rightarrow \mathrm{d}(\mathrm{Ru}))$ \\
\hline 480 & $\mathrm{TCLL} \pi(\mathrm{py}) \rightarrow \pi^{*}(\mathrm{NO})$ \\
& $\mathrm{TCML} \mathrm{t}_{2} \rightarrow \pi^{*}(\mathrm{NO})$ \\
\hline
\end{tabular}

a. Ref. 72.

b. Ref. 81 


\subsection{Fotólise do Complexo}

As irradiações do complexo trans-[Ru( $\left.\left(\mathrm{NH}_{3}\right)_{4}(\mathrm{py})(\mathrm{NO})\right]\left(\mathrm{BF}_{4}\right)_{3}$ foram realizadas primeiramente em pH $\sim 3$ (solução $\mathrm{CF}_{3} \mathrm{COOH} / \mathrm{NaCF}_{3} \mathrm{COO}$ ), com luz de $313 \mathrm{~nm}$, para efeito de comparação com a literatura, visando observar se o complexo sintetizado apresentaria o mesmo comportamento relatado [28].

Ocorre liberação de $\mathrm{NO}$ pelo complexo trans-[Ru(NH$\left.)_{4}(\mathrm{py})(\mathrm{NO})\right]\left(\mathrm{BF}_{4}\right)_{3}$ somente quando este é irradiado com luz de $313 \mathrm{~nm}$, pois o espectro da solução controle registrado após o tempo de fotólise foi coincidente com o espectro obtido no tempo $\mathrm{t}=0$.

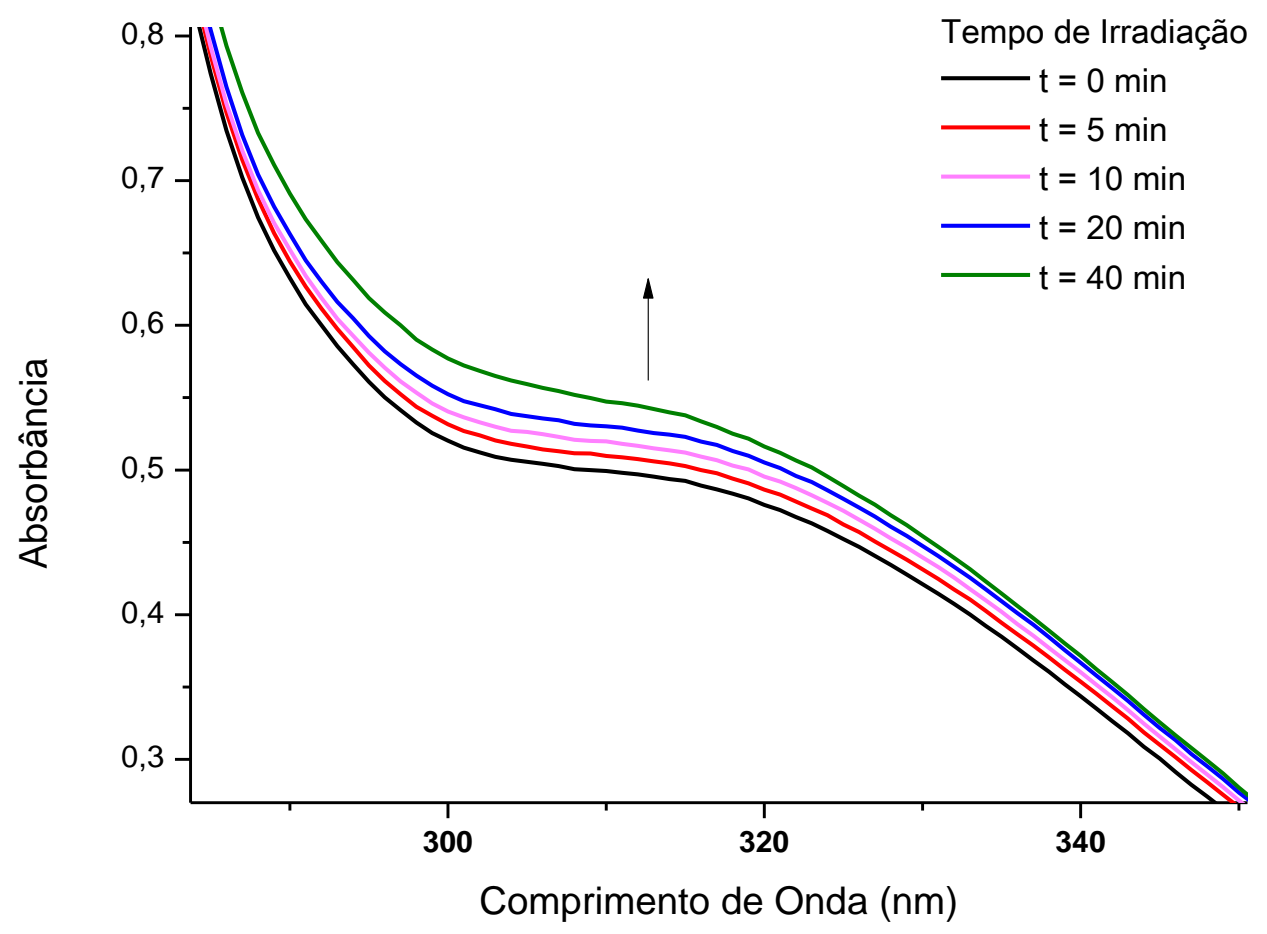

Figura 18 - Espectros de absorção eletrônica da irradiação com luz de 313 nm do complexo trans-[Ru( $\left.\left.\mathrm{NH}_{3}\right)_{4}(\mathrm{py})(\mathrm{NO})\right]\left(\mathrm{BF}_{4}\right)_{3}$ em solução $\mathrm{CF}_{3} \mathrm{COOH} / \mathrm{CF}_{3} \mathrm{COONa} \mathrm{pH} 3$, nos tempos $t=0,5,10,20$ e 40 minutos. 
A banda que apresenta atividade fotoquímica, que está envolvida na liberação de $\mathrm{NO}$ pelo complexo trans-[Ru(NH$\left.)_{4}(\mathrm{py})(\mathrm{NO})\right]\left(\mathrm{BF}_{4}\right)_{3}$ está centrada em torno de 330 nm [28]. Este processo é apresentadona equação 19 e 20 [82].

$$
\begin{aligned}
& \text { trans- }\left[\mathrm{Ru}\left(\mathrm{NH}_{3}\right)_{4} \mathrm{~L}(\mathrm{NO})\right]^{3+}+\mathrm{H}_{2} \mathrm{O} \stackrel{\mathrm{h} v}{\rightarrow} \operatorname{trans}-\left[\mathrm{Ru}\left(\mathrm{NH}_{3}\right)_{4} \mathrm{~L}\left(\mathrm{H}_{2} \mathrm{O}\right)\right]^{3+}+\mathrm{NO} \\
& \text { trans- }\left[\mathrm{Ru}\left(\mathrm{NH}_{3}\right)_{4}\left(\mathrm{H}_{2} \mathrm{O}\right)(\mathrm{L})\right]^{3+}+\mathrm{H}_{2} \mathrm{O} \rightleftharpoons \text { trans }-\left[\mathrm{Ru}\left(\mathrm{NH}_{3}\right)_{4}(\mathrm{OH})(\mathrm{L})\right]^{2+}+\mathrm{H}_{3} \mathrm{O}^{+} \\
& \mathrm{pK}_{\mathrm{a}}=3.1 \pm 0,1
\end{aligned}
$$

Como pode-se perceber pelas equações 17 e 18, as espécies formadas em solução dependem do $\mathrm{pH}$.

\subsection{Corantes}

A irradiação de corantes com luz de energias mais baixas, busca sensibilizar o estado excitado que conduz a liberação NO pelo complexo trans$\left[\mathrm{Ru}\left(\mathrm{NH}_{3}\right)_{4}(\mathrm{py})(\mathrm{NO})\right]\left(\mathrm{BF}_{4}\right)_{3}$. Com o uso de diversos corantes com bandas de absorção diferentes e de energia mais baixa do que a usada na fotoquímica sem sensibilizadores pode-se estimar a energia deste estado. 
Tabela 7 - Corantes escolhidos para a tentativa de sensibilização do complexo trans-[Ru( $\left.\left(\mathrm{NH}_{3}\right)_{4}(\mathrm{py})(\mathrm{NO})\right]\left(\mathrm{BF}_{4}\right)_{3}$.

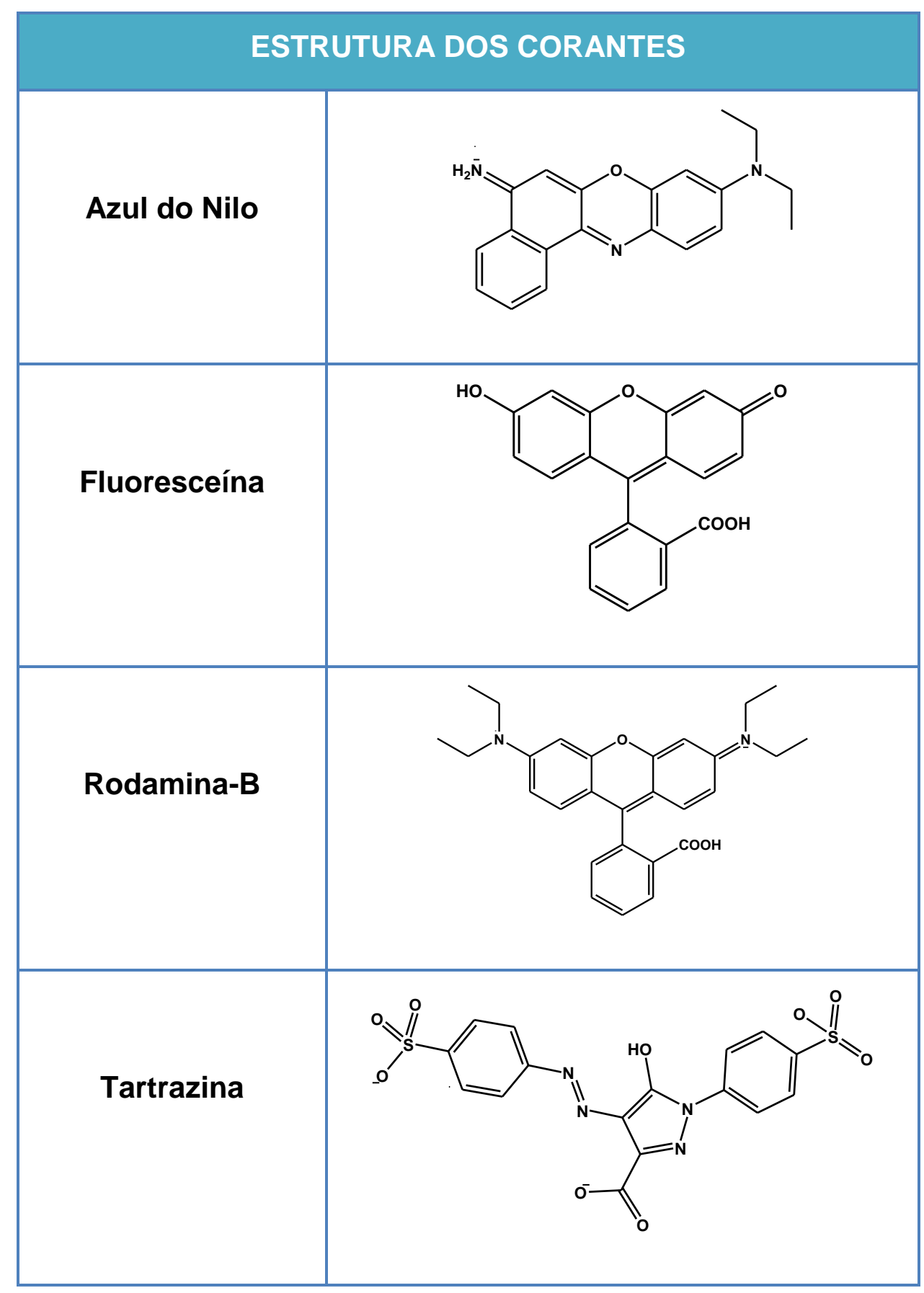




\subsection{Fotólise dos corantes}

Antes das fotólises do complexo trans- $\left[\mathrm{Ru}\left(\mathrm{NH}_{3}\right)_{4}(\mathrm{py})(\mathrm{NO})\right]\left(\mathrm{BF}_{4}\right)_{3}$ na presença dos corantes, foram realizados testes somente com os corantes para verificar sua estabilidade frente às condições experimentais.

\subsubsection{Azul do Nilo}

Azul do Nilo é um corante conhecido há mais de 110 anos, de nome IUPAC 9-(dietllamino)benzofenoxazin-5-one. Possui grupo imino que pode ser desprotonado sob condições básicas e protonado sob condições ácidas ( $\mathrm{pKa}=9,7$ ). Como característica bastante relevante, este corante tende a ter uma maior afinidade por células cancerosas do que saudáveis, além de ser um fotossensibilizador para oxigênio, o que pode ser bastante útil para terapia fotodinâmica [83], que é um dos objetivos deste estudo: trabalhar com corantes que possam ser utilizados para este fim.

O corante Azul do Nilo apresenta banda de absorção Uv-vis em torno de 635 nm em solução aquosa. Estudos sugerem que a concentração a ser utilizada deste corante em solução aquosa deve ser abaixo de $3 \times 10^{-5} \mathrm{~mol} \mathrm{~L}^{-1}$. Acima desta concentração, formam-se dímeros e, consequentemente, aparição de duas bandas, em 580 e $680 \mathrm{~nm}$ [84]. Por esta razão procurou-se utilizar concentrações abaixo de $3 \times 10^{-5} \mathrm{~mol} \mathrm{~L}^{-1}$. 


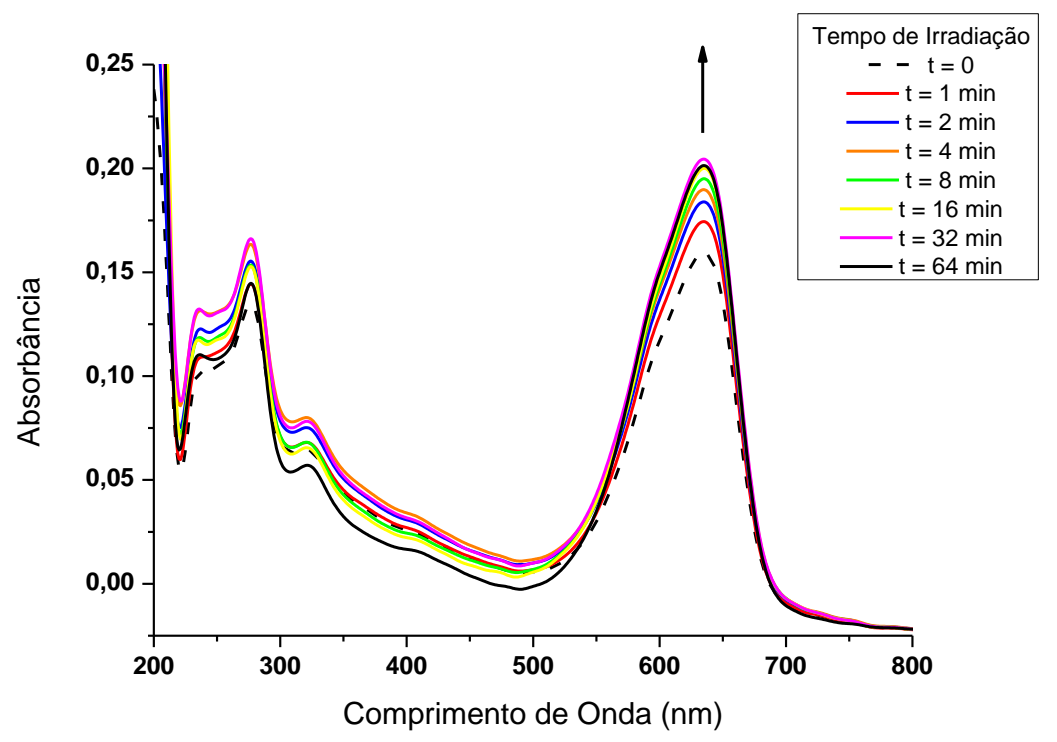

Figura 19 - Espectros obtidos na fotólise com luz de $577 \mathrm{~nm}$ de uma solução 7,64 X $10^{-7} \mathrm{~mol} \mathrm{~L}{ }^{-1}$ de corante Azul do Nilo em solução $\mathrm{CF}_{3} \mathrm{COOH} / \mathrm{CF}_{3} \mathrm{COONa}$ $\mathrm{pH} \sim 3$ nos tempos $0,1,2,4,8,16,32$ e 64 minutos.

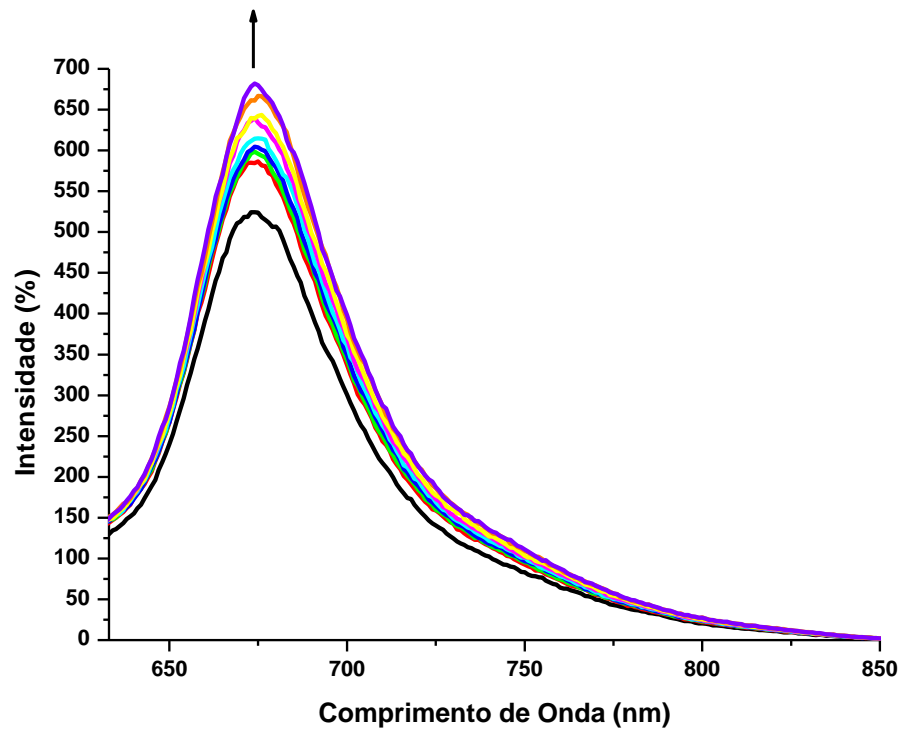

Figura 20 - Espectros de emissão de uma solução $7,64 \times 10^{-7} \mathrm{~mol} \mathrm{~L}^{-1}$ de corante Azul do Nilo em solução $\mathrm{CF}_{3} \mathrm{COOH} / \mathrm{CF}_{3} \mathrm{COONa} \mathrm{pH} \sim 3$ nos tempos 0,1 , 2, 4, 8, 16, 32 e 64 minutos, com comprimentos de onda de excitação de $630 \mathrm{~nm}$ e emissão em $674 \mathrm{~nm}$. 
A partir dos dados obtidos nos espectros eletrônicos de absorção (Figura 19) e de emissão do azul do Nilo (Figura 20), pode-se notar que este possui atividade fotoquímica quando irradiado com luz de $577 \mathrm{~nm}$, sendo, portanto descartado para o teste de sensibilização, pois se o composto apresenta atividade fotoquímica, provavelmente será consumido e introduzirá outras reações.

\subsubsection{Fluoresceína Sódica}

Fluoresceína é um composto orgânico de nome IUPAC ácido 2-(6-hidroxi-3oxo-3H-xanten-9-il)benzóico. Possui intensa fluorescência, e em sua forma neutra absorve luz em 492 nm e emite em 517 nm em solução aquosa [85]. Ela éum corante utilizado como sonda fluorescente em aplicações biológicas e bioquímicas devido à sua fácil agregação a biomoléculas. Sua florescência e absorção são bastante dependentes do meio (solvente) e pH. [86]. A fluoresceína pode ser encontrada em quatro diferentes formas (em solução aquosa): catiônica $(\mathrm{pH}<2)$, neutra ( $\mathrm{pH} \sim 3,3$ ), monoânion ( $\mathrm{pH} \sim 5,5)$ ou diânion ( $\mathrm{pH}>8$ ), que são formadas dependendo do pH do meio (Figura 21). Cada uma destas formas iônicas da fluoresceína apresenta propriedades fotofísicas diferentes, como por exemplo absorção e emissão [87]. 
<smiles>O=C(O)c1ccccc1-c1c2ccc(=O)cc-2oc2cc(O)ccc12</smiles>

Cátion $(\mathrm{pH}<2)$<smiles>O=C([O-])c1ccccc1-c1c2ccc(=O)cc-2oc2cc(O)ccc12</smiles>

Monoânion $(\mathrm{pH} \sim 5,5)$<smiles>O=C(O)c1ccccc1-c1c2ccc(=O)cc-2oc2cc(O)ccc12</smiles>

Neutro $(\mathrm{pH} \sim 3,3)$<smiles>COc1ccc2c(-c3ccccc3[N+](=O)[O-])c3ccc(=O)cc-3oc2c1</smiles>

Diânion ( $\mathrm{pH}>8)$

Figura 21 - Quatro diferentes formas iônicas em que a fluoresceína pode ser encontrada em meio aquoso dependendo do $\mathrm{pH}$ do meio.

Primeiramente obteve-se o espectro de excitação da solução de fluoresceína sódica 4,97 X $10^{-4} \mathrm{~mol} \mathrm{~L}^{-1}$ em tampão $\mathrm{CF}_{3} \mathrm{COOH} / \mathrm{CF}_{3} \mathrm{COONa} \mathrm{pH} \sim 3$. Um pico de absorção máxima foi registrado em $437 \mathrm{~nm}$. A partir deste dado, foi feita a irradiação em $438 \mathrm{~nm}$. 


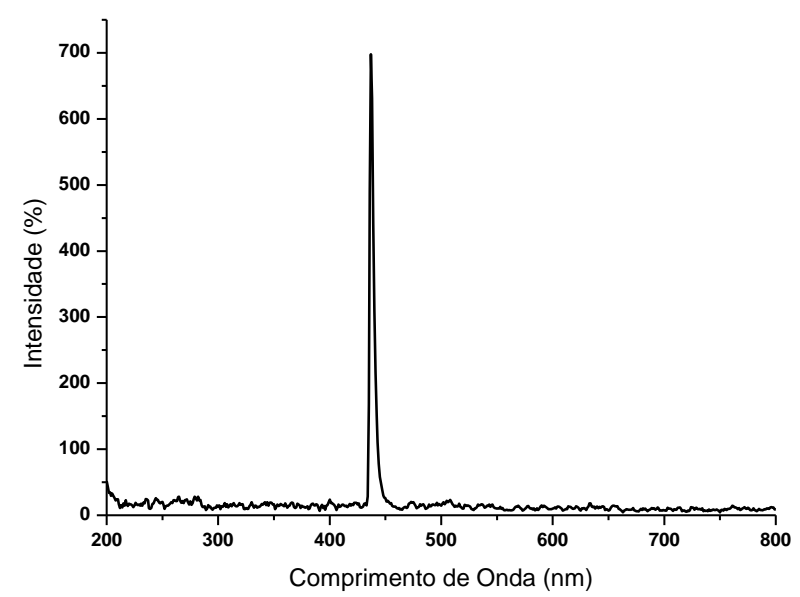

Figura 22 - Espectro de excitaçãoda solução de fluoresceína sódica $4,97 \times 10^{-4} \mathrm{~mol}$ $\mathrm{L}^{-1}$ em solução $\mathrm{CF}_{3} \mathrm{COOH} / \mathrm{CF}_{3} \mathrm{COONa} \mathrm{pH} \sim 3$. Pico de absorção máxima registrado em $437 \mathrm{~nm}$.

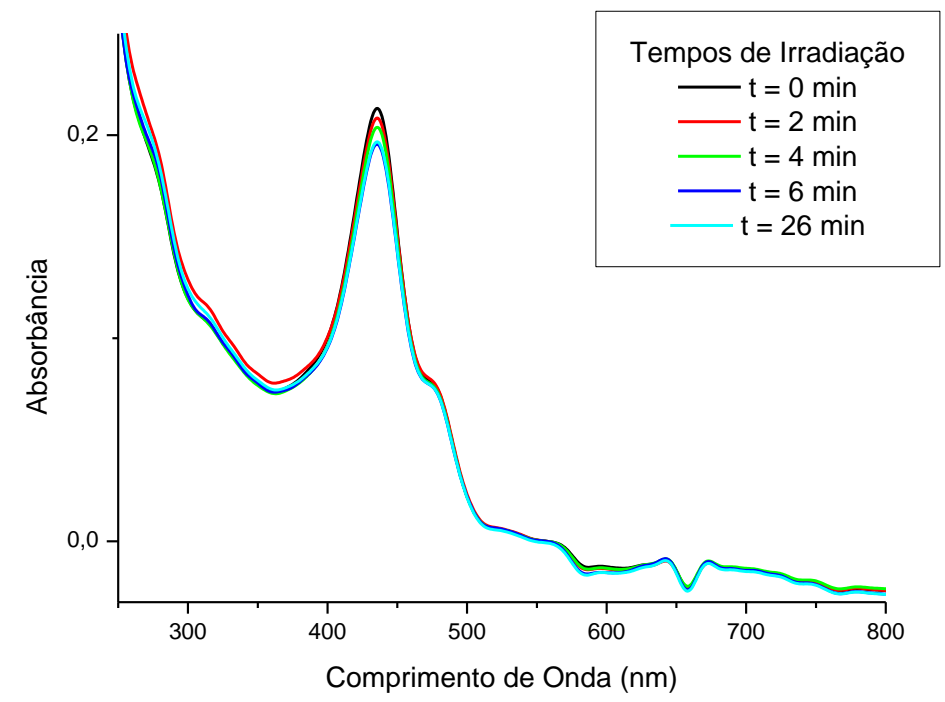

Figura 23 - Espectros Uv-vis obtidos na fotólise pela irradiação de uma solução de fluoresceína sódica $4,97 \quad \times \quad 10^{-4} \quad \mathrm{~mol}^{-1} \quad \mathrm{~L}^{-1}$ em solução $\mathrm{CF}_{3} \mathrm{COOH} / \mathrm{CF}_{3} \mathrm{COONa} \mathrm{pH} \sim 3$, com filtro de interferência de onda de 438 $\mathrm{nm}$, nos tempos $0,2,4,6$ e 26 minutos. 
Devido ao $\mathrm{pH}$ do meio ( $\mathrm{pH} \sim 3$ ), a banda de absorção máxima da fluoresceína que deveria aparecer por volta de $490 \mathrm{~nm}$ em sua forma neutra, deslocou-se para 437 nm,o que é correspondente à forma catiônica (Figura 24).

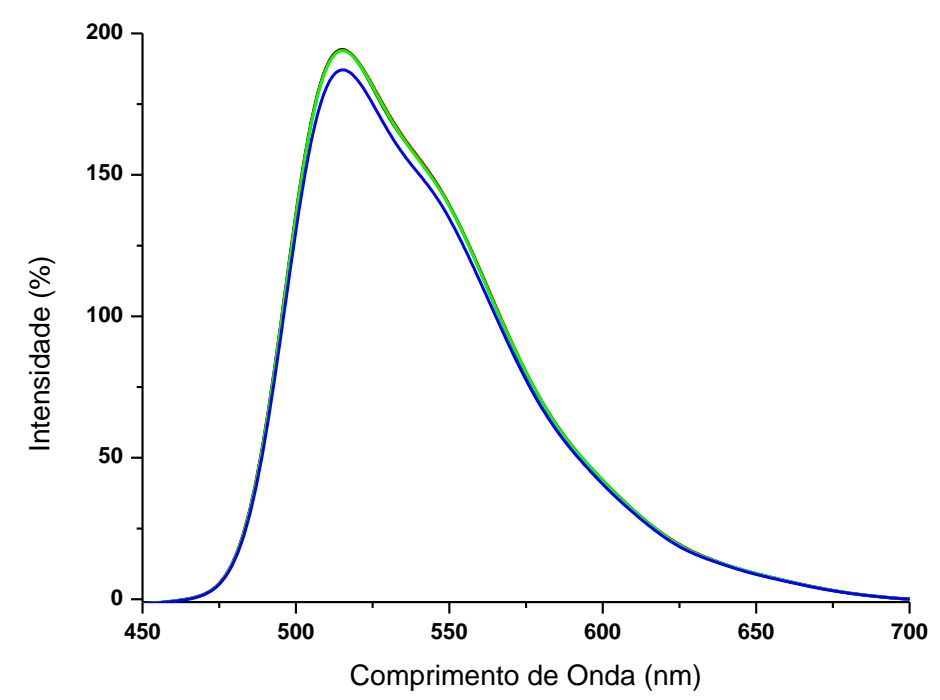

Figura 24 - Espectros de emissão de uma solução de $4,97 \times 10^{-4} \mathrm{~mol} \mathrm{~L}^{-1} \mathrm{de}$ fluoresceína sódica em solução $\mathrm{CF}_{3} \mathrm{COOH} / \mathrm{CF}_{3} \mathrm{COONa} \mathrm{pH} \sim 3$, irradiada em $438 \mathrm{~nm}$, nos tempos 0, 2, 4, 6 e 26 minutos. A linha de menor intensidade corresponde ao tempo 0 .

\subsubsection{Rodamina-B}

Rodamina-B é o nome usual dado ao composto de nome IUPAC cloreto de [9-(2-carboxifenil)-6-dietilamino-3-xantiliden]-dietilamonio. É um cromóforo da família dos corantes xantenos, utilizado em várias aplicações, tais como: marcadores biológicos, sondas fluorescentes, agentes de rastreamento, corantes de laser. Suas características espectrais dependem da concentração do corante, natureza do solvente, $\mathrm{pH}$ do meio e temperatura [88]. Alto rendimento quântico de fluorescência $(>0,5)$ é observado para baixas concentrações $\left(10^{-4}\right.$ a $\left.10^{-6} \mathrm{~mol} \mathrm{~L}^{-1}\right)$, enquanto em 
altas concentrações $\left(>10^{-3} \mathrm{~mol} \mathrm{~L}^{-1}\right) \circ$ rendimento cai para menos de 0,1 . A explicação para esta diminuição drástica do rendimento quântico de fluorescência é a formação de dímeros, que fornecem fraca contribuição para fluorescência. [89]. Por isso, utilizamos neste trabalho concentrações da ordem de $10^{-5} \mathrm{~mol} \mathrm{~L}^{-1}$.

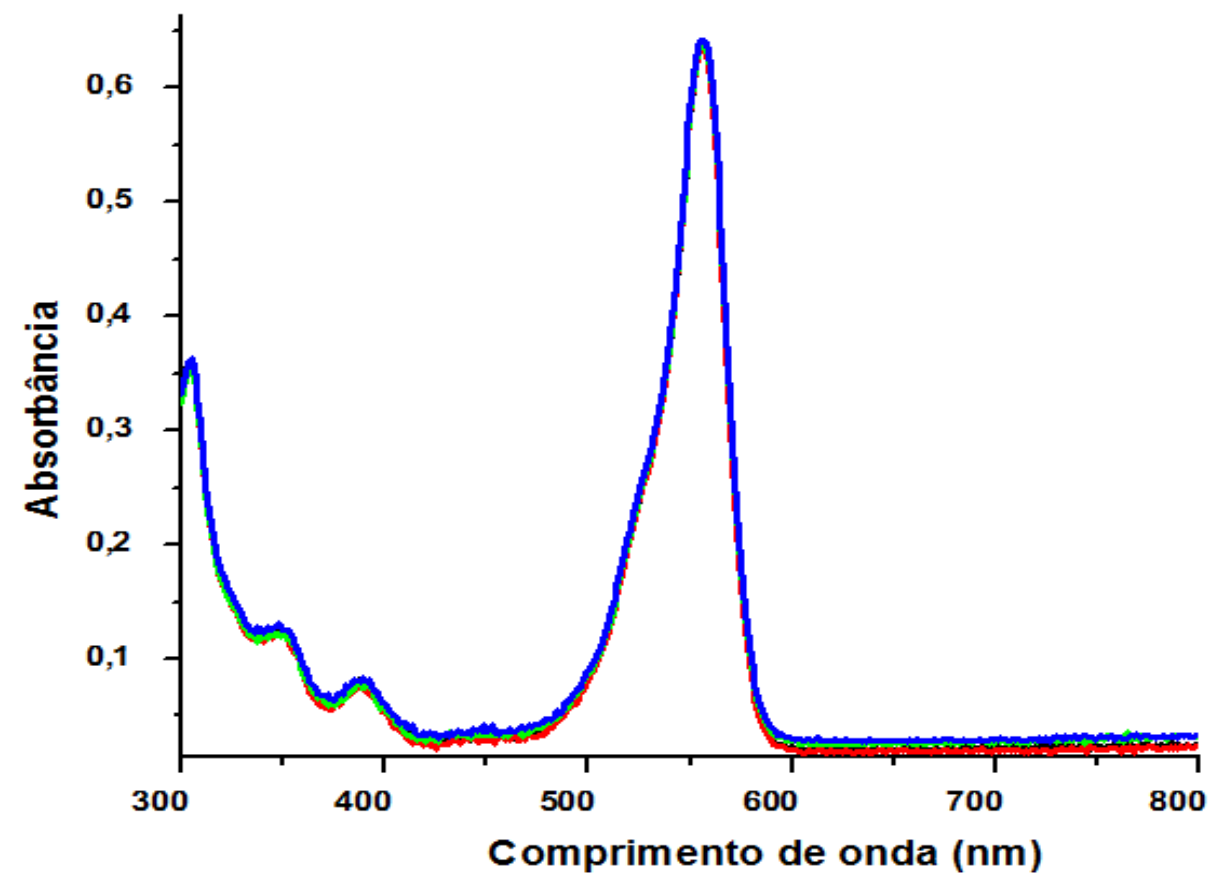

Figura 25 - Espectros Uv-vis obtidos na irradiação de uma solução de rodamina-B $1,00 \times 10^{-5} \mathrm{~mol} \mathrm{~L}^{-1}$ em solução $\mathrm{CF}_{3} \mathrm{COOH} / \mathrm{CF}_{3} \mathrm{COONa} \mathrm{pH} \sim 3$, com luz de $524 \mathrm{~nm}$, nos tempos 0 (linha vermelha), 5 (linha verde) e 10 minutos (linha azul).

\subsubsection{Tartrazina}

A tartrazina é um corante de nome IUPAC (4E)-5-oxo-1-(4-sulfonatofenil)-4[(4-sulfonatofenil)hidrazinilideno]-3-pirazolcarboxilato trisódico muito utilizado na indústria de alimentos e medicamentos, sendo considerado um corante artificial por não ser encontrado na natureza. Este tipo de corante, tido como sintético, 
comparando-se com os naturais, apresenta maior estabilidade a luz, oxigênio e pH [90]. Não ocorrem degradações ao se irradiar soluções de tartrazina de 300 a 500 nm [91]. Devido à possibilidade de agregação de moléculas de tartrazina, utilizou-se concentrações por volta de $2 \times 10^{-5} \mathrm{~mol} \mathrm{~L}^{-1}$ [92]. Por isso, procurou-se utilizar concentrações próximas das já utilizadas para outros corantes $\left(1,50 \times 10^{-5} \mathrm{~mol} \mathrm{~L}^{-1}\right)$.

Os espectros de absorbância (Figura 26) e emissão (Figura 27) do corante tartrazina em solução $\mathrm{CF}_{3} \mathrm{COOH} / \mathrm{CF}_{3} \mathrm{COONa} \mathrm{pH} \sim 3$ não apresentaram variações que pudessem sugerir que estivesse ocorrendo alguma reação ocasionada pela irradiação. Assim, apesar da banda de absorção máxima deste corante não estar dentro do intervalo de $500-600 \mathrm{~nm}$, como era proposto inicialmente, no caso de não ocorrer liberação de $\mathrm{NO}$ pelo complexo trans-[Ru( $\left.\left(\mathrm{NH}_{3}\right)_{4}(\mathrm{py})(\mathrm{NO})\right]\left(\mathrm{BF}_{4}\right)_{3}$, através da sensibilização pelos corantes rodamina-B e fluoresceína sódica, este corante seria uma tentativa de sobreposição de outra banda do complexo, localizada em 324 nm.

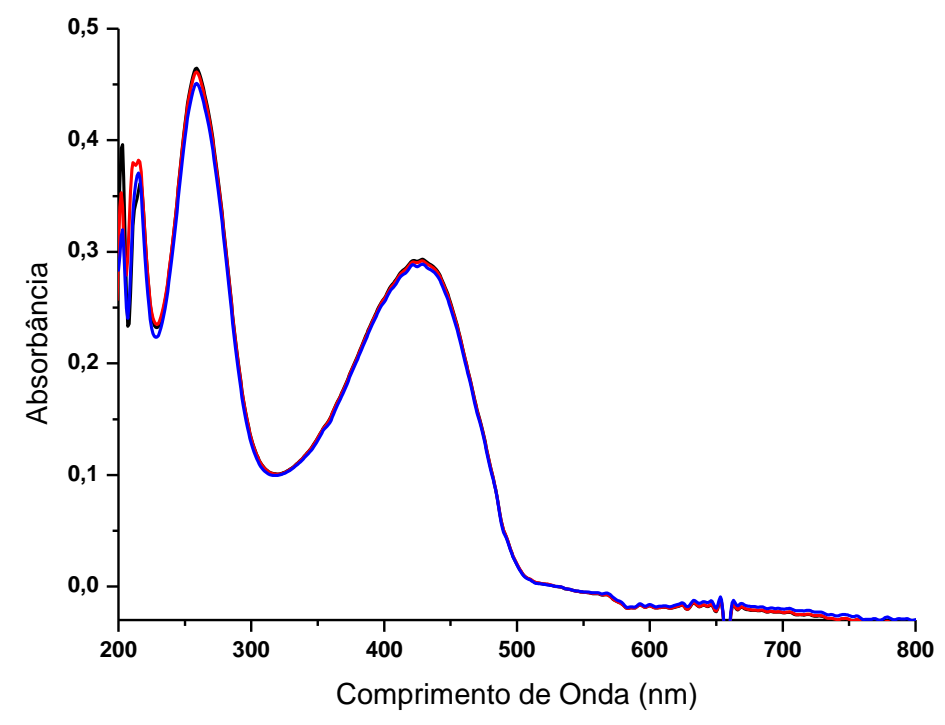

Figura 26 - Espectros Uv-vis obtidos na irradiação de uma solução de tartrazina 1,50 X $10^{-5} \mathrm{~mol} \mathrm{~L}^{-1}$ em solução $\mathrm{CF}_{3} \mathrm{COOH} / \mathrm{CF}_{3} \mathrm{COONa} \mathrm{pH} \sim 3$, com luz de 438 $\mathrm{nm}$, nos tempos 0,5 e 10 minutos. 


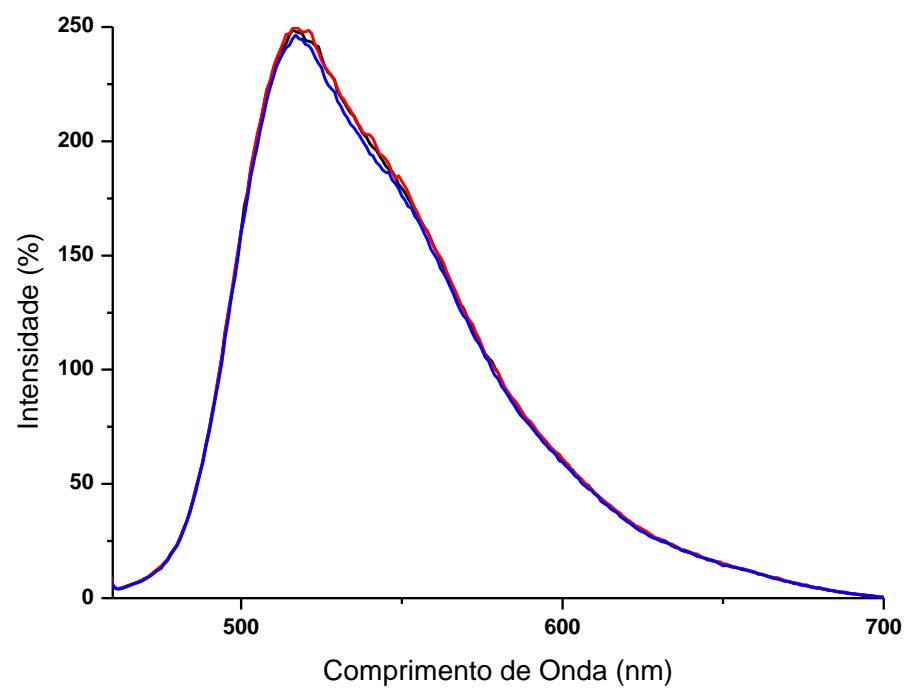

Figura 27 - Espectros de emissão de uma solução de tartrazina $1,50 \times 10^{-5} \mathrm{~mol} \mathrm{~L}^{-1}$ em solução $\mathrm{CF}_{3} \mathrm{COOH} / \mathrm{CF}_{3} \mathrm{COONa} \mathrm{pH} \sim 3$, irradiada com luz de $438 \mathrm{~nm}$, nos tempos 0, 5 e 10 minutos.

\subsection{Fotólise do complexo trans-[Ru(NH$\left.)_{4}(\mathrm{py})(\mathrm{NO})\right]\left(\mathrm{BF}_{4}\right)_{3}$ na presença de corantes}

Os espectros de absorção eletrônica do acompanhamento da irradiação das soluções contendo o complexo e a rodamina-B (Figura 28) e, da solução contendo o complexo e a fluoresceína sódica (Figura 29) não apresentaram mudanças significativas nas bandas de absorção dos corantes $(570 \mathrm{~nm}$ para rodamina-B e 437 nm para a fluoresceína sódica), no entanto, ocorreram mudanças nas bandas de absorção do complexo em torno de $300-350 \mathrm{~nm}$, o que sugeriu que poderia estar havendo liberação de NO através da transferência de energia do corante para o complexo.

Os espectros de emissão do acompanhamento da irradiação das soluções contendo o complexo e a Rodamina-B (Figura 30) e, da solução contendo o 
complexo e a fluoresceína sódica (Figura 31), assim como nos espectros de absorção eletrônica (Figura 28 e Figura 29), não apresentaram nenhuma variação que sugerisse estar ocorrendo alguma reação de degradação do corante, apenas uma pequena supressão, que poderia ser esperada caso ocorresse transferência de energia do corante para o complexo.

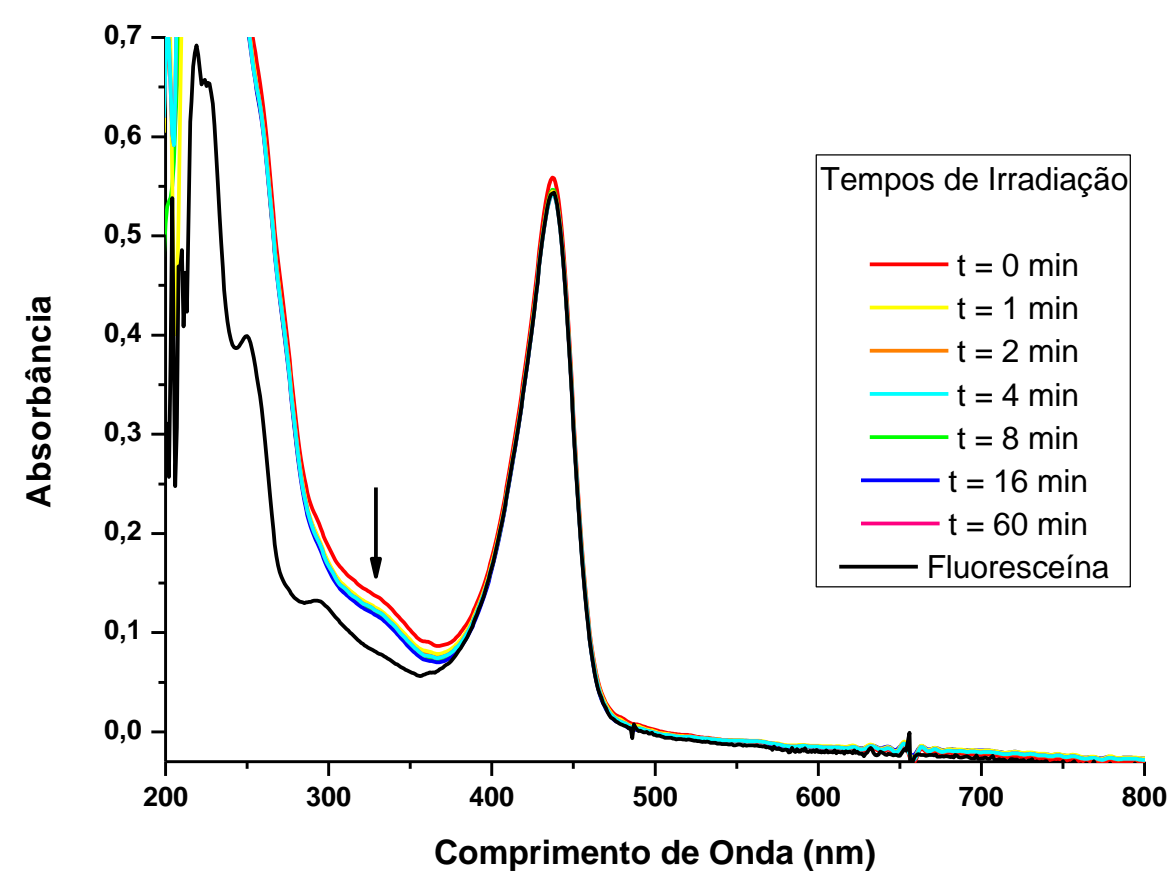

Figura 28 - Espectros de absorção eletrônica obtidos na irradiação com luz de 438 $n m$ de uma solução do complexo trans-[Ru(NH$\left.\left.)_{3}\right)_{4}(\mathrm{py})(\mathrm{NO})\right]\left(\mathrm{BF}_{4}\right)_{3}$ preparada a partir de uma solução de fluoresceína sódica $4,97 \times 10^{-4}$ mol L ${ }^{-1}$ em solução $\mathrm{CF}_{3} \mathrm{COOH} / \mathrm{CF}_{3} \mathrm{COONa} \mathrm{pH} \sim 3$, nos tempos $0,1,2,4$, 8,16 e 60 minutos. 


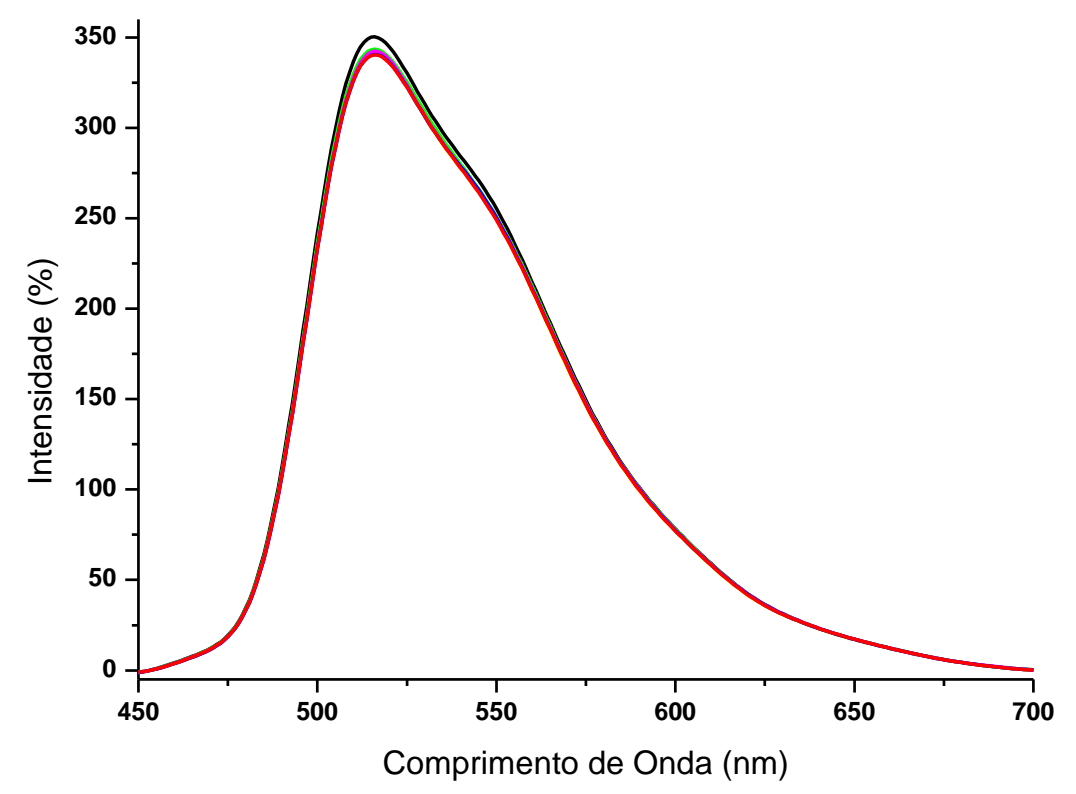

Figura 29 - Espectros de emissão obtidos na fotólise com luz de 438 nm de uma solução do complexo trans-[Ru(NH$\left.)_{4}(\mathrm{py})(\mathrm{NO})\right]\left(\mathrm{BF}_{4}\right)_{3}$ preparada a partir de uma solução de fluoresceína sódica $4,97 \times 10^{-4} \mathrm{~mol} \mathrm{~L}^{-1}$ em solução $\mathrm{CF}_{3} \mathrm{COOH} / \mathrm{CF}_{3} \mathrm{COONapH} \sim 3$, nos tempos $0,1,2,4,8,16$ e 60 minutos (Comprimento de onda de excitação foi de $450 \mathrm{~nm}$ e janela de 3/1,5). 


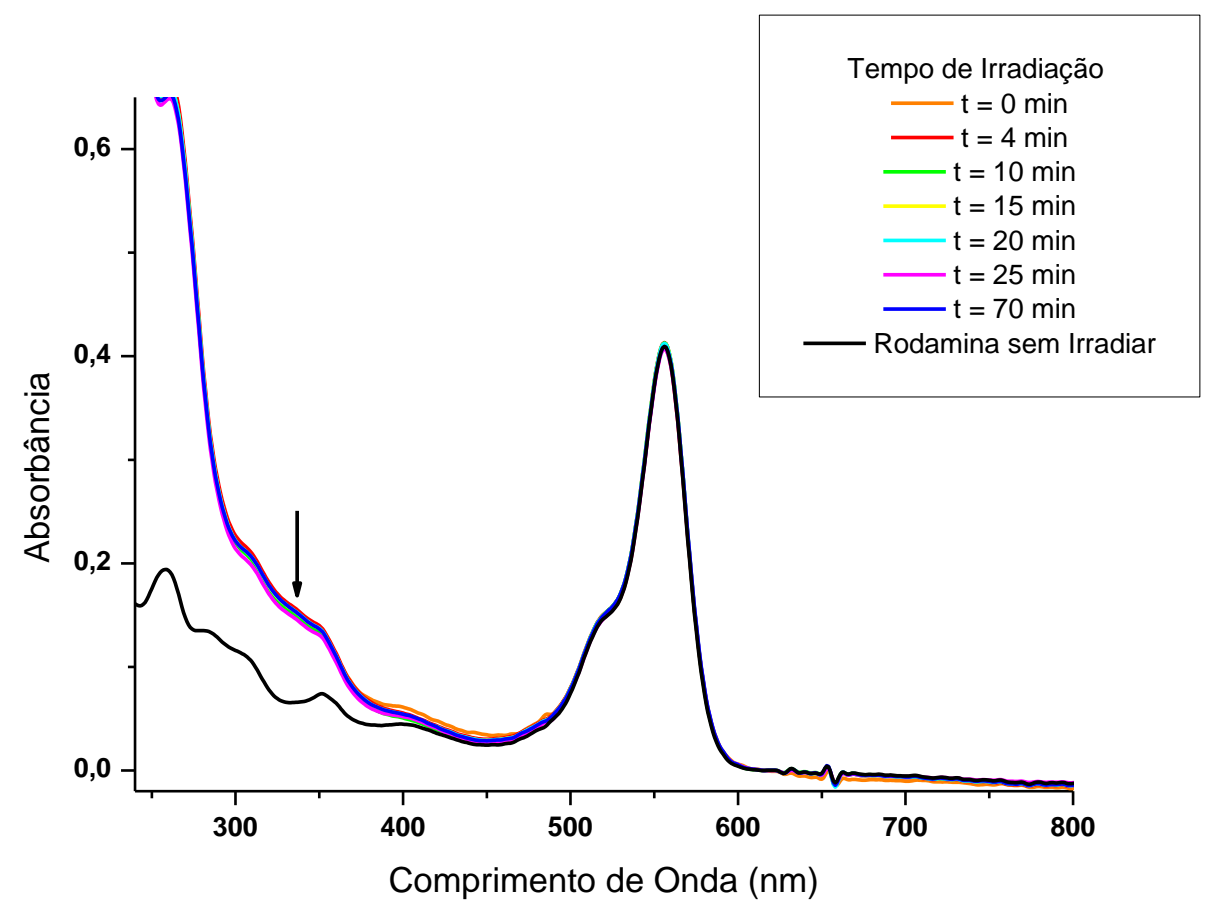

Figura 30 - Espectros de absorção eletrônica obtidos na irradiação com luz de 570 $n m$ de uma solução do complexo trans-[Ru( $\left.\left(\mathrm{NH}_{3}\right)_{4}(\mathrm{py})(\mathrm{NO})\right]\left(\mathrm{BF}_{4}\right)_{3} 1_{1,02} \mathrm{x}$ $10^{-3} \mathrm{~mol} \mathrm{~L}^{-1}$ preparada a partir de uma solução de rodamina-B $1,00 \times 10^{-5}$ mol L ${ }^{-1}$ em $\mathrm{CF}_{3} \mathrm{COOH} / \mathrm{CF}_{3} \mathrm{COONapH} \sim 3$, nos tempos $0,4,10,15,20$, 25 e 70 minutos. 


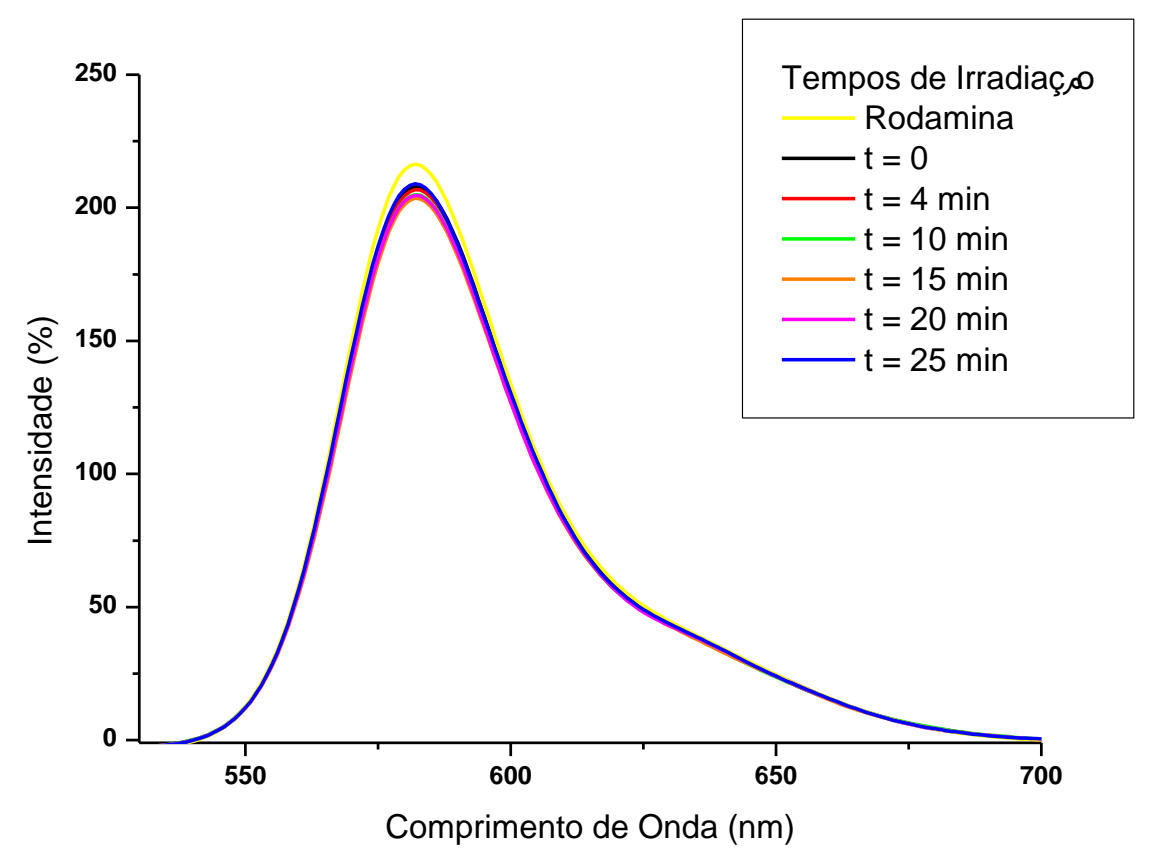

Figura 31 - Espectros de emissão obtidos na irradiação com luz de 438 nm de uma solução do complexo trans-[Ru( $\left.\left(\mathrm{NH}_{3}\right)_{4}(\mathrm{py})(\mathrm{NO})\right]\left(\mathrm{BF}_{4}\right)_{3} 1,02 \times 10^{-3} \mathrm{~mol} \mathrm{~L}^{-1}$ preparada a partir de uma solução de rodamina-B $1,00 \times 10^{-5} \mathrm{~mol} \mathrm{~L}^{-1} \mathrm{em}$ $\mathrm{CF}_{3} \mathrm{COOH} / \mathrm{CF}_{3} \mathrm{COONa} \mathrm{pH} \sim 3$, nos tempos $0,4,10,15,20,25$ e 70 minutos. (Comprimento de onda de excitação foi de $570 \mathrm{~nm}$ e janela de $5 / 3)$.

Somente os espectros de Uv-vis e emissão não foram suficientes para afirmar que ocorreu liberação de $\mathrm{NO}$ pelo complexo trans-[Ru( $\left.\left(\mathrm{NH}_{3}\right)_{4}(\mathrm{py})(\mathrm{NO})\right]\left(\mathrm{BF}_{4}\right)_{3}$ através da sensibilização por corantes. Para nos certificarmos de estar ocorrendo ou não a transferência de energia dos corantes para o estado excitado responsável pelas reações de fotossubstituição do complexo, outros métodos foram pesquisados. 


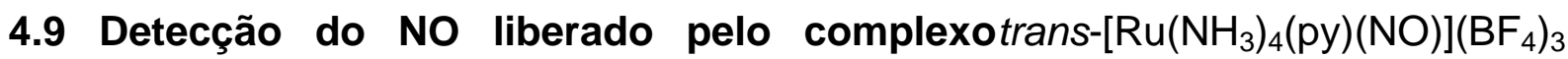 através da sensibilização por corantes}

Algumas alternativas foram levantadas para se detectar o NO liberado pelo complexo trans-[Ru( $\left.\left(\mathrm{NH}_{3}\right)_{4}(\mathrm{py})(\mathrm{NO})\right]\left(\mathrm{BF}_{4}\right)_{3}$ através da sensibilização por corantes, como a utilização de um sequestrador de NO cujo espectro de absorção UV-Visível permita não só a detecção, mas também a determinação do NO eventualmente liberado. Possíveis sequestradores seriam a porfirina Co(TPP)e a mioglobina.Uma outra alternativa, seria a análise de EPR através de adição do sequestrador de NO carboxy-PTIO.

\subsubsection{Co(TPP)}

A Co"(TPP) (tetrafenilporfirina de cobalto(II)), é uma porfirina formada por um anel porfirínico com um átomo de cobalto central e quatro anéis fenil adjacentes em posição meso (Figura 32). Possui banda Soret em 417 nm, bandas Q em 527 e $595 \mathrm{~nm}$ e, outras bandas em 660, 885 e $1055 \mathrm{~nm}$. As três ultimas bandas são associada às transições de transferência de carga metal-anel porfirínico e anel porfirinico-metal. As bandas $Q$ e Soret são associadas às transições $\pi \rightarrow \pi^{*}$ da porfirina [93]. 


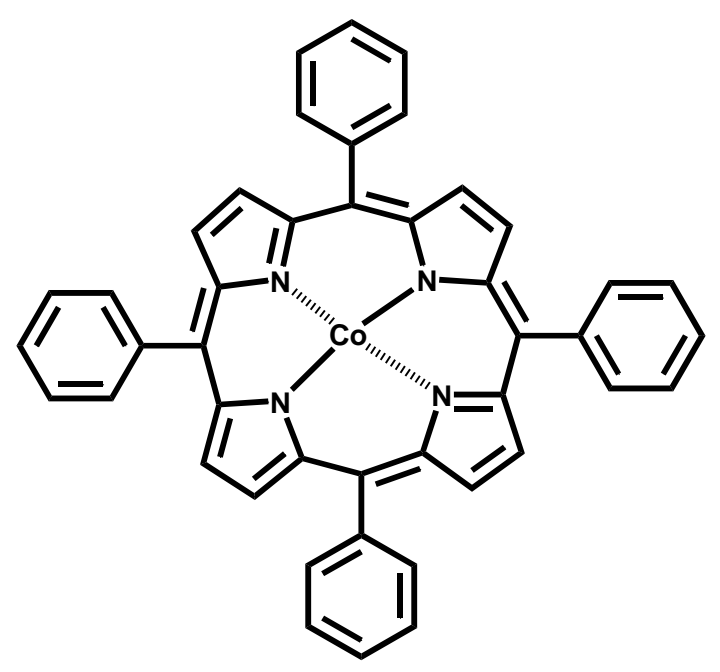

Figura 32 - Estrutura da tetrafenilporfirina de cobalto (Co(TPP)).

Em presença de óxido nítrico no meio, ocorre a nitrosilação da porfirina Co"l(TPP), formando a (NO)Co(TPP). Em solvente 2-metiltetraidrofurano, por exemplo, ao ocorrer a nitrosilação da Co"(TPP), ocorre diminuição da banda $Q$ localizada em $526 \mathrm{~nm}$ e aumento da banda Q localizada em $537 \mathrm{~nm}$ que é correspondente à forma nitrosilada da porfirina [94]. Devido a esta característica, esta porfirina já foi utilizada em trabalhos onde visava-se analisar a liberação de NO, como por exemplo, no caso da liberação de NO pelo complexo $\left[\mathrm{Ru}(\mathrm{NO})(\mathrm{NO})_{2} \mathrm{pc}\right](\mathrm{pc}$ = ftalocianina) em diclorometano, através da irradiação com luz de $660 \mathrm{~nm}$, sendo verificada a sua liberação através da mudança da banda $Q$ da Co(TPP) em 415 nm, que diminuiu claramente, para a formação de uma banda $Q$ em $440 \mathrm{~nm}$, correspondente à formação da (NO)Co(TPP)[63].

Apesar de serem encontrados inúmeros trabalhos na literatura para a analise da liberação de NO no meio reacional, nenhum deles foi feito em meio aquoso, que é o objetivo deste trabalho, devido à porfirina Co(TPP) ser insolúvel em meio aquoso. Portanto, esta alternativa foi descartada para verificar se ocorreu a liberação de $\mathrm{NO}$ por sensibilização do complexo trans-[Ru($\left.\left(\mathrm{NH}_{3}\right)_{4}(\mathrm{py})(\mathrm{NO})\right]\left(\mathrm{BF}_{4}\right)_{3}$ através de corantes. 


\subsubsection{Mioglobina}

A mioglobina é uma proteína globular de 153 aminoácidos, contendo um grupo prostético heme no centro, sendo que sua principal função no organismo é a ser um reservatório de $\mathrm{O}_{2}$. Embora sua maior concentração se encontre no músculo vermelho $\left(0,2-0,4 \mathrm{mmol} \mathrm{L}^{-1}\right)$, a mioglobina é insuficiente pra sustentar o metabolismo aeróbico do coração humano por mais de alguns segundos. Uma função secundária desta proteína é facilitar a difusão do $\mathrm{O}_{2}$ dos capilares para a mitocôndria, para sustentar a respiração mitocondrial. A liberação de NO pelo complexo trans$\left[\mathrm{Ru}\left(\mathrm{NH}_{3}\right)_{4}(\mathrm{py})(\mathrm{NO})\right]\left(\mathrm{BF}_{4}\right)_{3}$ na presença dos corantes rodamina-B e fluoresceína sódica poderia ser verificada através da adição de mioglobina, um sequestrador de NO já utilizado anteriormente com compostos semelhantes [51, 95].

As reações que envolvem NO com metaloproteínas de ferro, como mioglobina $(\mathrm{Mb}(\mathrm{III}))$, hemoglobina e citocromo $\mathrm{C}$, são algumas das reações mais importantes em meio biológico. A mioglobina reage com NO formando $\mathrm{Mb}$ (III)NO(Equação 19), que reage com $\mathrm{OH}^{-}$formando nitrito e $\mathrm{Mb}$ (II) (Equação 20) e, então reage com NO, formando Mb(II)NO (Equação 21) [96].

$$
\begin{aligned}
& \mathrm{Mb}^{\mathrm{III}}+\mathrm{NO} \rightleftharpoons \mathrm{Mb}^{\mathrm{III}}-\mathrm{NO}\left(\mathrm{K}_{\text {eq }}=1,4 \times 10^{4} \mathrm{~L} \mathrm{~mol}^{-1} \mathrm{em} \mathrm{pH}=6,5\right) \\
& \mathrm{Mb}^{\mathrm{III}}-\mathrm{NO}+\mathrm{HO}^{-} \rightarrow \mathrm{Mb}^{\mathrm{II}}+\mathrm{HNO}_{2} \quad\left(\mathrm{KOH}^{-}=3,2 \times 10^{2} \mathrm{~L} \mathrm{~mol}^{-1} \mathrm{~s}^{-1}\right) \\
& \mathrm{Mb}^{\mathrm{II}}+\mathrm{NO} \rightarrow \mathrm{Mb}^{\mathrm{II}}-\mathrm{NO} \quad\left(k_{\mathrm{NO}}=1,7 \times 10^{7} \mathrm{~L} \mathrm{~mol}^{-1} \mathrm{~s}^{-1}\right)
\end{aligned}
$$

A formação da nitrosilmioglobina pode ser acompanhada através de espectros de absorção eletrônica. Em tampão fosfato $(\mathrm{pH}=7,4)$, a Mb"I apresenta 
uma banda Soret com máximo de absorção em $408 \mathrm{~nm}\left(1,5 \times 10^{5} \mathrm{~mol} \mathrm{~L}^{-1} \mathrm{~cm}^{-1}\right) \mathrm{e}$ uma banda em $500 \mathrm{~nm}\left(1 \times 10^{4} \mathrm{~mol} \mathrm{~L}^{-1} \mathrm{~cm}^{-1}\right)$ na região das bandas $\mathrm{Q}$. Ao reagir com $\mathrm{NO}, \mathrm{Mb}^{\mathrm{III}}$ forma o aduto Mb"'NO, que possui banda Soret em $420 \mathrm{~nm}\left(1,29 \times 10^{5}\right.$ $\mathrm{mol} \mathrm{L}^{-1} \mathrm{~cm}^{-1}$ ) e duas bandas em 545 e $578 \mathrm{~nm}$, na região das bandas $\mathrm{Q}[51,96]$.

O espectro eletrônico de absorção do acompanhamento das irradiações com luz de $313 \mathrm{~nm}$ do complexo trans-[Ru($\left.\left(\mathrm{NH}_{3}\right)_{4}(\mathrm{py})(\mathrm{NO})\right]\left(\mathrm{BF}_{4}\right)_{3}$ em tampão fosfato $(\mathrm{pH}=$ $7,4)$ na presença de mioglobina está apresentado na Figura 33 , e os obtidos na presença dos corantes rodamina-B, irradiada com luz de $580 \mathrm{~nm}$ e $524 \mathrm{~nm}$ e, fluoresceína sódica, irradiada com luz de $438 \mathrm{~nm}$, e mioglobina em tampão fosfato $(\mathrm{pH}=7,4)$ estão apresentados nas Figuras 34,35 e 36. 


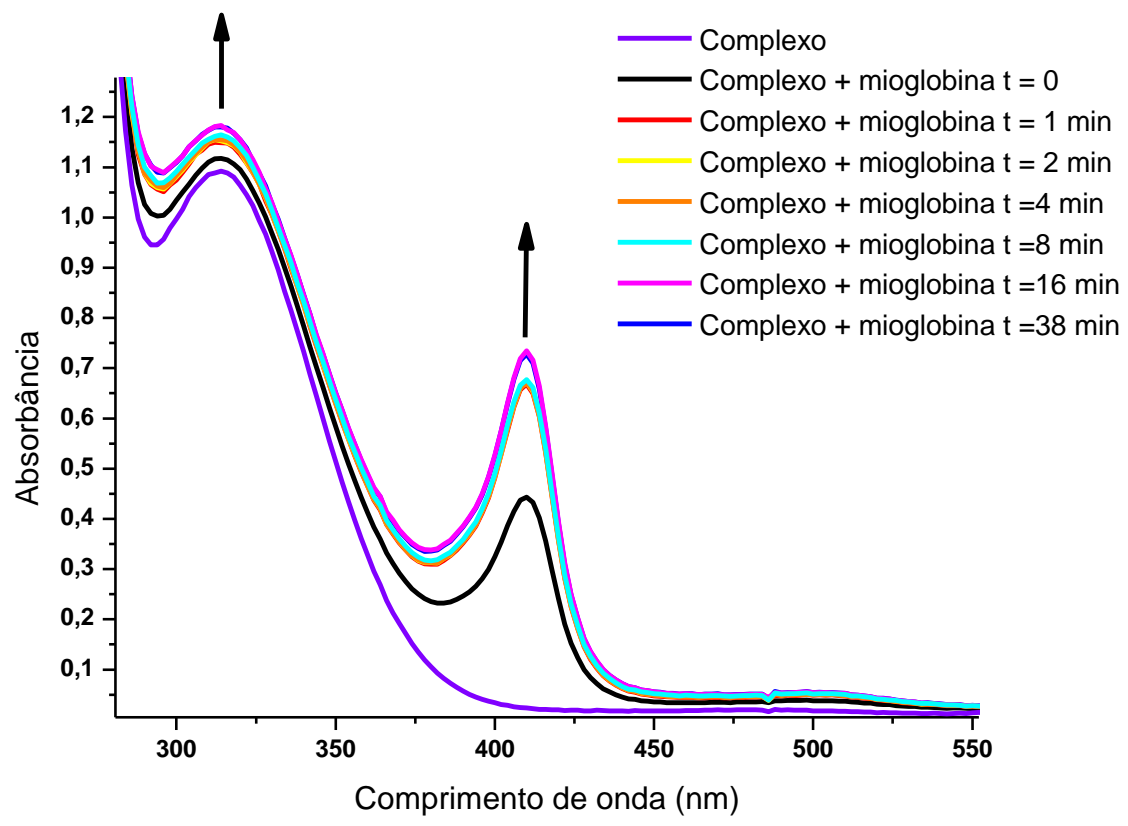

Figura 33 - Espectro eletrônico do acompanhamento das irradiações com luz de 313 $\mathrm{nm}$ de uma solução de $6,8 \times 10^{-3} \mathrm{~mol} \mathrm{~L}^{-1}$ do complexo trans$\left[\mathrm{Ru}\left(\mathrm{NH}_{3}\right)_{4}(\mathrm{py})(\mathrm{NO})\right]\left(\mathrm{BF}_{4}\right)_{3}$ em tampão fosfato $(\mathrm{pH}=7,4)$ na presença de mioglobina (banda registrada em $410 \mathrm{~nm}$ ) nos tempos $0,1,2,4,8,16 \mathrm{e}$ 38 minutos. 


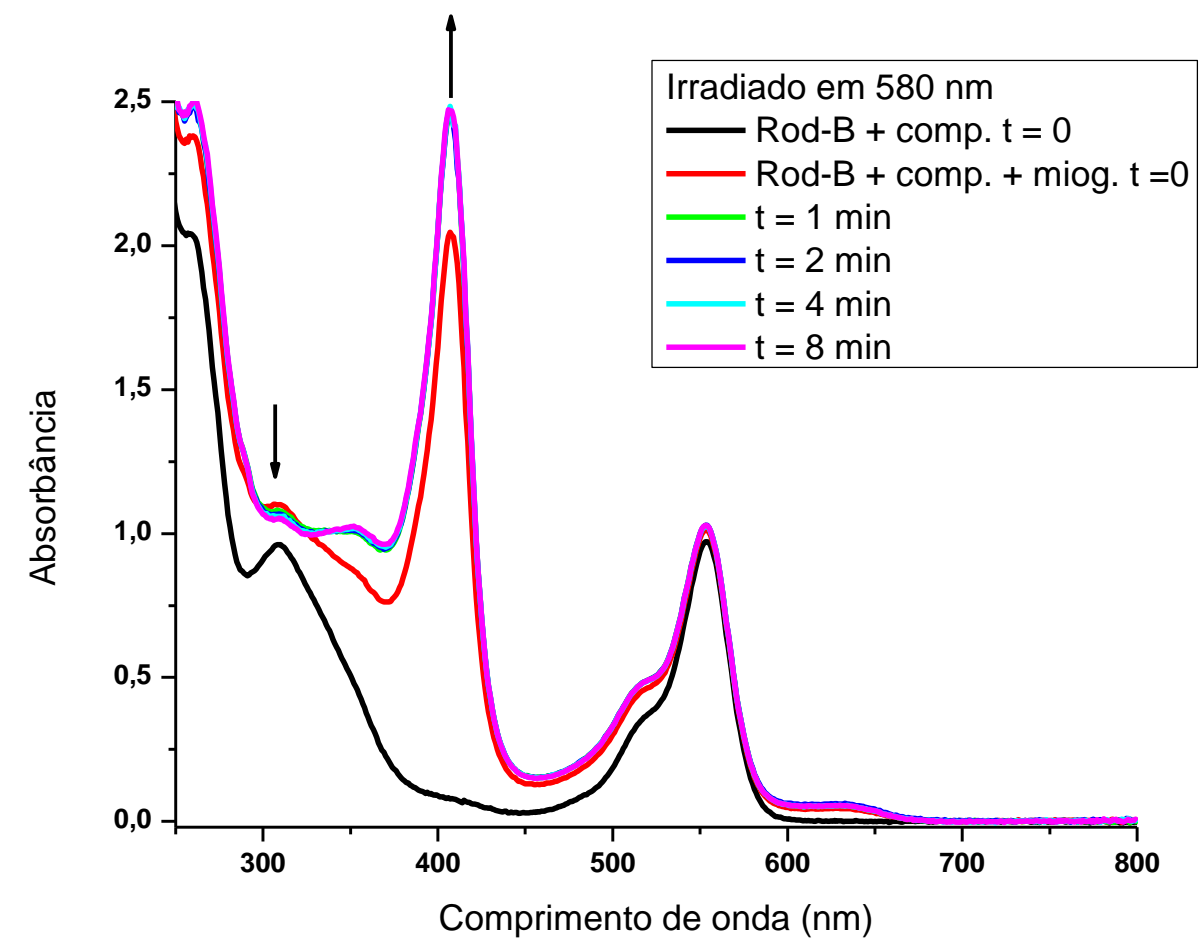

Figura 34 - Espectros de absorção eletrônica obtidos na irradiação com luz de 580 $\mathrm{nm}$ de uma solução trans-[Ru($\left.\left(\mathrm{NH}_{3}\right)_{4}(\mathrm{py})(\mathrm{NO})\right]\left(\mathrm{BF}_{4}\right)_{3} 1,03 \times 10^{-3} \mathrm{~mol} \mathrm{~L}^{-1}$ em solução Rodamina-B $1,00 \times 10^{-5} \mathrm{~mol} \mathrm{~L}^{-1}$ em tampão fosfato $(\mathrm{pH}=$ $7,4)$, na presença de mioglobina, nos tempos $t=0,1,2,4$ e 8 minutos. 


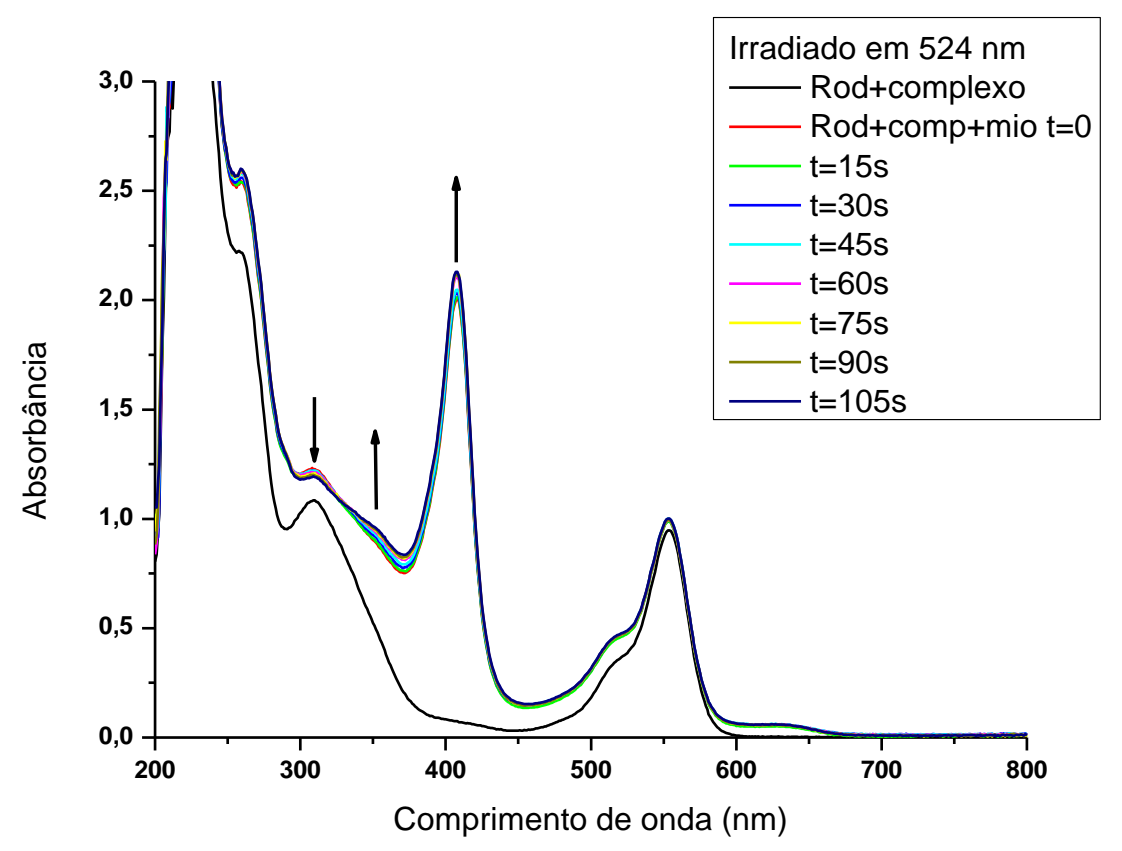

Figura 35 - Espectros de absorção eletrônica obtidos na irradiação com luz de 524 $\mathrm{nm}$ de uma solução trans-[Ru( $\left.\left(\mathrm{NH}_{3}\right)_{4}(\mathrm{py})(\mathrm{NO})\right]\left(\mathrm{BF}_{4}\right)_{3} 1,03 \times 10^{-3} \mathrm{~mol} \mathrm{~L}^{-1}$ em solução Rodamina-B $1,00 \times 10^{-5} \mathrm{~mol} \mathrm{~L}^{-1} \mathrm{em}$ tampão fosfato $(\mathrm{pH}=$ $7,4)$, na presença de mioglobina, nos tempos $t=0,15,30,45,60,75$, 90 e 105 segundos. 


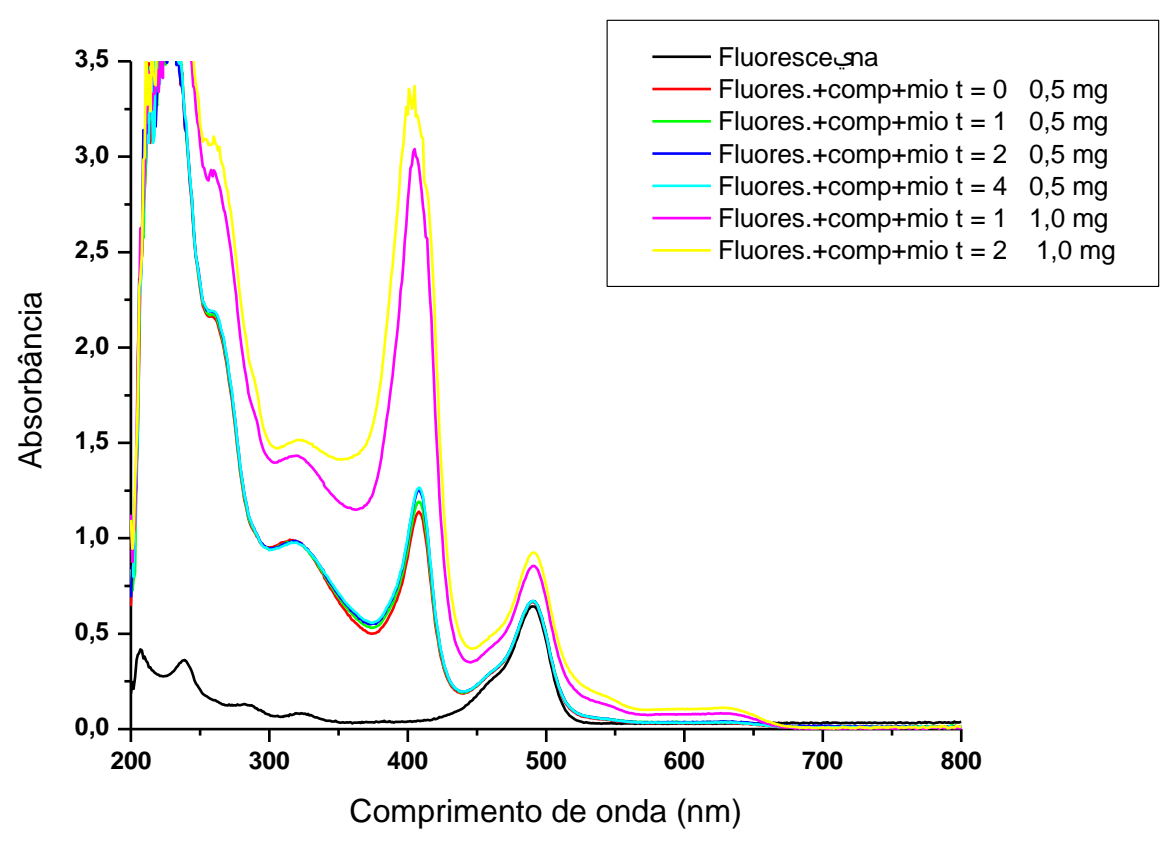

Figura 36 - Espectros de absorção eletrônica obtidos na irradiação com luz de 480 $\mathrm{nm}$ de uma solução trans-[Ru(NH$\left.)_{4}(\mathrm{py})(\mathrm{NO})\right]\left(\mathrm{BF}_{4}\right)_{3} \quad 1,03 \times 10^{-3} \mathrm{~mol} \mathrm{~L}^{-1}$ em solução fluoresceína sódica $1,05 \times 10^{-5} \mathrm{~mol} \mathrm{~L}^{-1}$ em tampão fosfato $(\mathrm{pH}=7,4)$, na presença de mioglobina, nos tempos $\mathrm{t}=0,5,10$ e 15 segundos.

Ao se adicionar a mioglobina ao sistema, observou-se o aparecimento de uma banda por volta de $408 \mathrm{~nm}$ que aumentou a cada irradiação. No entanto, era esperado que esta banda diminuísse e aparecesse uma banda em $420 \mathrm{~nm}$ referente à (NO)Mb(III) [95]. Relatos não documentados, por parte de outros, de comportamento semelhante na tentativa de determinar o NO por este método em alguns casos, às vezes solucionados com uma purificação prévia da mioglobina, levaram a buscar um outro método para essa determinação. 


\subsection{Análise por Ressonância Paramagnética Eletrônica (EPR) através de carboxy-PTIO}

Como o NO é uma molécula que possui elétron desemparelhado, ele pode ser detectado por EPR. Em determinadas soluções, a quantidade de NO pode estar abaixo do limite de detecção do equipamento, assim, seqüestradores de NO são geralmente empregados [97]. O PTIO (2-fenil-4,4,5,5-tetraimidazol-1-oxil-3-oxido) [98] (Figura 36) e seus derivados é muito utilizado como seqüestrador específico para NO. Este composto possui um elétron desemparelhado em um anel contendo dois átomos de nitrogênio. Com a ressonância, a densidade do elétron desemparelhado é igualmente distribuída em ambos os nitrogênios [99].

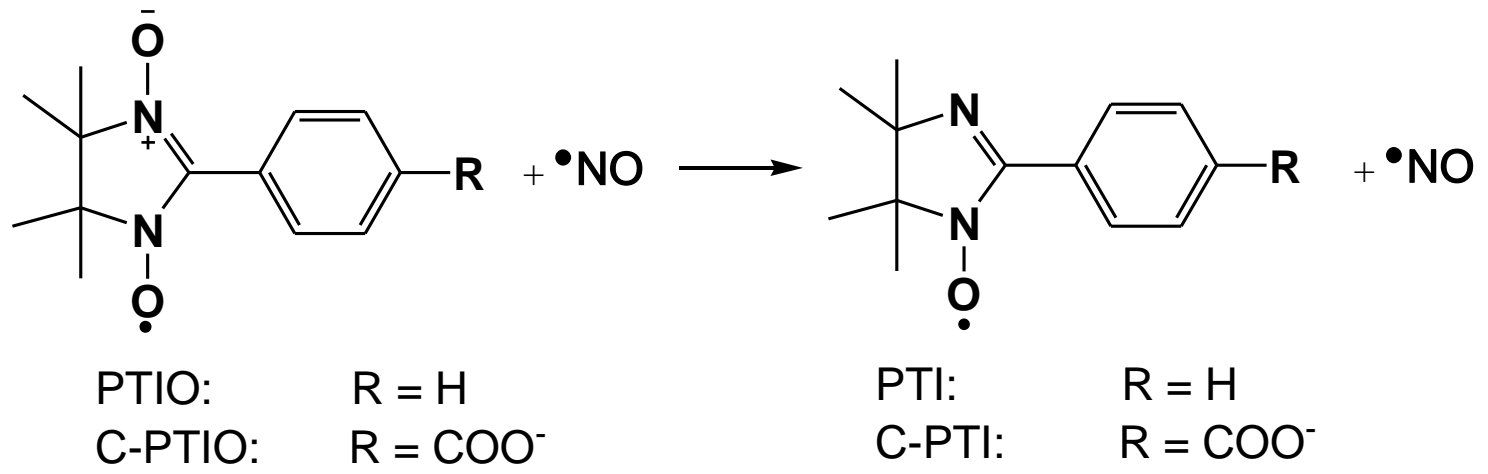

Figura 37 - Reação do PTIO e carboxi-PTIO com NO, formando carboxi-PTI ou PTI.

Soluções contendo trans-[Ru( $\left.\left(\mathrm{NH}_{3}\right)_{4}(\mathrm{py})(\mathrm{NO})\right]\left(\mathrm{BF}_{4}\right)_{3} \mathrm{e}$ carboxy-PTO, na ausência e na presença dos corantes rodamina-B, fluoresceína sódica, tartrazina e alaranjado de acridina, foram irradiados com luz de 355, 570 e 520, 440, 440 e 440 nm em tampão fosfato $(\mathrm{pH}=7,4)$. Tanto o carboxy PTIO, quanto carboxy-PTI são espécies paramagnéticas e portanto podem ser distinguidas por EPR. Os espectros de EPR obtidos foram registrados nas Figuras 38, 39, 40, 41 e 42. Foi possível observar a liberação de $\mathrm{NO}$ pelo complexo trans-[Ru(NH$\left.)_{4}(\mathrm{py})(\mathrm{NO})\right]\left(\mathrm{BF}_{4}\right)_{3}$ quando 
irradiado com laser de $355 \mathrm{~nm}$. Não foi observada liberação de NO ao se irradiar nas bandas de absorção dos corantes.

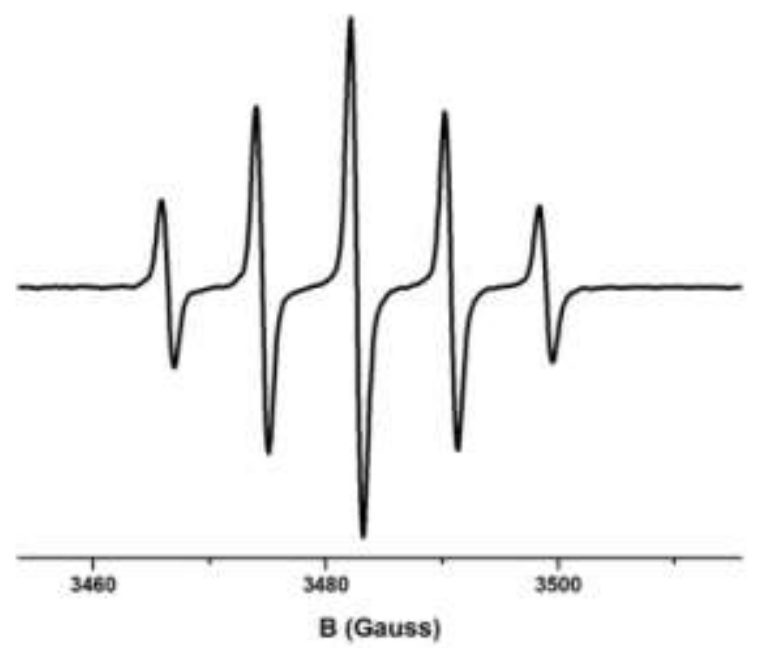

Figura 38 - Espectro de EPR da solução de carboxi-PTIO $\left(C_{\text {PTIO }}=6,3 \times 10^{-3} \mathrm{~mol} \mathrm{~L}^{-1}\right)$ em tampão fosfato $(\mathrm{pH}=7,4)$, irradiada por 10 minutos em $355 \mathrm{~nm}$.

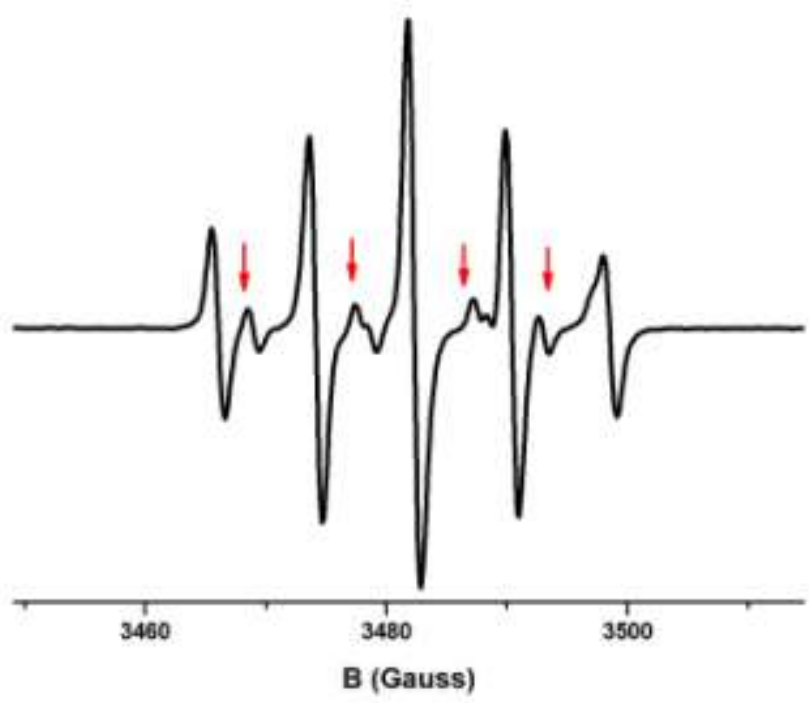

Figura 39 - Espectro de EPR da solução trans-[Ru(NH$\left.)_{3}(\mathrm{py})(\mathrm{NO})\right]\left(\mathrm{BF}_{4}\right)_{3}\left(C_{\mathrm{Ru}}=10^{-4}\right.$ mol L'1) na presença de carboxi-PTIO $\left(C_{\text {PTIO }}=6,3 \times 10^{-3} \mathrm{~mol} \mathrm{~L}^{-1}\right)$ irradiada por 10 minutos em $355 \mathrm{~nm}$. 
Os valores obtidos para as constantes foram $a_{N}{ }^{1,3}=0,82 \mathrm{mT}$ para o PTIO, $\mathrm{a}_{\mathrm{N}}{ }^{1}=0,98 \mathrm{mT}$ e $\mathrm{a}_{\mathrm{N}}{ }^{3}=0,44 \mathrm{mT}$ para o PTI, exatamente coincidentes com valores reportados previamente [99].
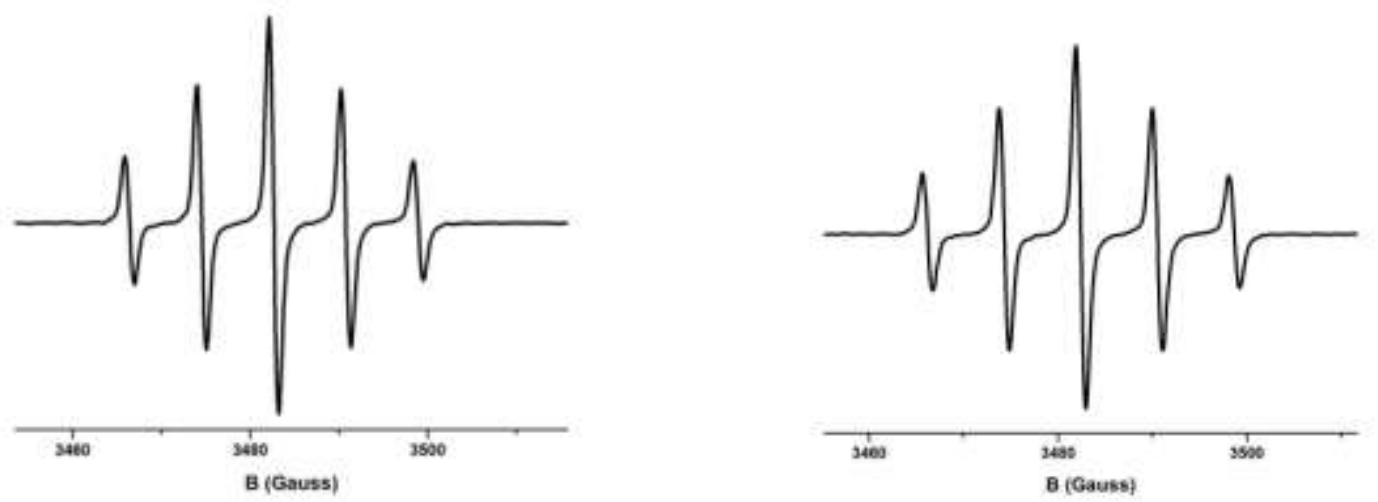

Figura 40 - Espectros de EPR da solução de carboxi-PTIO $\left(C_{\mathrm{PTIO}}=6,3 \times 10^{-3} \mathrm{~mol} \mathrm{~L}^{-}\right.$ $\left.{ }^{1}\right)$ e trans-[Ru( $\left.\left(\mathrm{NH}_{3}\right)_{4}(\mathrm{py})(\mathrm{NO})\right]\left(\mathrm{BF}_{4}\right)_{3}\left(C_{\mathrm{Ru}}=10^{-4} \mathrm{~mol} \mathrm{~L}-1\right)$ na presença de rodamina-B $\left(C_{\text {rod-B }}=5,76 \times 10^{-4} \mathrm{~mol} \mathrm{~L}^{-1}\right)$ irradiada por 15 minutos em $520 \mathrm{~nm}$ e em $570 \mathrm{~nm}$.
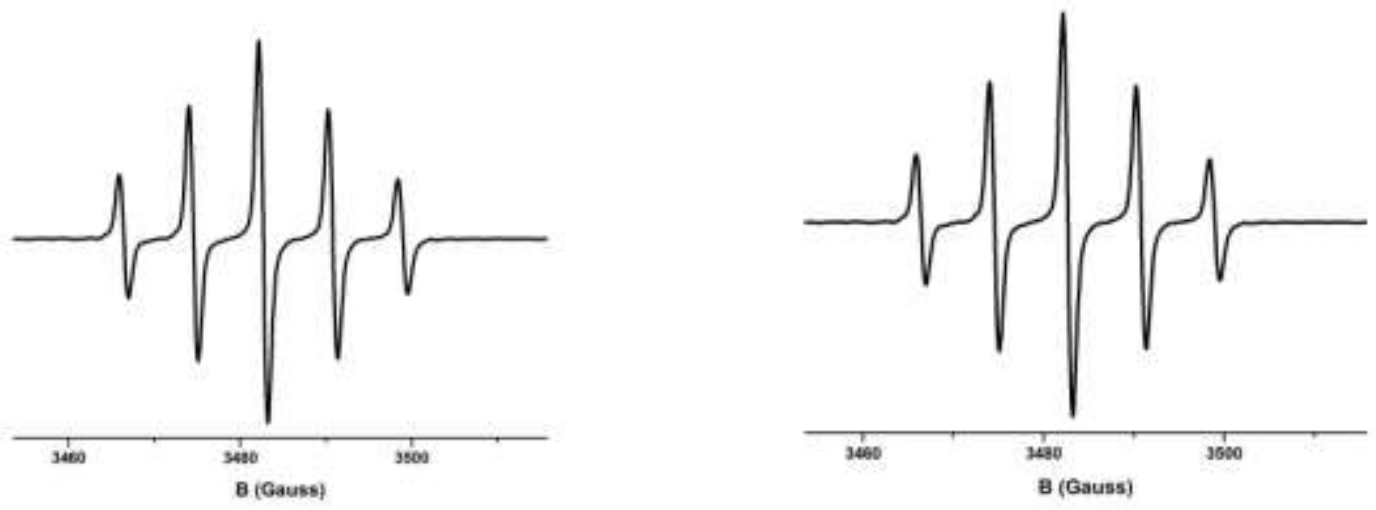

Figura 41 - Espectro de EPR da solução de carboxi-PTIO $\left(C_{\text {PTIO }}=6,3 \times 10^{-3} \mathrm{~mol} \mathrm{~L}^{-1}\right)$ e trans-[Ru(NH$\left.\left.)_{3}\right)_{4}(\mathrm{py})(\mathrm{NO})\right]\left(\mathrm{BF}_{4}\right)_{3}\left(C_{\mathrm{Ru}}=10^{-4} \mathrm{~mol} \mathrm{~L}{ }^{-1}\right)$ na presença de fluoresceína sódica $\left(C_{\text {fluor. }}=5,76 \times 10^{-4} \mathrm{~mol} \mathrm{~L}^{-1}\right)$ irradiada por 15 minutos em $440 \mathrm{~nm}$ e $490 \mathrm{~nm}$. 


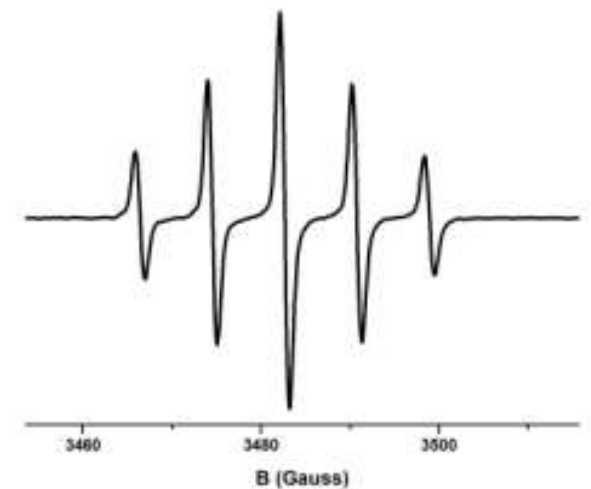

Figura 42 - Espectro de EPR da solução de carboxi-PTIO $\left(C_{\text {PTIO }}=6,3 \times 10^{-3} \mathrm{~mol} \mathrm{~L}^{-1}\right)$ e trans-[Ru(NH$\left.)_{4}(\mathrm{py})(\mathrm{NO})\right]\left(\mathrm{BF}_{4}\right)_{3}\left(C_{\mathrm{Ru}}=10^{-4} \mathrm{~mol} \mathrm{~L}-1\right)$ na presença de tartrazina $\left(\mathrm{C}_{\text {tart. }}\right.$. $=7,6 \times 10^{-4} \mathrm{~mol} \mathrm{~L}^{-1}$ ) irradiada por 15 minutos em $440 \mathrm{~nm}$.

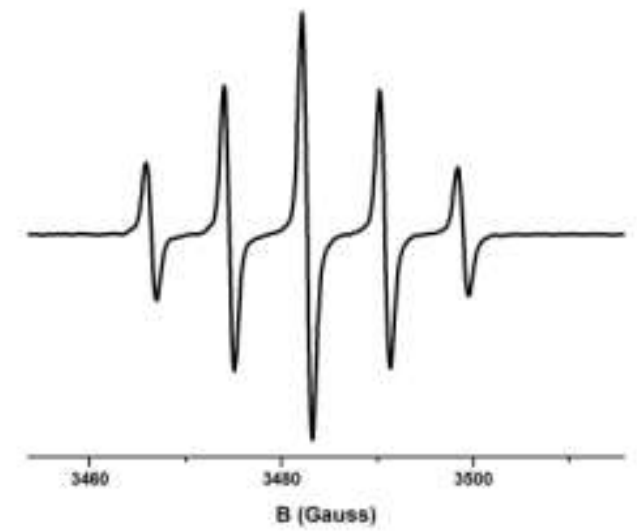

Figura 43 - Espectro de EPR da solução de carboxi-PTIO $\left(C_{\text {PTIO }}=6,3 \times 10^{-3} \mathrm{~mol} \mathrm{~L}^{-1}\right)$ e trans- $\left[\mathrm{Ru}\left(\mathrm{NH}_{3}\right)_{4}(\mathrm{py})(\mathrm{NO})\right]\left(\mathrm{BF}_{4}\right)_{3}\left(C_{\mathrm{Ru}}=10^{-4} \mathrm{~mol} \mathrm{~L}-1\right)$ na presença de alaranjado de acridina $\left(C_{\text {acrid. }}=7,4 \times 10^{-4} \mathrm{~mol} \mathrm{~L}^{-1}\right)$ irradiada por 15 minutos em $440 \mathrm{~nm}$. 


\section{CONSIDERAÇÕES FINAIS}

Foram sintetizados os compostos trans-[Ru( $\left.\left(\mathrm{HSO}_{3}\right)_{2}\left(\mathrm{NH}_{3}\right)_{4}\right]$, trans$\left[\mathrm{RuCl}\left(\mathrm{NH}_{3}\right)_{4}\left(\mathrm{SO}_{2}\right)\right] \mathrm{Cl}, \quad$ trans- $\left[\mathrm{Ru}\left(\mathrm{SO}_{4}\right)\left(\mathrm{NH}_{3}\right)_{4}(\mathrm{py})\right] \mathrm{Cl}, \quad$ trans- $\left[\mathrm{Ru}\left(\mathrm{NH}_{3}\right)_{4}(\mathrm{py})(\mathrm{NO})\right]\left(\mathrm{BF}_{4}\right)_{3}$ com modificações nas sínteses com objetivo de melhora nos rendimentos.

O complexo trans-[Ru( $\left.\left(\mathrm{NH}_{3}\right)_{4}(\mathrm{py})(\mathrm{NO})\right]\left(\mathrm{BF}_{4}\right)_{3}$ possui atividade fotoquímica, o que foi comprovado através de uma técnica que ainda não havia sido proposta para a verificação da liberação de NO por este complexo: espectroscopia de ressonância paramagnética eletrônica do complexo na presença do sequestrador carboxy-PTIO.

A utilização de corantes no meio reacional, para sensibilização do complexo trans- $\left[\mathrm{Ru}\left(\mathrm{NH}_{3}\right)_{4}(\mathrm{py})(\mathrm{NO})\right]^{3+}$, visando liberação de $\mathrm{NO}$ fotoquimicamente ao se irradiar com luz de comprimento de onda na região do visível, não proporciona esta liberação, como ocorre com o complexo similar $\left[\mathrm{Ru}\left(\mathrm{NH}_{3}\right)_{5}(\mathrm{py})\right]^{2+}$ (transferência de energia de Foster) que libera piridina e amônia por reação fotoquímica sensibilizada por corantes. Presume-se que, o processo de transferência de energia, portanto, seja do tipo Dexter. Alguns trabalhos são citados na literatura a respeito deste processo, onde o cromóforo é ligado diretamente ao rutênio.

Trabalhos futuros que podem ser citados aqui são: síntese de complexos ligados diretamente a corantes e irradiações dentro da janela terapêutica e, estudo das energias dos estados excitados envolvidos na fotorreação do complexo trans$\left[\mathrm{Ru}\left(\mathrm{NH}_{3}\right)_{4}(\mathrm{py})(\mathrm{NO})\right]\left(\mathrm{BF}_{4}\right)_{3}$. 


\section{REFERÊNCIAS BIBLIOGRÁFICAS}

[1] Ignarro, L. J. Nitric Oxide: Biology and Pathobiology. Academic Press: San Diego, Califórnia, 2000.

[2] Moncada, S.; Palmer, R. M. L.; Higgs, E. A. Nitric Oxide: Physiology, Pathophysiology, and Pharmacology. Pharmacological Reviews, 43 (1991) 709 142.

[3] Nathan, C. F.; Xie, Q. Nitric Oxide Synthases: Roles, Tolls and Controls. Cell, 78 (1994) $915-918$.

[4] Wink, D. A.; Mitchell, J. B. Chemical Biology of Nitric Oxide: Insights into Regulatory Cytotoxic, and Cytoprotective Mechanisms of Nitric Oxide. Free Radical Biology \& Medicine, 25 (1998) 434-456

[5] McCleverty, J. A. Chemistry of Nitric Oxide Relevant to Biology. Chemical Reviews, 104 (2004) $403-418$.

[6] Thomas, D. D.; Ridnour, L. A.; Isenberg, J. S.; Flores-Santana, W.; Switzer, C. H.; Donzelli, S.; Hussaind, P.; Vecoli, C.; Paolocci, N.; Ambs, S.; Coltonf, C. A.; Harris, C. C.; Roberts, D. D.; Wink, D. A. The chemical biology of nitric oxide: Implications in cellular signaling. Free Radical Biology \& Medicine, 45 (2008) 1831. 
[6b] Ridnour, L. A.; Thomas, D. D.; Switzer, C.; Flores-Santana, W.; Isenberg, J. S.; Ambs, S.; Roberts, D. D.; Wink, D. A. Molecular mechanisms for discrete nitric oxide levels in câncer. Nitric Oxide, 19 (2008) $73-76$.

[7]Wang, P. G.; Xian, M.; Tang, X.; Wu, X.; Wen, Z.; Cai, T.; Janczuk, A. J. Nitric

Oxide Donors: Chemical Activities and Biological Applications. Chemical Reviews, 102 (2002) $1091-1134$.

[8]Ford, P. C.; Lorkovic, I. M. Mechanistic Aspects of the Reactions of Nitric Oxide with Transition-Metal Complexes. Chemical Reviews,102 (2002) 993 1018.

[9] Toledo Jr., J. C.; Augusto, O. Connecting the Chemical and Biological Properties of Nitric Oxide. Chemical Research in Toxicology, 25 (2012) 975 - 989.

[10] Knott, A. B.; Bossy-Wetzel, E..Nitric Oxide in Health and Disease of the Nervous System. Antioxidants \& Redox Signaling, 11 (2009) 541 - 553.

[11] Fukuto, J. M.; Ignarro L. J. In Vivo Aspects of Nitric Oxide (NO) Chemistry: Does Peroxynitrite (ONOO-) Play a Major Hole in Citotoxicity? Accounts of Chemical Research, 30 (1997) $149-152$.

[12] Wink, D. A.; Vodovotz, Y.; Laval, J.; Laval, F.; Dewhirst, M. W.; Mitchell, J. B. The multifaceted roles of nitric oxide in cancer.Carcinogenesis, 19 (1998)711721. 
[13a] Kradin, R.; Matsubara, O.; Mark, E. J. Endothelial nitric oxide synthase expression in pulmonary capillary hemangiomatosis. Experimental and Molecular Pathology, 79 (2005) 194 - 197.

[13b] Low, D. A.; Shibasaki, M.; Davis, S. L.; Keller, D. M.; Crandall, C. G.Does local heating-induced nitric oxide production attenuate vasoconstrictor responsiveness to lower body negative pressure in human skin? Journal of Applied Physiology, 102 (1997) 1839 - 2007.

[14] Lockwood, A.; Patka, J.; Rabinovich, M.; Wyatt, K.; Abraham, P. Sodium nitroprusside-associated cyanide toxicity in adult patients - fact or fiction? A critical review of the evidence and clinical relevance.Open Access Journal of Clinical Trials, 2 (2010) 133-148.

[15] Friederich, J. A.; Butterworth, J. F.Sodium Nitroprusside: Twenty Years and Counting. Anethesia \& Analgesia, 81 (1995) $152-161$.

[16] Arnold, W. P.; Longnecker, D. E.; Epstein, R. M. Photodegradation of Sodium Nitroprusside: Biologic Activity and Cyanide Release. Anesthesiology, 61 (1984) $254-260$.

[17] Pasch, T; Schulz, V.; Hoppelshauser, G. Nitroprusside-Induced Formation of Cyanide and Its Detoxication with Thiosulfate During Deliberate Hypotension. Journal of Cardiovascular Pharmacology, 5 (1983) 77 - 85. 
[18] Zanichelli, P. G.; Estrela, H. F. G.; Spadari-Bratfisch, R. C.; Grassi-Kassisse, D. M.; Franco, D. W. The effects of ruthenium tetraammine compounds on vascular smooth muscle.Nitric Oxide, 16 (2007) 189-196.

[19] Fricker, S. P. Ruthenium, Nitric Oxide and Disease. A Novel Inorganic Chemistry Approach to Drug Design.Platinum Metals Review, 39 (1995) 150 159.

[20] Yoo, J.; Fukuto, J. M. Oxidation of N-hydroxyguanidine by Nitric Oxide and The Possible Generation of Vasoactive Species. Biochemical Pharmacology, 50 (1995) $1995-2000$.

[21] Thatcher, G. R. J.; Nicolescu, A. C.; Bennett, B. M.; Toader, V. Serial Review: Mechanisms and Novel Directions in the Biological Applications of Nitric Oxide Donors. Free Radical Biology \& Medicine, 37 (2004) 1122-1143.

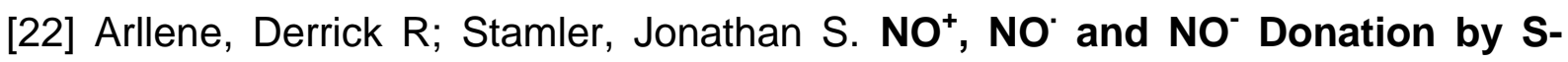
Nitrosothiols: Implications for Regulation of Physiological Functions by SNitrosylation and Acceleration of Disulfide Formation. Archives of Biochemistry and Biophysics, 318 (1995) $279-285$.

[23] Seabra, A. B.; Martins, D.; Simoes, M. M. S. G.; da Silva, Regiane; Brocchi, M.; de Oliveira, M. G. Antibacterial Nitric Oxide-Releasing Polyester for the Coating of Blood-Contacting Artificial Materials. Artificial Organs, 34 (2010) E204-E214. 
[24] Keefer, L. K.; Flippen-Anderson, J. L.; George, C.; Shanklin, A. P.; Dunams, Te. M.; Christodoulou, D.; Saavedra, J. E.; Sagan, E. M.; Bohle, S. Chemistry of the Diazeniumdiolates. I. Structural and Spectral Characteristics of the $[\mathrm{N}(\mathrm{O}) \mathrm{NO}]^{-}$ Functional Group. Nitric Oxide: Biology and Chemistry, 5 (2001) 377 - 394.

[25] Davies, Keith M.; Wink, David A.; Saavedra, Joseph E.; Keefer, Larry K. Chemistry of the Diazeniumdiolates. 2. Kinetics and Mechanism of Dissociation to Nitric Oxide in Aqueous Solution. Journal of the American Chemical Society, $123(2001) 5473-5481$.

[26] Ford, P. C.; Bourassa; J. Miranda, K; Lee, B.; Lorkovic, I.; Boggs, S.; Kudo, S.; Laverman, L. Photochemistry of metal nitrosyl complexes. Delivery of nitric oxide to biological targets.Coordination Chemistry Reviews, 171 (1998) 185 - 202.

[27] Oszajca, J.;Stochel, G.; Wasielewska, E.; Stasicka, Z.; Gryglewski, R. J.; Jakubowski, A.; Cieslik, K. Cyanonitrosylmetallates as potential NO-donors. Journal of Inorganic Biochemistry, 69 (1998) 121 - 127.

[28] Carlos, R. M.; Ferro, A. A.; Silva, H. A. S.; Gomes, M. G.; Borges, S. S. S.; Ford, P. C.; Tfouni, E.; Franco, D. W. Photochemical reactions oftrans$\left[\mathrm{Ru}\left(\mathrm{NH}_{3}\right)_{4} \mathrm{~L}(\mathrm{NO})\right]^{3+}$ complexes. Inorganica Chimica Acta, 357 (2004) 1381 - 1388.

[29] Szaciłowski, K.; Oszajca, J.; Barbieri, A.; Karocki, A.; Sojka, Z.; Sostero, S.; Boaretto, R.; Stasicka, Z. Photochemistry of the $\left[\mathrm{Fe}(\mathrm{CN})_{5} \mathrm{~N}(\mathrm{O}) \mathrm{SR}\right]^{3-}$ complex. A mechanistic study.Journal of Photochemistry and Photobiology A: Chemistry,143 (2001) 99-108. 
[30] Toledo Jr., J. C.; Lopes, L. G. F.; Alves, A. A.; Silva, L. P.; Franco, D. W. Release of NO by a nitrosyl complex upon activation by the mitochondrial reducing power. Journal of Inorganic Biochemistry, 89 (2002) 267 - 271.

[31] Ford, P. C.;Wecksler, S. Photochemical reactions leading to NO and NOx generation.Coordination Chemistry Reviews, 249 (2005) 1382 - 1395.

[32] Rose, M. J.; Mascharak, P. K. Photoactive ruthenium nitrosyls: Effects of light and potential application as NO donors. Coordination Chemistry Reviews, $252(2008) 2093-2114$.

[33] Serli, B.; Zangrando, E.; Gianferrara, T.; Yellowlees, L.; Alessio, E. Coordination and release of NO by ruthenium-dimethylsulfoxide complexes limplications for antimetastases activity. Coordination Chemistry Reviews, 245 (2003) $73-83$.

[34] Tfouni, E.; Doro, F. G.; Figueiredo, L. E.; Pereira, J.C.M.; Metzker, G.; Franco, D. G. Tailoring NO Donors Metallopharmaceuticals: Ruthenium Nitrosyl Ammines and Aliphatic Tetraazamacrocycles. Current Medicinal Chemistry, 17 (2010) 3643 -3657 .

[35] Tfouni, E.; Krieger, M.; McGarvey, B. R.; Franco, D. W. Structure, chemical and photochemical reactivity and biological activity of some ruthenium amine nitrosyl complexes. Coordination Chemistry Reviews, 236 (2003) 57 -69. 
[36]Neuman, D.; Ostrowski, A. D.; Absalonson, R. O.; Strouse, G. F.; Ford, P. C. Photosensitized NO Release from Water-Soluble Nanoparticle Assemblies. Journal of the American Chemical Society, 129 (2007) 4146-4147.

[37] Tfouni, E.; Doro, F. G.; Gomes, A. J.; da Silva, R. S.; Metzker, G.; Benini, P. G. Z.; Franco, D. W. Immobilized ruthenium complexes and aspects of their reactivity. Coordination Chemistry Reviews, 254 (2010) 355-371.

[38] Tfouni, E.; Ferreira, K. Q.; Doro, F. G.; Silva, R. S.; Rocha, Z. N. Ru(II) and $\mathrm{Ru}(\mathrm{III})$ complexes with cyclam and related species. Coordination Chemistry Reviews, 249 (2005) 405-418.

[39] Tfouni, E.; Truzzi, D. R.; Tavares, A.; Gomes, A. J.; Figueiredo, L. E.; Franco, D. W. Biological activity of ruthenium nitrosyl complexes. Nitric Oxide, 26 (2012) 38-53.

[40] Clarke, M. J. Ruthenium metallopharmaceuticals. Coordination Chemistry Reviews, 236 (2003) $209-233$.

[41] Henry, Y.; Guissani, A. Interactions of nitric oxide with hemoproteins: roles of nitric oxide in mitochondria. Cellular and Molecular Life Sciences, 55 (1999) $1003-1014$.

[42] Bratsos, I.; Serli, B.; Zangrando, E.; Katsaros, N.; Alessio, E.Replacement of Chlorides with Dicarboxylate Ligands in Anticancer Active Ru(II)-DMSO Compounds: A New Strategy That Might Lead to Improved Activity. Inorganic Chemistry, 46 (2007) $975-992$. 
[43]Levina, A.; Mitra, A.; Lay, P. A.Recent developments in ruthenium anticancer drugs. Metallomics, 1 (2009) $458-470$.

[44] Aitken, J. B.; Levina, A.; Lay, P. A. Studies on the Biotransformations and Biodistributions of Metal-Containing Drugs Using X-Ray Absorption Spectroscopy.Current Topics in Medicinal Chemistry, 11 (2011) 553 - 571.

[45] Vacca, A. Bruno, M. Boccarelli, A. Coluccia, M. Ribatti, D. Bergamo, A. Garbisa, S. Sartor, L. Sava, G. Inhibition of endothelial cell functions and of angiogenesis by the metastasis inhibitor NAMI-A.British Journal of Cancer , 86 (2002) 993 998.

[46a] Mazuryk, A.; Kurpiewska, K.; Lewiński, K.; Stochel, G.; Brindell, M. Interaction of apo-transferrin with anticancer ruthenium complexes NAMI-A and its reduced form.Journal of Inorganic Biochemistry, 116 (2012) 11-18.

[46b] Gianferrara, T.; Bratsos, I.; lengo, E.; Milani, B.; Oštrić, A.; Spagnul, C.; Zangrando, E.; Alessio, E. Synthetic strategies towards ruthenium-porphyrin conjugates for anticancer activity. Dalton Transactions, (2009) 10742-10756.

[47] Marchesi, M. S. P.; Cicillini, S. A.; Prazias, A. C. L.; Bendhack, L. M.; Batista, A. A.; da Silva, R. S. Chemical mechanism of controlled nitric oxide release fromtrans-[RuCl([15]aneN $\left.\left.{ }_{4}\right) \mathrm{NO}\right]\left(\mathrm{PF}_{6}\right)_{2}$ as a vasorelaxant agent. Transition Metal Chemistry, 37 (2012) 475-479. 
[48] Holanda, A. K. M.; Pontes, D. L.; Diógenes, I. C. N.; Moreira, I. S.; Lopes, L. G.

F. NO release fromtrans- $\left[\mathrm{Ru}\left(\mathrm{NH}_{3}\right)_{4} \mathrm{~L}(\mathrm{NO})\right]^{3+}$ complexes upon reduction $(\mathrm{L}=\mathbf{1}$ methylimidazole or benzoimidazole).Transition Metal Chemistry, 29 (2004) 430436.

[49] Rose, M. J.; Patra, A. K.; Alcid, E. A.; Olmstead, M. M.; Mascharak, P. K. Ruthenium Nitrosyls Derived from Polypyridine Ligands with Carboxamide or Imine Nitrogen Donor(s): Isoelectronic Complexes with Different NO Photolability. Inorganic Chemistry, 46 (2007) 2328-2338.

[50] Videla, M.; Jacinto, J. S.; Baggio, R.; Garland, M. T.; Singh, P.; Kaim, W.; Slep,

L. D.; Olabe, J. A. New Ruthenium Nitrosyl Complexes with Tris(1pyrazolyl)methane (tpm) and 2,2'-Bipyridine (bpy) Coligands. Structure, Spectroscopy, and Electrophilic and Nucleophilic Reactivities of Bound Nitrosyl.Inorganic Chemistry, 45 (2006) 8608 - 8617.

[51]Doro, F. G.;Pepe, I. M.; Galembeck, S. E.;Carlos, R. M.; da Rocha, Z. N.;Bertotti, M.; Tfouni, E. Reactivity, photolability, and computational studies of the ruthenium nitrosyl complex with a substituted cyclamfac$\left[\mathrm{Ru}(\mathrm{NO}) \mathrm{Cl}_{2}\left(\mathrm{~K}^{3} \mathrm{~N}^{4}, \mathrm{~N}^{8}, \mathrm{~N}^{11}\right.\right.$ (1-carboxypropyl)cyclam]Cl. $\mathrm{H}_{2} \mathrm{O}$. Dalton Transactions, 40 (2011) $6420-6432$.

[52] Bonaventura, D.; Lima, R. G.; Vercesi, J. A.; Silva, R. S.; Bendhack, L. M. Comparison of the mechanisms underlying the relaxation induced by two nitric oxide donors: Sodium nitroprusside and a new ruthenium complex. Vascular Pharmacology. 46 (2007) 215-222. 
[53] Holanda, A. K. M.; Silva, F. O. N.; Sousa, J. R.; Diógenes, I. C. N.; Carvalho, I. M. M.; Moreira, I. S.; Clarke, M. J.; Lopes, L. G. F. Photochemical NO release from nitrosyl Rull complexes with C-bound imidazoles. Inorganica Chimica Acta, 361 (2008) $2929-2933$.

[54] Fry, N. L.; Mascharak, P. K. Photoactive Ruthenium Nitrosyls as NO Donors: How To Sensitize Them toward Visible Light. Accounts of Chemical Research, 44 (2011) $289-298$.

[55] Marcondes, F. G.; Ferro, A. A.; Souza-Torsoni, A.; Sumitani, M.; Clarke, M. J.; Franco, D. W.; Tfouni, E.; Krieger, M. H. In vivo effects of the controlled NO donor/scavenger ruthenium cyclam complexes on blood pressure. Life Sciences, 70 (2002) 2735-2752.

[56]Bordini, J.; Ford, P. C.; Tfouni, E. Photochemical release of nitric oxide from a regenerable, sol-gel encapsulated Ru-salen-nitrosyl complex.Chemical Communications, (2005) $4169-4171$.

[57] Ferreira, K. Q.;Schneider, J. F.; Nascente, P. A. P.; Rodrigues, P. U.; Tfouni, E. Design of an NO photoinduced releaser xerogel based on the controlled nitric oxide donortrans-[Ru(NO)Cl(cyclam) $]\left(\mathrm{PF}_{6}\right)_{2}$ (cyclam $=1,4,8,11$ tetraazacyclotetradecane). Journal of Colloid and Interface Science, 300 (2006) 543 $-552$. 
[58] Doro, F. G.; Rodrigues-Filho, U. P.; Tfouni, E. A regenerable ruthenium tetraammine nitrosyl complex immobilized on a modified silica gel surface: Preparation and studies of nitric oxide release and nitrite-to-NO conversion. Journal of Colloid and Interface Science, 307 (2007) 405-417.

[59] Gomes, A. J.; Barbougli, P. A.; Espreafico, E. M.; Tfouni, E. trans$\left[\mathrm{Ru}(\mathrm{NO})\left(\mathrm{NH}_{3}\right)_{4}(\mathrm{py})\right]\left(\mathrm{BF}_{4}\right)_{3} \cdot \mathrm{H}_{2} \mathrm{O}$ encapsulated in PLGA microparticles for delivery of nitric oxide to B16-F10 cells: Cytotoxicity and phototoxicity. Journal of Inorganic Biochemistry, 102 (2008) 757-766.

[60] Gomes, A. J.; Barbougli, P. A.; Espreafico, E. M.; Tfouni, E. trans$\left[\mathrm{Ru}(\mathrm{NO})\left(\mathrm{NH}_{3}\right)_{4}(\mathrm{py})\right]\left(\mathrm{BF}_{4}\right)_{3} \cdot \mathrm{H}_{2} \mathrm{O}$ encapsulated in PLGA nano and microparticles for delivery of nitric oxide to neoplasic cells. The FASEB Journal, 22 (2008) Meeting Abstract Supplement 624.4.

[61] Masters, B. R.; So, P. T. C.; Gratton; E. Multiphoton Excitation Fluorescence Microscopy and Spectroscopy of In Vivo Human Skin. Biophysical Journal, 72 (1997) $2405-2412$.

[62] Wecksler, S. R.;Mikhailovsky, A.; Korystov, D.; Ford, P. C. A Two-Photon Antenna for Photochemical Delivery of Nitric Oxide from a Water-Soluble, DyeDerivatized Iron Nitrosyl Complex Using NIR Light.Journal of the American Chemical Society, 128 (2006) $3831-3837$.

[63]Rocha, Z, N.; Lima, R. G.; Doro, F. G.; Tfouni, E.; da Silva, R. S. Photochemical production of nitric oxide from a nitrosyl phthalocyanine ruthenium complex 
by irradiation with light in the phototherapeutic window. Inorganic Chemistry Communications, 11 (2008) 737 - 740.

[64]De Rosa, F.; Bu, X.; Pohaku, K.; Ford, P. C. Synthesis and Luminescence Properties of $\mathrm{Cr}(\mathrm{III})$ Complexes with Cyclam-Type Ligands Having Pendant Chromophores, trans-[ $\left.\mathrm{Cr}(\mathrm{L}) \mathrm{Cl}_{2}\right] \mathrm{Cl}$. Inorganic Chemistry, 44 (2005) 4166 - 4174.

[65] Rose, M. J.; Fry, N. L.; Marlow, R.; Hinck, L.; Mascharak, P.K. Sensitization of Ruthenium Nitrosyls to Visible Light via Direct Coordination of the Dye Resorufin: Trackable NO Donors for Light-Triggered NO Delivery to Cellular Targets. Journal of American Chemical Society, 130 (2008) 8834 - 8846.

[66] Carlos, R. M.; Neumann, M. G.; Tfouni, E. Energy of the Photosubstitutionally Reactive Excited State of Pentaammine(pyridine)ruthenium(II). Inorganic Chemistry, 35 (1996) $2229-2234$.

[67] Sauaia, M. G.; de Lima, R. G.; Tedesco, A. C.; da Silva, R. S. Photoinduced NO Release by Visible Light Irradiation from Pyrazine-Bridged Nitrosyl Ruthenium Complexes. Journal of the American Chemical Society, 125 (2003) $14718-14719$.

[68] Gorczyńska, K.; Labudzińska, A. The UV difference spectra as a characteristic feature of phenols and aromatic amines.Journal of Molecular Structure, 349 (1995) $469-472$. 
[69] Allen, A. D.; Bottomley, F.; Harris, R. D.; Reinslau, V. P.; Senoff, C. V. Inorganic Syntheses, 1970, 12, 2.

[70] Marchant, J. J.; Matsubara, T.; Ford, P. C. Syntheses and Properties of the Ruthenium(III) Complexescis- andtrans- $\mathrm{Ru}\left(\mathrm{NH}_{3}\right)_{4}(\mathrm{~L}) \mathrm{X}^{2+}$. Application of Cyclic Voltammetry to Study Cis and Trans Effects on Substitution Reactions of the Ruthenium(II) Analogues. Inorganic Chemistry. 16 (1977) 2160 - 2165.

[71]Vogt, L. H.; Katz, J. L.; Wiberley, S. E.The Crystal and Molecular Structure of Ruthenium-Sulfur Dioxide Coordination Compounds. I. Chlorotetraammine(sulfur dioxide)ruthenium(II) Chloride. Inorganic Chemistry, 4 (1965) $1157-1163$.

[72] Borges, S. S.; Davanzo, C. U.; Castellano, E. E.; Z-Schpector, J.; Silva, S. C.; Franco, D. W. Ruthenium Nitrosyl Complexes with N-Heterocyclic Ligands. Inorganic Chemistry, 37 (1998) 2670 - 2677.

[73] Vidal, R. S.; Doro, F. G.; Ferreira, K. Q.; Rocha, Z. N.; Castellano, E. E.; Nikolaou, S.; Tfouni, E. Cis-trans isomerization in the syntheses of ruthenium cyclam complexes with nitric oxide. Inorganic Chemistry Communications, 15 (2012) 93-96.

[74] Hatchard, C. G.; Parker, C. A. A New Sensitive Chemical Actinometer. II. Potassium Ferrioxalate as a Standard Chemical Actinometer. Proceedings of The Royal Society A, 235 (1956) $518-536$. 
[75] Pavanin, L. A. Estudo das cis-tetraaminas de $\mathbf{R u ( I I )}$ com ligantes heterocíclicos nitrogenados aromáticos. São Paulo, 1988. Tese de Doutorado, Instituto de Química - USP.

[76] Kuhn, H. J.; Braslavsky, S. E.; Schmidt, R. I. Chemical Actinometry (IUPAC Technical Report). Pure and Applied Chemistry, 76 (2004) 2105 - 2146.

[77] Montalti, M.; Credi, A.; Prodi, L.; Gandolfi, M. T. com seções introdutórias de Michl, J e Balzani, V. Handbook of Photochemistry. Terceira Edição.CRC Press Taylor \& Francis Group. 2006. Cap. 12, p. 601.

[78] Sima, J. e Makánová, J. Photochemistry of iron(III) complexes.Coordination Chemistry Reviews, 160 (1997) 161 - 189.

[79] Allen, A. D.; Bottomley, F.; Harris, R. D.; Reinslau, V. P.; Senoff, C. V. Pentaamine(nitrogen)ruthenium(II) salts and other ammines of ruthenium.Inorganic Syntheses, University of Utah, Salt Lake City, Utah, 12 (1970) 2.

[80] Silverstein, R. M.; Webster, F. X.; Kiemle, D. J. Identificação Espectrométrica de Compostos Orgânicos. 7ª Edição. Editora LCT. 2006

[81] Gorelsky, S. I.; da Silva, S. C.; Lever, A. B. P.; Franco, D. W. Electronic spectra oftrans- $\left[\mathrm{Ru}\left(\mathrm{NH}_{3}\right)_{4}(\mathrm{~L}) \mathrm{NO}\right]^{3+} /{ }^{2+}$ complexes. Inorganica Chimica Acta, 300-302 (2000) 698-708. 
[82] Bezerra, C. W. B.; da Silva, S.; Gambardella, M. T. P.; Santos, R. H. A.; Plicas,

L. M. A.; Tfouni, E.; Franco, D. W. Water $\pi$-Donation in transTetraammineruthenium(II): Effect on Coordinated-Water Properties Induced by a Trans NO Ligand. Inorganic Chemistry, 1999, 38, 5660 - 5667.

[83] Jose, J.; Ueno, Y.; Burgess, K. Water-Soluble Nile Blue Derivatives: Syntheses and Photophysical Properties. Chemistry - A European Journal, 15 (2000) $418-423$

[84] Gilania, A. G.; Moghadama, M.; Hosseinia, S. E.; Zakerhamidib, M. S. A comparative study on the aggregate formation of two oxazine dyes in aqueous and aqueous urea solutions. Spectrochimica Acta Part A, 83 (2011) 100-105.

[85] Sun, W.; Gee, K. R.; Klaubert, D. H.; Haugland, R. P. Synthesis of Fluorinated Fluoresceins. Journal of Organic Chemistry, 62 (1997) $6469-6475$.

[86] Crovetto, L.; Paredes, J. M.; Rios, R.; Talavera, E. M.; Alvarez-Pez, J. M. Photophysics of a Xanthenic Derivative Dye Useful as an "On/Off" Fluorescence Probe. The Journal of Physical Chemistry A, 111 (2007) 13311 13320.

[87] McQueen, P. D.; Sagoo, S.; Yao, H.; Jockusch, R. A. On the Intrinsic Photophysics of Fluorescein.Angewandte Chemie International Edition, 49 (2010) $9193-9196$. 
[88] Sagoo, S. K. and Jockusch, R. A. The fluorescence properties of cationic rhodamine B in the gas phase. Journal of Photochemistry and Photobiology A: Chemistry, 220 (2011) 173-178.

[89] Setiawan, D.; Kazaryan, A.; Martoprawirob, M. A.; Filatov, M. A first principles study of fluorescence quenching in rhodamine B dimers: how can quenching occur in dimeric species?Physical Chemistry Chemical Physics, 12 (2010) 1123811244.

[90] Llamas, N. E.; Garrido, M.; Di Nezio, M. S.; Band, B. S. F. Second order advantage in the determination of amaranth, sunset yellow FCF and tartrazine by UV-vis and multivariate curve resolution-alternating least squares. Analytica Chimica Acta, 655 (2009) 38-42.

[91] Abbruzzetti, S.; Viappiani, C.; Murgida, D. H.; Erra-Balsells, R.; Bilmes, G. M. Non-toxic, water-soluble photocalorimetric reference compounds for UV and visible excitation. Chemical Physics Letters, 304 (1999) 167-172.

[92] Shahir, A. A.; Javadian, S.; Razavizadeh, B. B. M.; Gharibi, H. Comprehensive Study of Tartrazine/Cationic Surfactant Interaction. The Journal of Physical Chemistry B, 115 (2011) $14435-14444$.

[93] Owens, J. W.; Perry, M.; Seybert, D. W. Adducts of nitric oxide with cobaltous tetraphenylporphyrin and phthalocyanines: potential nitric oxide sorbents. Inorganica Chimica Acta, 277 (1998) 1 - 7. 
[94] Hoshino, M.; Arai, S.; Yamaji, M.; Hama, Y. Laser Photolysis Studies of NItric

Oxide Adducts of Cobalt(II) Porphyrins.Photoinduced Denitrosylation at the Temperature Range 160-300 K. The Journal of Physical Chemistry,90 (1986) 2109 $-2111$.

[95] Carlos, R. M.; Cardoso, D. R.; Castellano, E. E.; Osti, R. Z.; Camargo, A. J.; Macedo, L. G.; Franco, D. W. Reactivity of Radicals Generated on Irradiation oftrans-[Ru( $\left.\left(\mathrm{NH}_{3}\right)_{4}\left(\mathrm{NO}_{2}\right) \mathrm{P}(\mathrm{OEt})_{3}\right]\left(\mathrm{PF}_{6}\right)$. Journal of the American Chemical Society, $126(2004) 2546-2555$.

[96] Hoshino, M.; Maeda, M.; Konishi, R.; Seki, H.; Ford, P. C. Studies on the Reaction Mechanism for Reductive Nitrosylation of Ferrihemoproteins in Buffer Solutions. Journal of the American Chemical Society, 118 (1996) 5702 - 5707.

[97] Hogg, N. Detection of nitric oxide by electron paramagnetic resonance spectroscopy. Free Radical Biology \& Medicine, 49 (2010) 122-129.

[98] Goldstein, S.; Russo, A.; Samuni, A. Reactions of PTIO and Carboxy-PTIO with NO, $\mathrm{NO}_{2}$, and $\mathrm{O}_{2}$. The Journal of Biological Chemistry, 278 (2003) 50949 50955.

[99] Akaike, T.; Yoshida, M.; Miyamoto, Y.; Sato, K.; Kohno, M.; Sasamoto, K.; Miyazaki, K.; Ueda, S.; Maeda, H. Antagonistic Action of Imidazolineoxyl NOxides against Endothelium-Derived Relaxing Factor/NO through a Radical Reaction. Biochemistry, 32 (1993) $827-832$. 
[100] Brindell, M.; Stochel, G.; Bertolasi, V.; Boaretto, R.; Sostero, S. Photochemistry of trans- and cis-[RuCl$\left.{ }_{2}(\mathrm{dmsO})_{4}\right]$ in Aqueous and Nonaqueous Solutions. European Journal of Inorganic Chemistry, 2007, 2353-2359.

[101] Silva, H. A. S.; McGarvey, B. R.; Santos, R. H. A.; Bertotti, M.; Mori, V.; Franco, D. W. Sulfate as a ligand in ruthenium(II) and (III) ammines. Canadian Journal of Chemistry, 79 (2001) 679-687.

[102] Silva, H. A. S.; Carlos, R. M.; Camargo, A. J.; Picchi, C. M. C.; Santos, R. H. A.; McGarvey, B. R.; Mori, V.; Franco, D. W. Study of the $\mathbf{O}-\mathbf{R u}-\mathbf{N}$ bonding in trans$\left[\mathrm{Ru}\left(\mathrm{NH}_{3}\right)_{4}\left(\mathrm{SO}_{4}\right) \mathrm{L}\right]^{+}$complexes $(\mathrm{L}=$ imidazole, histidine and substituted pyridines): a X-ray, EPR, spectroscopic and theoretical MO study.

[103] Lang, L.; Davis, J.; Lopes, L. G. F.; Ferro, A. A.; Vasconcellos, L. C. G.; Prock, A.; Franco, D. W.; Tfouni, E.; Wierasko, A.; Clarke, M. J. A Controlled NOReleasing Compound: Synthesis, Molecular Structure, Spectroscopy, Electrochemistry, and Chemical Reactivity of R,R,S,S-trans$[\mathrm{RuCl}(\mathrm{NO})(\mathrm{cyclam})]^{2+}(1,4,8,11$-tetraazacyclotetradecane). Inorganic Chemistry, 39 (2000) $2294-2300$. 